\title{
UNCERTAINTIES IN THE ANALYSIS \\ OF PLUTONIUM FUELED LIGHT WATER \\ MODERATED ASSEMBLIES
}

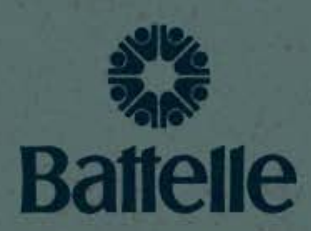

Pacific Northwest Laboratories

Richland, Washington 99352

MAY 1973

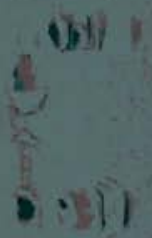

Prepared for the U.S. Atomic Energy Commission under Contract AT(45-1):1830 


\title{
NOTICE
}

This report was prepared as an account of work sponsored by the United States Government. Neither the United States nor the United States. Atomic Energy Commission, nor any of their employees, makes any warranty, express or implied, or assumes any legal liability or responsibility for the accuracy, completeness or usefulness of any information, apparatus, product, or process disclosed, or represents that its use would not infringe privately-owned rights.

\author{
PACIFIC NORTHWEST LABORATORY \\ operated by \\ BATTELLE \\ for the
}

U.S. ATOMIC ENERGY COMMISSION Under Contract AT(45-1)-1830

Printed in the United States of America

$$
\text { Available from }
$$

National Technical Information Service

U.S. Department of Commerce

5285 Port Royal Road

Springfield, Virginia 22151

Price: Printed Copy \$3.00; Microfiche $\$ 0.95$ 
UNCERTAINTIES IN THE ANALYSIS OF PLUTONIIIM FUELED LIGHT WATER MODERATED ASSEMBLIES

Report Written By:

R. C. Liikala

V. 0. Uotinen

$U$. P. Jenquin
Work Performed By:

R. C. Liikala

V. 0 . Uotinen

U. P. Jenquin

G. L. Gelhaus

S. R. Dwivedi

J. L. Carter

May 1973

BATTELLE MEMORIAL INSTITUTE PACIFIC NORTHWEST LABORATORIES RICHLAND, WASHINGTON 99352 


\section{ACKNOWLEDGMENTS}

The analysis of plutonium fueled assemblies reported here has been a continuing study at Pacific Northwest Laboratory. As a result many individuals at various stages have made significant inputs to this work. The authors wish to express appreciation to the following people for their contributions: to J. R. Worden and W. A. Reardon who were helpful in shaping the philosophy adopted in these studies; to B. R. Leonard, Jr., for the many helpful discussions and suggestions on neutron cross sections; to M. A. Robkin for the suggestions and discussions concerning scattering kernels and thermalization theory; to W. L. Purcell, T. M. Traver, and R. H. Holeman for their assistance in performing the calculations; to F. G. Dawson and L. C. Schmid for their programmatic guidance; and finally to Sally Taylor for typing the manuscript. 


\section{$\underline{\text { ABSTRACT }}$}

A theoretical analysis of $\mathrm{UO}_{2}-\mathrm{PuO}_{2}$ fueled, light-water-moderated lattice experiments has been performed to aid in establishing technical bases and design criteria for the utilization of plutonium bearing fuel in thermal power reactors. Results for $\mathrm{UO}_{2}$ and $\mathrm{Al}-\mathrm{Pu}$ lattices are included in order to understand the effects due to uranium and plutonium separately. The problems involved in calculating high leakage critical experiments are discussed. Estimates of the effects of various approximations inherent in the theoretical methods and/or analysis procedures are included along with the consequence on the results of the correlation. Uncertainties in the measurements and the neutron cross-section data are related to uncertainties in the calculated values of $k_{\text {eff }}$. The results of other studies which bear on evaluating the calculational methods are summarized. Areas which should be investigated in future analyses are also identified. 


\section{CONTENTS}

ACKNOWLEDGMENTS

ABSTRACT

LIST OF TABLES .

LIST OF FIGURES

I. INTRODUCTION

II. TECHNICAL APPROACH.

III. BRIEF CHRONOLOGICAL REVIEW OF PNL CORRELATIONS OF THEORY WITH MEASUREMENT FOR UNIFORM LATTICE EXPERIMENTS. • • • • • 5

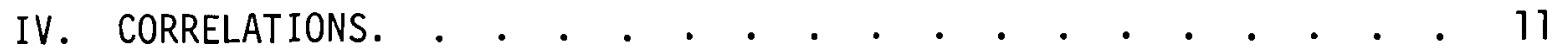

A. Experiments Correlated . . . . . . . . . . . . . 11

1. Lattices . . . . . . . . . . . . . . . 11

2. Homogeneous Criticals . • . . . . . . . . . . 12

B. Results . . . . . . • . . . . . . • . • . . 12

1. Lattices . • . • . . • • • . . • . . 12

2. Homogeneous Criticals . . . . . . . . . . . 24

C. Summary of the Correlation. . . . . . . . . . . . . 29

V. EVALUATION OF SOME OF THE UNCERTAINTIES IN THE ANALYSIS . • 33

A. Representation of Fuel and Lattices. . . . . . . . . 34

1. Particulate Fuel. . . . . . . . . . . . . 34

2. Lattice Hardware Ignored . . • • • • • • . . 37

3. Manufacturing Tolerances . . . . . . . • . . 37

B. Cell Calculations. . . . . . . . . . . . . . 43

1. Uncertainties in Neutron Cross Sections . . . . . . 43

2. Slowing Down Calculation . . . . . . . . . . 61

3. Thermalization Calculation . . . . . . . . . 62

C. Leakage Calculations. . . . . . . . . . . . 67

1. Separability of Flux in Axial and Radial Components . 67

2. Axial Leakage Representation. • . • • . . . • . 69

3. Number of Energy Groups . . . . . . . . . . 70

4. Two Region Model of the Assembly . . . . . . . . 71

5. Transport Theory Solution. . . . . . . . . . 72

D. Summary of the Errors and/or Uncertainties in the Analysis . 75 


\section{CONTENTS (contd)}

VI. SUMMARY OF OTHER CORRELATIONS

A. Correlations of $k_{\infty} \cdot$. . . . . . . . . . . . . 79

B. Correlations of $\rho^{28}$ and $\delta 28$. . . . . . . . . 80

C. Burnup Calculations. . . . . . . . . . . . . . 82

D. Power Distributions. . . . . . . . . . . . . 82

E. Temperature Coefficients. . . . . . . . . . 83

VII. CONCLUSIONS AND RECOMMENDATIONS . . . . . . . . . . . 85

A. Cross Sections . . . . . . . . . . . . . . 89

B. Cell Methods . . . . . . . . . . . . . . . 89

C. Leakage Calculation. . . . . . . . . . . . . 90

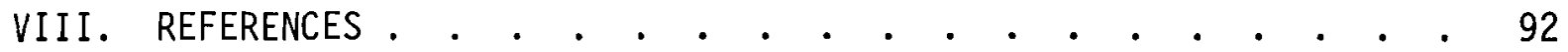

APPENDIX A: DESCRIPTION OF THE CROSS SECTIONS, THEORETICAL

METHODS AND ANALYSIS PROCEDURES . . . . . . . . . A.1

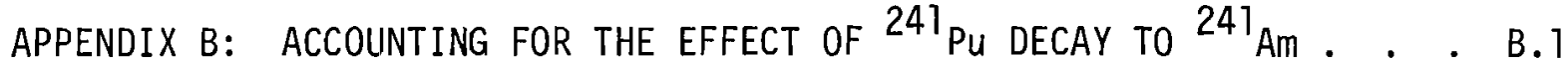

APPENDIX C: EFFECTS OF CERTAIN IMPROVEMENTS MADE IN THE

THEORY OF THE SLOWING DOWN CALCULATION. . . . . . . C. 


\section{LIST OF TABLES}

1 Chronological Summary of Correlations 7

2 Summary of $\mathrm{UO}_{2}$ Fueled Experiments 13

3 Summary of Experimental Results for Aqueous

Solution Experiments $\quad 14$

4. Calculated Values of $k_{\text {eff }}$ for Al-Pu Criticals 15

$5 \quad$ Calculated Values of $\mathrm{k}_{\text {eff }}$ for $\mathrm{UO}_{2}$ Lattices 16

6 Calculated Values of $\mathrm{k}_{\text {eff }}$ for $\mathrm{UO}_{2}-\mathrm{PuO}_{2}$ Criticals 17

$7 \quad$ Calculated Values of $\mathrm{k}_{\text {eff }}$ for $\mathrm{UO}_{2} 6.6 \mathrm{wt} \% \mathrm{PuO}_{2}$ Criticals 18

8 Values of $k_{\text {eff }}$ for Aqueous Solution Criticals 28

9 - Mean Values and Standard Deviation for Lattice Multiplication Studies $\quad 30$

10 Estimates of the Effects of Experimental Uncertainties 39

11 Corrected Values of $k_{\text {eff }}$ for $\mathrm{UO}_{2}-\mathrm{PuO}_{2}$ Lattices to Account for $\mathrm{PuO}_{2}$ Particle Self Shielding 42

12 Uncertainties in Neutron Multiplication of Lattice Experiments due to Uncertainties in Isotopic Cross Sections 44

13 Source of Cross-Section Data for Cross Sections Sensitivity Calculations

14 Effect of Changing Cross Sections on Calculated values of $k_{\text {eff }}$

15 Comparison of Multiplication Parameters for Yankee $\mathrm{UO}_{2}$ Lattices

16 Comparison of Multiplication Parameters for

17 Comparison of Multiplication Parameters for

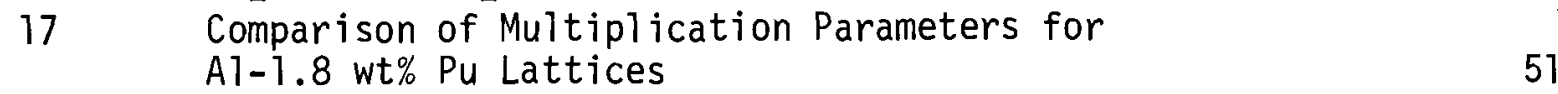

18 Nonthermal Parameters for the $0.80 \mathrm{in}$. Lattice of $\mathrm{UO}_{2}-2$ wt\% $\mathrm{PuO}_{2}$ ( $8 \%$ 240Pu) Fuel

19 Components of the Infinite Dilute Resonance Integrals used in HRG3

Cross Section Components of the ${ }^{238} \mathrm{U}$ Floor in HRG3

Comparison of Diffusion Coefficient Definitions in HRG3

for $0.80 \mathrm{in}$. Lattice of $\mathrm{UO}_{2}-2 \mathrm{wt} \% \mathrm{PuO}_{2}(8 \% 240 \mathrm{Pu})$

22 Diffusion Theory Results for $0.80 \mathrm{in}$. Lattice of $\mathrm{UO}_{2}-2 \mathrm{wt} \% \mathrm{PuO}_{2}$ ( $8 \%$ 240 Pu)

23 Effect of Changing the Diffusion Coefficient on

Calculated Values of $k_{\text {eff }}$ 
Comparison of Thermal Utilization, Disadvantage Factor and Thermal Value of $\bar{n} f$ for Reflecting and Qhite Boundary Conditions in the Thermalization Calculation

Comparison of Cell Averaged Thermal Cross Sections, and the Effects on Criticality for the $\mathrm{UO}_{2}-1.5 \mathrm{wt} \% \mathrm{Pu} 020.55 \mathrm{in}$. Lattice Which Include and Neglect Resonance Shielding

One and Two Dimensional Diffusion Theory Solutions for the 1.05 in. Al-5 wt\% Pu Fueled Lattice

Effect on Calculated $k_{\text {eff }}$ of Increasing the Number of Energy Groups

Transport Theory (DTF-IV) Results for $0.80 \mathrm{in}$. Lattice of $\mathrm{UO}_{2}-2 \mathrm{wt} \% \mathrm{PuO}_{2}(8 \% 240 \mathrm{Pu})$ 


\section{LIST OF FIGURES}

1 Variation of Calculated Multiplication with Buckling for $\mathrm{UO}_{2}$ Lattices

2 Variation of Calculated Multiplication with Buckling for Al-Pu Lattices

3 Variation of Calculated Multiplication with Buckling for $\mathrm{UO}_{2}-\mathrm{PuO}_{2}$ Lattices

4 Variation of Calculated Multiplication with $\mathrm{H} /{ }^{235} \mathrm{U}$ Atom Ratio for $\mathrm{UO}_{2}$ Lattices

5 Variation of Calculated Multiplication with H/Pu Atom Ratio for A1-Pu Lattices

6 Variation of Calculated Multiplication with H/Pu Atom Ratio for $\mathrm{UO}_{2}-\mathrm{PuO}_{2}$ Lattices

7 Reactivity Effect of Finite $\mathrm{PuO}_{2}$ Particles Relative to Homogeneous Fuel 
BNWL-1656

\section{UNCERTAINTIES IN THE ANALYSIS OF PLUTONIUM \\ FUELED LIGHT WATER MODERATED ASSEMBLIES}

\section{INTRODUCTION}

The accurate prediction of the time dependent neutronic behavior of a power reactor is a complex problem. Many simplifying assumptions have to be made in developing a mathematical model which describes the neutron processes. Some of these stem simply from the need to make the mathematics tractable whereas others are dictated by the desire to obtain practical solutions for engineering design. Nevertheless, valid technical bases and design criteria are required to assure that an engineered design meets its objectives. The establishment of valid design bases and criteria hinges on a thorough understanding of the principal neutronic events in a reactor system and the knowledge of the degree of mathematical rigor required to produce a given accuracy in a predicted neutronic design parameter. Historically, much of this understanding and knowledge has been gained by conducting theory-experiment correlation studies whereby the adequacy of the mathematical model (cross sections, neutronic theory and design procedures) is evaluated.

Experiments conducted in idealized reactor systems have played a significant role in the development of this portion of the nuclear technology. Idealized systems are studied in an attempt to limit the numbers of variables and concentrate on evaluating the adequacy of the cross sections and/ or neutronic theory, which represent the fundamental reactor physics aspects of power reactor systems. The technology is then developed further by building upon this base and extending the evaluation to systematically include the other variables present in the design problem, ultimately developing the mathematical models to the point where they can be used with confidence in designing power reactor systems. Thus, uniform lattice experiments form the base upon which these evaluations are made. 
The philosophy generally adopted in the nuclear industry is that uniform lattice experiments are fundamentally a test of the multigroup neutron spectrum calculation. The multigroup neutron spectrum calculation is usually made using cell codes. Since the unit cell calculation consists of cross sections and theory, the lattice experiments can be used to evaluate the adequacy of the neutron cross sections, the theoretical methods, or both.

The Plutonium Utilization Program was initiated in 1956 with the objectives of developing the base technology for safe and economical recycle of plutonium fuel in power reactor systems and demonstrating plutonium recycle in a practical manner. The program was conducted by the Pacific Northwest Laboratories Division, Battelle Memorial Institute under sponsorship of the AEC Division of Reactor Development and Technology. One phase of this program which received major emphasis was obtaining the data required to assure early commercial application of plutonium fuels in water reactors. Consistent with this was the effort of investigating the detailed physics properties of plutonium-fueled, water-moderated reactor systems.

On the basis of the rationale described above, these investigations focused on the more basic reactor physics aspects. Approach-to-critical and critical experiments were conducted for assemblies comprised of uniform lattice arrays of plutonium fuel rods and light water moderator. Measurements were made to determine the critical numbers of rods (i.e., $k_{\text {eff }}=1.000$ ) using plutonium fuels of differing content and romposition arrayed in lattices having a wide range of spacings between the fuel rods. These data formed the base upon which the adequacy of mathematical models have been evaluated. These investigations, which were initiated around 1962, were a continuing effort as both the data base expanded and the mathematica? models were improved. In this report, we give a chronological review of the findings of these studies leading to the most recent evaluations. As the title implies, we attempt to delineate the uncertainties that presently exist in the mathematical model.

In Section II, the technical approach which has been consistently used in these studies is given. A chronological review of this work is outlined in Section III, leading to the most recent results. The results of the 
correlations are presented in Section IV. The areas in the mathematical model where calculational errors and uncertainties are known to exist are discussed in Section $V$. To put this work in proper perspective to the overall problem of reactor design, the other reactor physics work conducted in the Plutonium Recycle Program at Pacific Northwest Laboratory (PNL) which bears on this is reviewed in Section VI. In the last section (VII) conclusions are stated and recommendations are given to guide future investigations which would build upon our work. The cross sections, theoretical methods and assembly modeling procedures used in this study are given in Appendix A. Some technical details of interest are included in Appendix B and Appendix C. 


\section{TECHNICAL APPROACH}

The technical approach that was adopted for this study is consistent with that which was developed and used in other similar programs conducted for the USAEC. In this approach the critical experiments provide a base upon which to evaluate the accuracy of the neutron cross sections and/or reactor physics methods used for calculating the spectrum of neutrons slowing down and thermalizing in a unit lattice cell. The focus of these studies was on the determination of inherent limitations in the cross sections and/or the theory so as to guide the development of improved methods and the experimental program itself. No attempts were made to develop an engineered normalized mathematical model since it was expected that the industrial organizations interested in plutonium recycle would accomplish this independently.

A consistent mathematical model has been employed in these studies. It consists of using an evaluated set of neutron cross sections, transport theory methods for performing cell calculations, and diffusion theory methods for performing leakage calculations. The neutron cross sections used in developing libraries for the cell codes were obtained from the master file developed and maintained over the years at PNL, $(1,2,3)$ culminating in the adoption and utilization of the ENDF/B system. (4) The transport theory cell methods adopted at the outset were the THERMOS type code $^{(5)}$ for performing neutron thermalization calculations and the GAM type code ${ }^{(6)}$ for performing slowing down calculations. These codes were imported around 1962 and subsequently utilized and modified over the years culminating in the most recent versions labelled BRT-I ${ }^{(7)}$ and HRG-3. ${ }^{(8)}$ The balance of neutrons in the critical assembly to obtain the neutron multiplication factor, $k_{\text {eff }}$, has usually been calculated using multigroup diffusion theory methods. The bulk of these calculations were made in one dimension using the computer code, HFN. ${ }^{(9)}$ Supplemental calculations using two dimensional diffusion theory methods and one dimensional transport theory methods have been made to assess the adequacy of the use of the HFN code for this purpose. Through the years, there have been variations and permutations within this framework, however, this was the basic approach employed. 


\section{II . BRIEF CHRONOLOGICAL REVIEW OF PNL CORRELATIONS OF THEORY} WITH MEASUREMENT FOR UNIFORM LATTICE EXPERIMENTS

Developing the neutronic technology for utilizing plutonium in light water reactors required basically three closely related technical tasks. The first task was to carry out the experimental program to generate the data needed for evaluating the accuracy of existing design methods. The second task was the conduction of a theory-experiment correlation program to evaluate the accuracy of neutronic design methods, identify where the theory or cross sections needed to be improved, and provide guidance to obtain additional experimental information. The third task was the theoretical development program, whereby limitations in the theory were removed and the course sought to obtain the most practical means of solving the neutronic design problem. We feel that it is instructive to chronologically review the development of lattice physics technology in the Plutonium Utilization Program to provide the reader insight into the evolution of technological improvement and the impact on design philosophy.

The first set of lattice measurements in water moderated lattices was made at PNL using plutonium-aluminum alloy fuel rods. $(10,11,12)$ At that time, this type of fuel was regarded as bridging the gap of knowledge between highly enriched uranium fuels and plutonium fuels. (13) Some analytical studies which predate our analyses were made to compare measured and calculated values of $k_{\text {eff }}$ for these lattires. Since these analyses helped to shape the pathway to follow in our analyses, we summarize the salient results of these studies here. Regimbal ${ }^{(14)}$ made calculations of the $\mathrm{A} 1-1.8 \mathrm{wt} \% \mathrm{Pu}$ and the $\mathrm{Al}-5 \mathrm{wt} \% \mathrm{Pu}$ fueled lattices. The principal results of his analysis were: (1) illustrating the sensitivity of the various cross sections in calculating $k_{\text {eff }}$ and (2) showing that measured and calculated values of $k_{\text {eff }}$ could be made to agree to within $1 \% \Delta \mathrm{k} / \mathrm{k}$ by adjusting $\nu$ for ${ }^{239} \mathrm{Pu}$. These results were valuable since they showed which areas of the calculation were the most sensitive in calculating $k_{\text {eff }}$ and thereby provided direction to subsequent physics developments. Aline and McWhorter ${ }^{(15)}$ also calculated the 1.8 wt\% Pu-Al fueled experiments. Their aim was to determine the $2200 \mathrm{~m} / \mathrm{sec}$ value of $\eta$ for ${ }^{239} \mathrm{Pu}$ which best fit the 
measured values of $k_{\text {eff }}$ for these experiments. At that time, two evaluations of the $2200 \mathrm{~m} / \mathrm{sec}$ parameters for ${ }^{239} \mathrm{Pu}$ existed, those of Leonard, and those of Sher and Felberbaum. (17) One result of Aline and McWhorter's analysis was that, for the two evaluations, the $2200 \mathrm{~m} / \mathrm{sec}$ cross sections recommended by Sher and Felberbaum for ${ }^{239} \mathrm{Pu}$ resulted in better agreement between measured and calculated values of $k_{\text {eff }}$. These studies by Regimbal and by Aline and McWhorter showed that the principal events in the multiplication of these lattices were the thermal and near thermal absorptions of neutrons with the thermal spectrum-averaged cross sections for ${ }^{239} \mathrm{Pu}$ being the most important cross sections in calculating $k_{\text {eff }}$.

Our calculations of plutonium lattice experiments began around the year 1963. At that time the plutonium recycle demonstration experiment using $\mathrm{UO}_{2}-\mathrm{PuO}_{2}$ fuel in the Experimental Boiling Water Reactor (EBWR) at Argonne National Laboratory was being scoped. $(18,19,20)$ One part of this demonstration program was to conduct critical experiments at PNL using this fuel to evaluate physics design methods. The data from the Al-Pu fueled lattice experiments along with selected data for $\mathrm{UO}_{2}$ fueled lattice experiments $(21,22)$ were used to evaluate the accuracy of neutronic calculational methods and provide a basis for making predictions of critical masses for the EBWR type mixed oxide fueled lattices. The results of these analyses are the basis for comparing results obtained in subsequent years. In Table 1 we show, summarily, the results of our theory experiment correlation for $\mathrm{UO}_{2}, \mathrm{Al}-\mathrm{Pu}$, and $\mathrm{UO}_{2}-\mathrm{PuO}_{2}$ lattices over the years since 1963. In the narrative below, we briefly describe the major changes in our analysis methods which resulted in the change of the correlation.

Our initial analysis (time period 1963-65) gave the following results. For the $\mathrm{UO}_{2}$ fueled experiments, ${ }^{(23)}$ the calculated values of $k_{\text {eff }}$ were lower than experiment by $1 \% \Delta k / k$, with little trend apparent with either lattice pitch, H/U ratio, or buckling. For the Al-Pu fueled lattices, (24) the calculated values of $k_{\text {eff }}$ were generally larger than measured values. Our findings for the Al-Pu fueled systems corroborated those of Aline and McWhorter, ${ }^{(15)}$ in that the agreement between measurement and calculation was better using Sher's and Felderbaum's recommended $2200 \mathrm{~m} / \mathrm{sec}$ constants 
TABLE 1. Chronological Summary of Correlations

\begin{tabular}{|c|c|c|c|c|c|c|c|c|}
\hline \multirow[b]{3}{*}{ Time Period } & \multicolumn{6}{|c|}{ Results* } & \multirow{2}{*}{\multicolumn{2}{|c|}{$\begin{array}{l}\text { Identification } \\
\text { Of Code \& } \\
\text { Data Changes } \\
\end{array}$}} \\
\hline & \multicolumn{2}{|c|}{$\mathrm{UO}_{2}$ Fueled Lattices } & \multicolumn{2}{|c|}{ Al-Pu Fueled Lattices } & \multicolumn{2}{|c|}{$\mathrm{UO}_{2}-\mathrm{PuO}_{2}$ Fueled Lattices } & & \\
\hline & 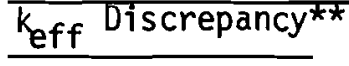 & $\overline{\text { Trends }}$ & $\mathrm{k}_{\text {eff }}$ Discrepancy & Trends & $k_{\text {eff }}$ Discrepancy & $\bar{\star}$ Trends & Codes & Section \\
\hline $1963-65$ & $v-1$ & None & +3 to -2 & $\begin{array}{l}\text { Lattice } \\
\text { Spacing }\end{array}$ & -0.1 to -0.5 & None & - & - \\
\hline $1965-67$ & -3 to -1 & $\begin{array}{l}\text { Lattice } \\
\text { Spacing }\end{array}$ & +5 to -0.5 & $\begin{array}{l}\text { Lattice } \\
\text { Spacing }\end{array}$ & +1 to -2 & $\begin{array}{l}\text { Lattice } \\
\text { Spacing }\end{array}$ & HRG & Oxygen \\
\hline $1967-69$ & -3 to -1 & $\begin{array}{l}\text { Lattice } \\
\text { Spacing }\end{array}$ & +4 to +1.4 & $\begin{array}{l}\text { Lattice } \\
\text { Spacing }\end{array}$ & -1 to +3 & $\begin{array}{l}\text { Lattice } \\
\text { Spacing }\end{array}$ & $\begin{array}{l}\text { HRG \& } \\
\text { THERMOS }\end{array}$ & $\begin{array}{l}\text { Thermal } \\
\text { S Fissiles }\end{array}$ \\
\hline $1969-71$ & +.4 to -0.5 & $\begin{array}{l}\text { Lattice } \\
\text { Spacing }\end{array}$ & +4 to +0.1 & $\begin{array}{l}\text { Lattice } \\
\text { Spacing }\end{array}$ & -1.5 to +1.6 & $\begin{array}{l}\text { Lattice } \\
\text { Spacing }\end{array}$ & HRG & $\begin{array}{l}\text { Hydrogen } \\
\text { and } \\
238 U\end{array}$ \\
\hline $1971-$ & +.4 to -0.5 & $\begin{array}{l}\text { Lattice } \\
\text { Spacing }\end{array}$ & +2 to +0.5 & $\begin{array}{l}\text { Lattice } \\
\text { Spacing }\end{array}$ & $\pm 7 \%$ & $\begin{array}{l}\mathrm{H} / \mathrm{Pu}, \mathrm{Ro} \\
\text { Size and } \\
\text { Lattice } \\
\text { Spacing }\end{array}$ & & - \\
\hline
\end{tabular}

* The experimental data base was expanding so that the results are not in one-for-one correspondence with time but rather a generalized observation for each type of fueled lattice.

** $\frac{k_{\text {eff }} \text { calculated- } k_{\text {eff }} \text { measured }}{k_{\text {eff }} \text { measured }} \times 100$ 
for ${ }^{239} \mathrm{Pu}$ than with Leonard's recommended values. The predicted critical loadings of $\mathrm{UO}_{2}-1.5 \mathrm{wt} \% \mathrm{PuO}_{2}$ fuel (EBWR type) were quite close to the values which were subsequently measured. $(25,26,27)$ The suspected reason for such good agreement between prediction and observation for the EBWR type mixed oxide criticals was compensating errors, namely the net effect of calculating larger multiplication values for Al-Pu fueled systems and smaller multiplication values for $\mathrm{UO}_{2}$ fueled systems. The only significant trend in discrepancies between measured and calculated values of $k_{\text {eff }}$ was with lattice pitch for the A1-Pu fueled systems (largest discrepancy at the tightest lattice, smallest discrepancy at the loosest lattice). Therefore, the area of further theoretical investigation centered around the calculation of thermalization events (e.g., boundary conditions, scattering kernels, ${ }^{240} \mathrm{Pu}$ and ${ }^{239} \mathrm{Pu}$ resonance overlap, etc.).

Though the thermalization area was suspected as the cause of the discrepancies between calculation and experiment for the Al-Pu systems, the change in agreement between calculated and measured values as noted by the time period 1965-67 stemmed from improvements in other areas of the calculation. As shown in Table 1, the agreement between calculation and experiment got worse for the time period $1965-67^{(28,29,30)}$ relative to the period 1964-65. Reanalysis of experimental data resulted in minor changes between calculated and measured values. The principal changes were due to improvements in neutron slowing down and resonance absorption theory $(31,32)$ plus the discovery of errors in the description of the high energy cross sections for oxygen. The trends observed in the correlations suggested major errors in calculating resonance absorption in ${ }^{238} \mathrm{U}$ (evidenced by the $\mathrm{UO}_{2}$ results), and errors in calculating thermalization events in plutonium fueled lattices (evidenced by the A1-Pu results), with the mixed oxide lattices reflecting a certain degree of error cancellation. In the interim between this period and the next, attention was focused on the calculation of resonance absorption in ${ }^{238} \mathrm{U}$ because of the discrepancy in the $\mathrm{UO}_{2}$ lattice results and the thermalization calculation because of the discrepancy in the A1-Pu lattice results. 
Even though status of knowledge of the $2200 \mathrm{~m} / \mathrm{sec}$ constants was presumably improved, ${ }^{(33)}$ and improvements were made in the mathematical modeling of the lattices, little improvement was observed in the correlation as evidenced by comparing results of the 1967-69(34) and 1965-67 time periods. We speculated that the lack of discrepancy trends with leakage or other parameters could itself be due to compensating errors. Therefore, the lattices with the largest leakage component were selected as the basis for evaluating the leakage calculation. A series of measurements were made for the optimum moderated lattice with boron additions made in water to increase the size of the core and reduce the leakage. (35) A random sample of A1-Pu fuel rods were gamma scanned to determine if axial enrichment variations were present and selected rods were destructively analyzed to check the plutonium content and isotopic composition and to determine if poisons (e.g., rare earth contaminants) were present in the fuel. These analyses failed to uncover anything which could explain the noted discrepancies. The correlation of the A1-5 wt\% Pu borated lattice measurements showed a discrepancy in calculated and measured values of $k_{\text {eff }}$ which were independent of amount of boron in the moderator. ${ }^{(36)}$ since the discrepancy was independent of core size suspicion of an inadequate calculation of leakage was not confirmed. The net result was to continue focusing on the resonance absorption and thermalization calculation.

In the 1969-71 time period, the results of the correlation for $\mathrm{UO}_{2}$ fueled lattices changed significantly and the discrepancies were reduced for the other lattice correlations. $(37,38)$ Prior to this time, the crosssection data for ${ }^{238} \mathrm{U}$ and the other isotopes used in the unit cell codes (HRG and THERMOS) were derived from an early version $(1,2)$ of the Battelle Northwest Master Library (BNWML). ${ }^{(3)}$ In this early version the differential values of the radiation widths for the ${ }^{238} U$ resonances were arbitrarily adjusted upwards from the evaluated values ${ }^{(2)}$ (within stated uncertainties) to force agreement with the recommended value for the $238_{U}$ infinite dilution resonance integral (280b.). (39) In this period (1969-71) the values for the ${ }^{238} \mathrm{U}$ resonance cross sections were adjusted to reflect the values recommended in version I of the ENDF/B file. ${ }^{(40)}$ The principal 
difference in other isotopic cross sections between the 1969 version of the BNWML and the earlier version was for hydrogen in the MeV region. The major effect on the correlation was due to the ${ }^{238} \mathrm{U}$ cross sections. The ENDF/B-I data for ${ }^{238} \mathrm{U}$ significantly reduced the trend with lattice spacing between measured and calculated values of $\mathrm{k}_{\text {eff }}$ for $\mathrm{UO}_{2}$ lattices. The effect of changes in the $\mathrm{H}$ cross sections was to reduce the magnitude of the discrepancy with lattice spacing for the Al-Pu lattices (and also to bring calculated and measured age in water in agreement). The net effect of ${ }^{238} \mathrm{U}$ and $\mathrm{H}$ data changes for the mixed oxide fueled systems was to improve the correlation slightly.

In the last analysis made in 1971, the results of the correlations have not changed drastically. The principal cause of improving the agreement between calculation and experiment for the Al-Pu fueled systems is revised experimental data resulting from reanalysis of the original experiments. ${ }^{(41)}$ The analyses were essentially terminated in 1971 with a few sensitivity studies commissioned thereafter. One significant finding of these few sensitivity studies was that the degree of agreement between calculation and experiment as evidenced by the 1971 results in Table 1 is significantly changed due primarily to two causes. The most significant is changing from version I to version II of ENDF/B cross sections. The net effect is to yield calculated values of $\mathrm{k}_{\text {eff }}$ for $\mathrm{UO}_{2}$ and $\mathrm{UO}_{2}-\mathrm{PuO}_{2}$ fueled lattices which are roughly 1 to $3 \%$ lower than measured values with the largest discrepancy evident for tight lattices. The second cause is the effect of changing from diffusion to transport theory in calculating the leakage from the critical assemblies. For the limited number of cases studied, it appears that the use of diffusion theory leads to overestimating the assembly leakage by around $1 \% \Delta k / k$ (i.e., diffusion theory calculates low values of $\left.k_{\text {eff }}\right)$. In the following sections we

- present the results of our correlations of critical experiments made in 1971.

- show the differences in calculated results resulting from use of improved cross sections and use of higher order calculations.

- and examine the effects of uncertainties in calculating these experimental systems to provide perspective in the degree of correlation that the designer should expect. 


\section{CORRELATIONS}

The results of critical size measurements form a base upon which calculational methods can be tested. The methods developed and used at Battelle-Northwest for calculating plutonium enriched systems are evaluated in this section by comparing calculated and measured values of $k_{\text {eff }}$ for plutonium fueled lattices. (41) A detailed description of the methods and the cross sections used in this correlation are given in Appendix A. However, this comparison alone cannot be considered a thorough test of the calculational methods. Extending the correlation to include experimental data from other critical experiments adds to the validity of the test. Therefore, experimental information on $\mathrm{k}_{\text {eff }}$ for slightly enriched $\mathrm{UO}_{2}$ lattices and some homogeneous critical experiments was used to broaden the base on which the calculational methods were tested. The results of these additional correlations are also given in this section.

The correlation of measured and calculated values of $k_{\text {eff }}$ is not an exhaustive evaluation of the calculational methods. Studies of correlating other neutronic parameters have also been made at Battelle-Northwest. A summary of the pertinent results of these studies is given in Section $V$.

\section{A. EXPERIMENTS CORRELATED}

The selection of experiments for this analysis was limited to those critical assemblies which are considered to be uniform, clean systems. The critical assemblies included both lattices and homogeneous reactor systems. 1. Lattices

The plutonium fueled uniform lattice experiments summarized in Reference 41 provided the base of data for the theory-experiment correlation. These included three enrichments of plutonium in aluminum-plutonium alloy fuels and four enrichments of $\mathrm{PuO}_{2}$ in $\mathrm{UO}_{2}-\mathrm{PuO}_{2}$ fuels.

A number of slightly enriched $\mathrm{UO}_{2}$ lattice critical experiments were also included in the analysis. $(21,22,41,42)$ Having data on assemblies which contain only plutonium in the fuel (the Al-Pu fueled systems) and on 
assemblies which contain only uranium in the fuel (the $\mathrm{UO}_{2}$ fueled systems) allows us to gain insight into the combined effects of uranium and plutonium in the mixed oxide fueled assemblies. The $\mathrm{UO}_{2}$ lattices were selected to cover a range of enrichments, lattice spacings and clad types. A summary of the key experimental results is given in Table 2.

\section{Homogeneous Criticals}

Some aqueous solution critical experiments were included in the evaluation of the calculational methods. They consist of four experiments conducted at Dak Ridge using uranyl $\left({ }^{235} \mathrm{U}\right)$ nitrate solution ${ }^{(45)}$ and two experiments conducted at Battelle-Northwest using plutonium nitrate solution. (46) The Dak Ridge experiments were large bare systems. The results have been used extensively throughout the years as benchmark experiments for ${ }^{235} U$ systems. ${ }^{(47)}$ The fact that they are homogeneous, bare, spherical and physically large systems makes them attractive for calculational benchmarks because of their simplicity. The plutonium nitrate systems consist of one bare and one fully water reflected sphere. An extensive analysis of plutonium nitrate solution criticals had been made previously. ${ }^{(48)}$

The intent in our analysis was to bridge the gap resulting from the use of different theoretical methods and cross sections from the previous analysis. The experimental results for these homogeneous criticals are given in Table 3.

\section{B. RESULTS}

A measure of the adequacy of our calculational model in predicting $k_{\text {eff }}$ for the various experiments is shown in Tables 4 through 7 where we show the calculated $k_{\text {eff }}$ for each individual experiment and also the mean value of $k_{\text {eff }}$ for each series of experiments.

1. Lattices

Looking first at the plutonium only systems, it is seen that the calculated results for the Al-Pu criticals shown in Table 4 are high. The calculated values of $k_{\text {eff }}$ for the Al-1.8 wt\% Pu and Al-5 wt\% Pu fueled lattices range from 0.04 to $1.13 \%$ high with no apparent trend with lattice spacing. 
TABLE 2. Summary of $\mathrm{UO}_{2}$ Fueled Experiments

\begin{tabular}{|c|c|c|c|c|c|c|c|c|c|}
\hline \multirow{3}{*}{ Laboratory } & \multirow{3}{*}{ Reference } & \multirow{2}{*}{\multicolumn{2}{|c|}{ Fuel }} & & & \multirow{3}{*}{$\begin{array}{l}\text { Lattice } \\
\text { Spacing } \\
\text { (in.) } \\
\end{array}$} & \multirow{3}{*}{$\begin{array}{l}\text { Moderator-to } \\
\text { Fuel Volume } \\
\text { Ratio } \\
\end{array}$} & \multicolumn{2}{|c|}{ Experimental Results } \\
\hline & & & & & & & & Critical & \\
\hline & & $w t \% 235_{U}$ & $\begin{array}{l}\text { Pellet Dia. } \\
\text { (in.) }\end{array}$ & Material & $\begin{array}{l}\text { Clad } \\
\text { Thickness(in) }\end{array}$ & & & Number & $\begin{array}{l}\text { Geometrical } \\
\text { Buckl }\end{array}$ \\
\hline WAPD & 21 & 2.734 & 0.300 & $304-S S$ & 0.01608 & 0.405 & 1.048 & 3043 & 40.75 \\
\hline WAPD & 21 & 2.734 & 0.300 & $304-S S$ & 0.01608 & 0.435 & 1.405 & 1851 & 53.23 \\
\hline WAPD & 21 & 2.734 & 0.300 & $304-S S$ & 0.01608 & 0.470 & 1.853 & 1301 & 63.26 \\
\hline WAPD & 22 & 2.734 & 0.300 & $304-S S$ & 0.01608 & 0.573 & 3.357 & 826 & 65.64 \\
\hline WAPD & 22 & 2.734 & 0.300 & $304-S S$ & 0.01608 & 0.615 & 4.078 & 790 & 60.07 \\
\hline WAPD & 22 & 2.734 & 0.300 & $304-S S$ & 0.01608 & 0.665 & 4.984 & 813 & 52.92 \\
\hline BNW & 42 & 2.350 & 0.440 & $\mathrm{Al}$ & 0.0300 & 0.750 & 2.408 & 385 & 94.3 \\
\hline BAPL & 43 & 1.328 & 0.383 & A1 & 0.0280 & $0.613^{*}$ & 1.330 & 2308 & 32.59 \\
\hline BAPL & 43 & 1.328 & 0.383 & Al & 0.0280 & $0.711 *$ & 2.235 & 1706 & 34.22 \\
\hline B\&W & 44 & 2.490 & 0.4054 & Al & 0.0320 & 0.595 & 1.371 & 190 & 70.1 \\
\hline
\end{tabular}

*Triangular lattices; all others are square. 
TABLE 3. Summary of Experimental Results for Aqueous Solution Experiments $(45,46)$

Uranyl Nitrate Solution

Sphere Diameter

Experiment \#

\section{]}

2

(in.)

$\mathrm{H} /{ }^{235} \mathrm{U}$

Corrected Measured

]

27.24

1378

1.00026

3

27.24

1177

0.99975

4

27.24

1033

0.99994

10

27.24

972

0.99924

1835

1.00031

Plutonium Nitrate Solution

Sphere Diameter

(in.)

H/Pu Atom Ratio

$\begin{array}{cc}\text { Reflector } & \text { Measured k } \\ \begin{array}{cc}\mathrm{H}_{2} \mathrm{O} & 1.0000 \\ \text { None } & 1.0000\end{array}\end{array}$

15.2

553

15.2

668

None

1.0000 
TABLE 4. Calculated Values of $k_{\text {eff }}$ for Al-Pu Criticals* (Measured $k_{\text {eff }}=1.0000$ )

\begin{tabular}{|c|c|c|c|c|}
\hline \multirow{2}{*}{$\begin{array}{l}\text { Lattice } \\
\text { Spacing } \\
\text { (in.) }\end{array}$} & \multicolumn{2}{|c|}{ Al-1.8 wt\% Pu } & \multicolumn{2}{|c|}{ Al-2.0 wt\% Pu } \\
\hline & H/Pu Atom Ratio & $k_{\text {eff- }}$ & H/Pu Atom Ratio & $k_{\text {eff- }}$ \\
\hline 0.75 & 630 & 1.0086 & 578 & 1.0182 \\
\hline 0.80 & 810 & 1.0099 & 743 & 1.0240 \\
\hline 0.85 & 1000 & 1.0079 & 918 & 1.0213 \\
\hline 0.90 & 1204 & 1.0072 & 1104 & 1.0198 \\
\hline 0.95 & 1418 & 1.0045 & 1300 & 1.0189 \\
\hline & Mean $=1.00$ & \pm 0.002 & Mean $=$ & \pm 0.00 \\
\hline
\end{tabular}

\begin{tabular}{|c|c|c|c|}
\hline & & Al-5 wt\% Pu & \\
\hline $\begin{array}{l}\text { Lattice } \\
\text { Spacing } \\
\text { (in.) }\end{array}$ & $\begin{array}{l}\text { Boron } \\
\text { in } \mathrm{H}_{2} 0 \\
\text { (wppm) } \\
\end{array}$ & H/Pu Atom Ratio & $k_{\text {eff- }}$ \\
\hline 0.85 & 0 & 355 & 1.0067 \\
\hline 1.05 & 0 & 665 & 1.0113 \\
\hline 1.05 & 48 & 665 & 1.0004 \\
\hline 1.05 & 101 & 665 & 1.0072 \\
\hline 1.05 & 164 & 665 & 1.0042 \\
\hline 1.05 & 229 & 665 & 1.0029 \\
\hline 1.05 & 285 & 665 & 1.0050 \\
\hline 1.30 & 0 & 1150 & 1.0069 \\
\hline
\end{tabular}

*The uncertainties assigned to the mean values are standard deviations for a typical value rather than for the mean value. 
TABLE 5. Calculated Values of $\mathrm{k}_{\text {eff }}$ for $\mathrm{UO}_{2}$ Lattices*

Lattice

Spacing (in.) $H / U \quad H /{ }^{235} U$ Enrichment Pellet 0.405 Atom Ratio Atom Ratio $(\% 235 \mathrm{U})$ Dia.(in.) $k_{\text {eff- }}$ 0.435 3.06 112

2.734

0.300 1.0035

0.470

4.11

150

2.734

$\begin{array}{ll}0.300 & 1.0017\end{array}$

0.573

5.42

198

2.734

0.300

1.0002

0.615

9.86

361

2.734

0.300

0.9989

0.665

11.93

436

2.734

0.300

0.9980

0.750

533

2.734

0.300

0.9969

$0.6134^{\star \star}$

7.85

334

2.35

0.440

1.0028

$0.711^{\star \star}$

4.06

306

1.328

0.383

0.9962

0.595

6.82

514

1.328

0.383

0.9952

159

2.490

$0.4054 \quad 1.0013$

Mean $=\overline{0.995 \pm 0.0029}$

\footnotetext{
*The uncertainties assigned to the mean values are standard deviations for a typical value rather than for the mean.

**Triangular pitch; all others square.
} 
TABLE 6. Calculated Values of $\mathrm{k}_{\text {eff }}$ for $\mathrm{UO}_{2}-\mathrm{PuO}_{2}$ Criticals*

(Measured $k_{\text {eff }}=1.0000$ )

\begin{tabular}{|c|c|c|c|c|c|}
\hline \multirow{2}{*}{$\begin{array}{c}\text { Lattice } \\
\text { Spacing } \\
\text { (in.) }\end{array}$} & \multirow{2}{*}{$\begin{array}{l}\text { H/Pu } \\
\text { Atom } \\
\text { Ratio } \\
\end{array}$} & \multicolumn{4}{|c|}{$-2-2 \frac{10}{k_{e}}$} \\
\hline & & $8 \%{ }^{240} \mathrm{Pu}$ & $16 \%{ }^{240} \mathrm{Pu}$ & \multicolumn{2}{|c|}{$24 \%{ }^{240} \mathrm{Pu}$} \\
\hline 0.80 & 238 & 0.9920 & -- & \multicolumn{2}{|c|}{0.9942} \\
\hline 0.93 & 391 & 0.9979 & 0.9982 & \multicolumn{2}{|c|}{0.9963} \\
\hline 1.05 & 554 & 0.9913 & 0.9931 & \multicolumn{2}{|c|}{0.9981} \\
\hline 1.143 & 693 & 0.9992 & 1.0000 & \multicolumn{2}{|c|}{1.0007} \\
\hline 1.32 & 991 & 0.9999 & 0.9995 & \multicolumn{2}{|c|}{0.9985} \\
\hline \multirow[t]{2}{*}{1.386} & 1113 & 0.9979 & 0.9964 & \multicolumn{2}{|c|}{0.9971} \\
\hline & Mean & $0.9964 \pm 0.0043$ & $0.9974 \pm 0.0024$ & 0.9975 & 0.0022 \\
\hline \multicolumn{3}{|c|}{$\mathrm{UO}_{2}-4 \mathrm{wt} \% \mathrm{PuO}{ }_{2}$} & \multicolumn{3}{|c|}{$\mathrm{UO}_{2}-1.5 \mathrm{wt} \% \mathrm{PuO}_{2}$} \\
\hline $\begin{array}{l}\text { Lattice } \\
\text { Spacing } \\
\text { (in.) } \\
\end{array}$ & $\begin{array}{l}\mathrm{H} / \mathrm{Pu} \\
\text { Atom } \\
\text { Ratio } \\
\end{array}$ & $k_{e f f-}$ & $\begin{array}{c}\text { Lattice } \\
\text { Spacing } \\
\text { (in.) } \\
\end{array}$ & $\begin{array}{l}\mathrm{H} / \mathrm{Pu} \\
\text { Atom } \\
\text { Ratio } \\
\end{array}$ & $k_{e f f-}$ \\
\hline 0.85 & 153 & 0.9964 & 0.55 & 230 & 1.0035 \\
\hline 0.93 & 203 & 0.9940 & 0.60 & 326 & 0.9988 \\
\hline 1.05 & 289 & 1.0035 & 0.71 & 567 & 0.9988 \\
\hline 1.143 & 414 & 1.0024 & 0.80 & 794 & 0.9968 \\
\hline 1.386 & 578 & 1.0062 & 0.90 & 1077 & 0.9971 \\
\hline 1.60 & 805 & 1.0047 & 0.93 & 1169 & 0.9989 \\
\hline 1.70 & 922 & 1.0031 & Mean & 0.9999 & Ju \\
\hline
\end{tabular}

*The uncertainties assigned to the mean values are standard deviations for a typical value rather than for the mean value. 
TABLE 7. Calculated Values of $\mathrm{k}_{\text {eff }}$ for $\mathrm{UO}_{2}-6.6$ wt\% $\mathrm{PuO}_{2}$ Criticals*

\begin{tabular}{lccc}
$\begin{array}{l}\text { Lattice } \\
\begin{array}{c}\text { Spacing } \\
\text { (in.) }\end{array}\end{array}$ & $\begin{array}{c}\text { H/Pu } \\
\text { Atom Ratio }\end{array}$ & & \\
\cline { 1 - 2 } 0.52 & 75 & $k_{\text {eff }}$ \\
0.56 & 97 & 1.0094 \\
0.735 & 210 & 1.0081 \\
0.792 & 253 & 0.9996 \\
& & 1.0041 \\
\hline & Mean $=$ & $1.0053 \pm 0.0053$
\end{tabular}

*The uncertainties assigned to the mean values are standard deviations for a typical value rather than for the mean value. **These were all square pitch lattices. 
Adding boron to the moderator for the 1.05 inch lattice containing A1-5 wt\% Pu fuel does not significantly perturb the result of the correlation. The purpose of conducting the measurements using boron in this lattice was to evaluate the effect of neutron leakage from the lattice since adding boron requires more rods to maintain critical which in turn lowers the radial leakage. The rationale rests on the assumption that the only parameters which change significantly with boron addition are the thermal utilization, $f$, and the neutron leakage, both being reduced. Therefore, if the calculational trends do not change systematically with boron addition, then it can be inferred that both of these quantities ( $f$ and $D B^{2}$ ) are being calculated correctly, or incorrectly with the errors just compensating. Since the results for the lattices do not produce a corresponding systematic effect, it could be concluded that the leakage calculation is adequate, assuming $f$ is also calculated correctly. The calculated values of $k_{\text {eff }}$ for the A1-2 wt\% Pu series are approximately $2 \%$ higher than the other results. Because the discrepancy for this particular series of experiments is so much greater than for any of the other experiments, it was suspected that something could be systematically wrong with the experiments. The fuel rods have been nondestructively and destructively re-examined. (49) A chemical analysis and an isotopic analysis was made to determine plutonium concentration and composition, and a spectrochemical analysis was performed in search of impurities. This re-examination of the fuel did not produce any new information that could explain why the discrepancy would be so much larger for this series of experiments than for the other experiments. The correlation results remain, as they always have over the years, ${ }^{(24)}$ unexplainable in terms of the difference from the results obtained for the A1$1.8 w t \%$ and $5.0 w t \%$ Pu fueled experiments. An explanation of the cause of the discrepancy remains an open question.

The calculated results of $k_{\text {eff }}$ for the uranium dioxide criticals, shown in Table 5, range from about $0.5 \%$ low to about $0.4 \%$ high. A trend such that the calculated $k_{\text {eff }}$ value decreases with increasing lattice pitch is noticeable for the six $2.734 \mathrm{wt} \%{ }^{235} \mathrm{U}$ fueled lattices. The span of this trend is $0.66 \% \Delta \mathrm{k} / \mathrm{k}$. 
The correlations for the mixed oxide systems, shown in Tables 6 and 7, show some systematic trends. For the $\mathrm{UO}_{2}-1.5 \mathrm{wt} \% \mathrm{PuO}_{2}$ fueled lattices, a general trend with lattice spacing is discernible for the spacings from $0.55 \mathrm{in}$. to $0.90 \mathrm{in.;}$ however, $k_{\text {eff }}$ increases slightly for the $0.93 \mathrm{in.}$ lattice. The results for the $\mathrm{UO}_{2}-2 \mathrm{wt} \% \mathrm{PuO}_{2}$ fueled criticals appear to be randomly distributed. There is no trend with lattice spacing and it does not appear that the effect of changes in Pu composition exhibit any noticeable trend either. Similar results are obtained for the $\mathrm{UO}_{2}-4 \mathrm{wt} \% \mathrm{PuO}_{2}$, and $\mathrm{UO}_{2}-6.6 \mathrm{wt} \% \mathrm{PuO}_{2}$ fueled systems as shown in Tables 6 and 7 respectively.

Lattice criticals containing slightly enriched fuel rods are typically high leakage systems. Since leakage is one of the more obvious candidates as a source of error in the theoretical analysis, it is instructive to examine the results in terms of leakage to determine if systematic effects are evident. The calculated values of $k_{\text {eff }}$ for all of the lattices are plotted as a function of the buckling in Figure 1 for the $\mathrm{UO}_{2}$ fueled lattices, in Figure 2 for the Al-Pu fueled lattice, and in Figure 3 for the mixed oxide fueled lattices.

Examining the results plotted in Figures 1-3 no noticeable trends are evident for the $\mathrm{UO}_{2}, \mathrm{Al}-\mathrm{Pu}$ and $\mathrm{UO}_{2}-\mathrm{PuO}_{2}$ fueled assemblies. Thus, lacking trends, it would appear that our analysis of leakage from these assemblies is adequate, or if an error exists it is being compensated for by errors somewhere else in the analysis.

One of the reasons for conducting critical experiments using many different lattice spacings with the same fuel rods is to provide data which cover a range of moderator-to-fuel volume ratios. Having data in which the only variable that changes is the ratio of moderator to fuel allows the evaluation of theoretical models for systematic errors. It is generally conceded that a calculation made for overmoderated lattices is the least susceptible to calculational error because the effects of the many approximations made in the theoretical analysis are much smaller for these types of assemblies. Therefore, it is instructive to examine the results of the calculation to see if a trend exists when $k_{\text {eff }}$ is plotted as a function of 
BNWL-1656

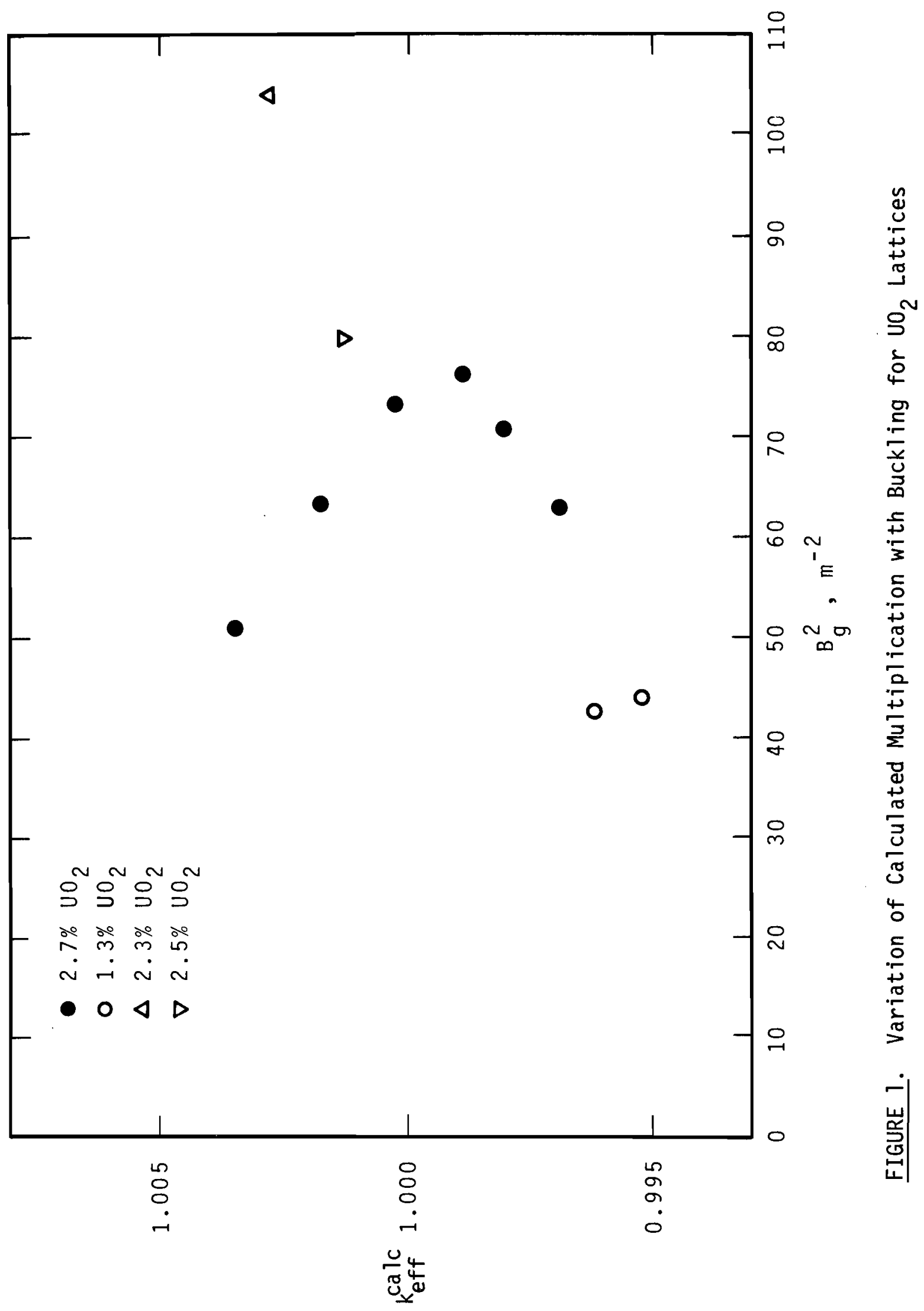


BNWL-1656

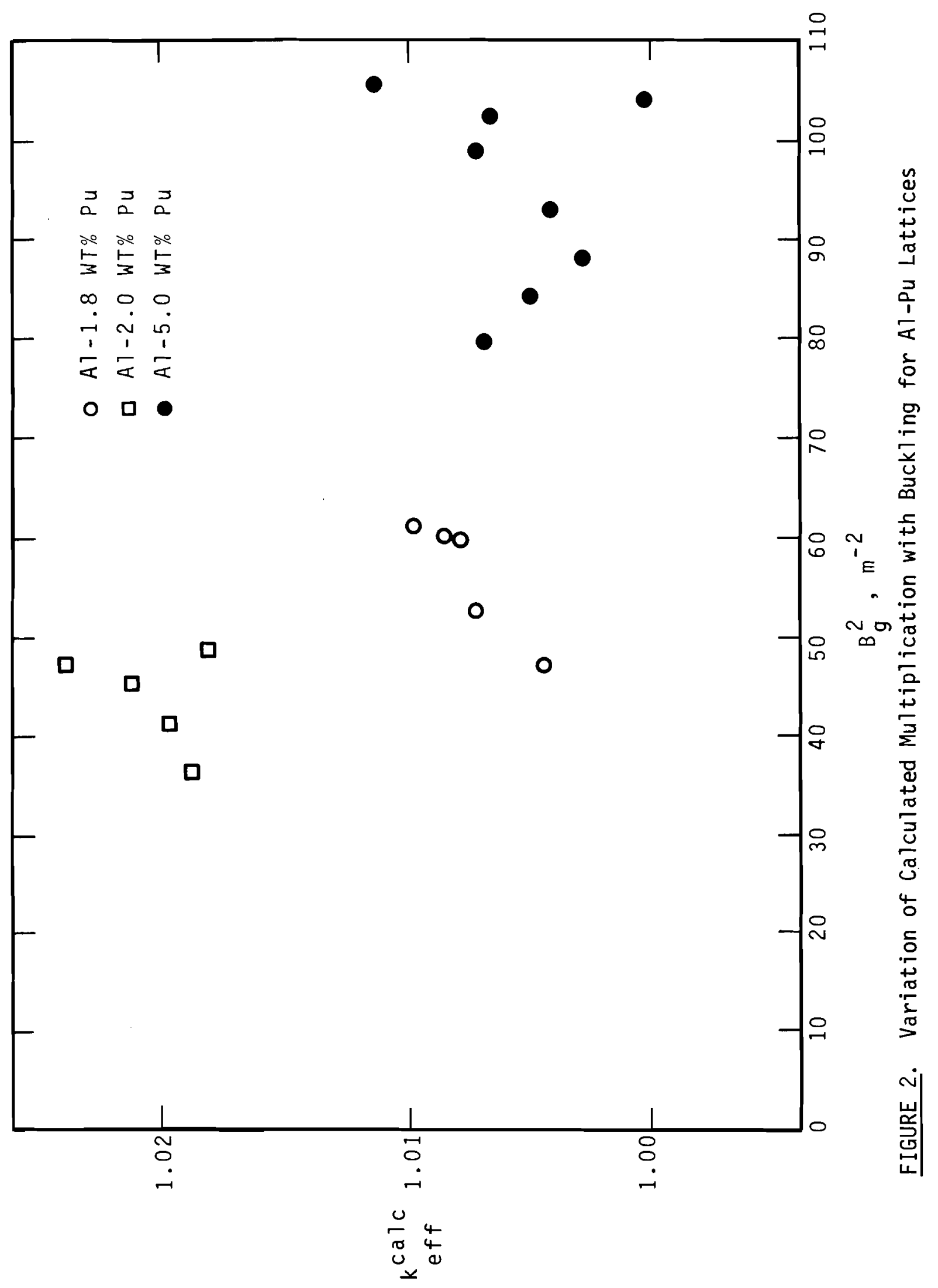




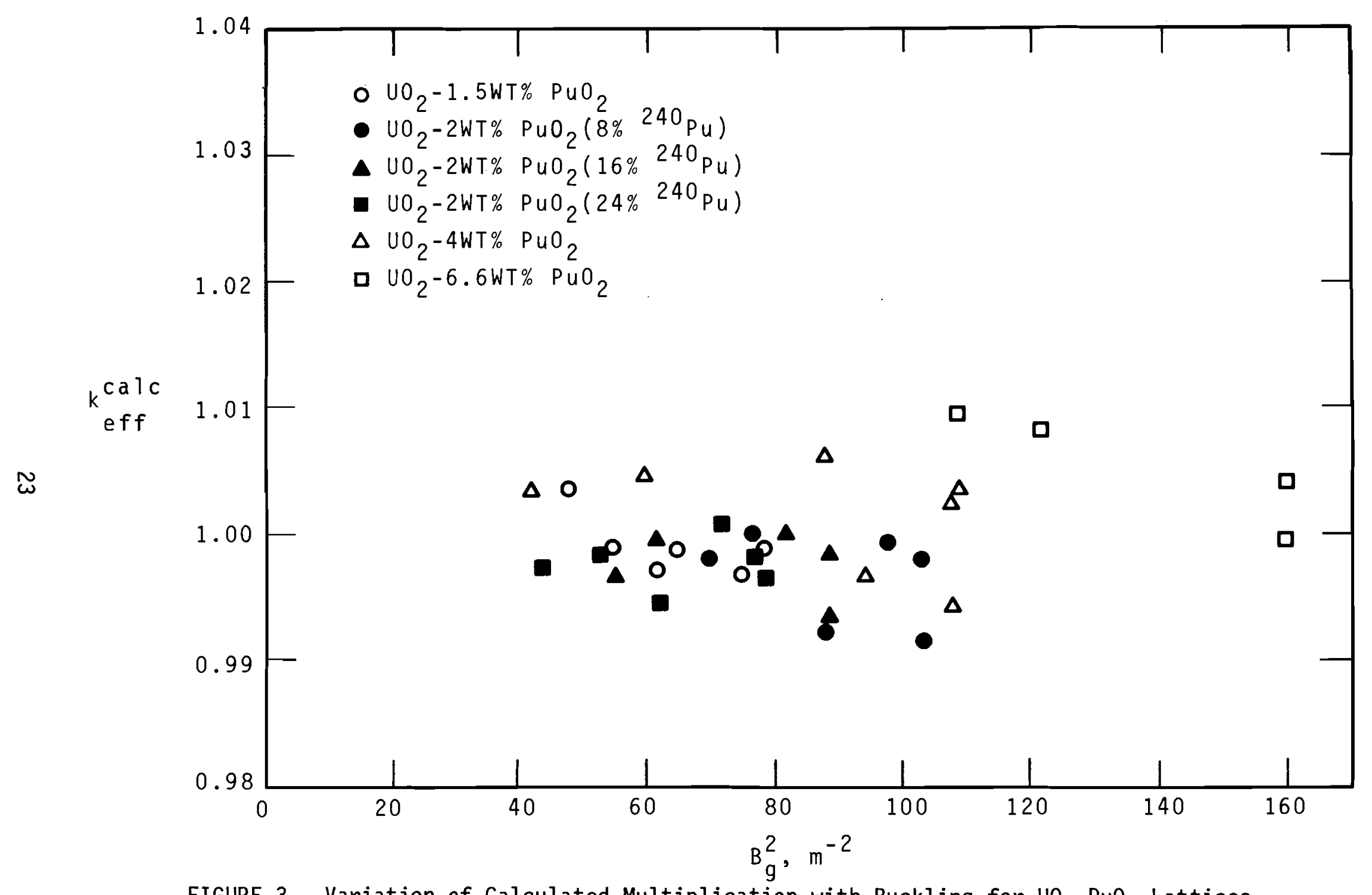

FIGURE 3. Variation of Calculated Multiplication with Buckling for $\mathrm{UO}_{2}-\mathrm{PuO}_{2}$ Lattices 
moderator-to-fuel ratio. A plot of calculated $k_{\text {eff }}$ versus hydrogen-touranium-235 atom ratio is shown in Figure 4 for the $\mathrm{UO}_{2}$ fueled experiments. Plots of $k_{\text {eff }}$ versus hydrogen-to-plutonium atom ratio are shown in Figures 5 and 6 for the plutonium fueled critical experiments.

The only trends noticeable are for the $\mathrm{UO}_{2}$ fueled lattices. Neglecting the point at $\mathrm{H}^{235} \mathrm{U}$ of 330 which appears out of line, a trend is observable in the curve (Figure 4) for the $\mathrm{UO}_{2}$ fueled lattices. The larger the $\mathrm{H} /{ }^{235} \mathrm{U}$ ratio the lower the calculated $\mathrm{k}_{\text {eff }}$. Using the argument presented above concerning which lattices should be the easiest to calculate, we would arrive at the judgment that the calculational methods are causing about a $-0.5 \%$ error in $k_{\text {eff }}$ since this is the discrepancy for open lattices having $\mathrm{H} /{ }^{235} \mathrm{U}$ ratios of $>500$.

The results of this analysis do not show very many systematic variations in calculated values of $k_{\text {eff }}$. The only trends which are discernable are: (1) the calculated values of $\mathrm{k}_{\text {eff }}$ are consistently larger than the measured values for the A1-Pu fueled lattices, and (2) the calculated values of $\mathrm{k}_{\text {eff }}$ for the $\mathrm{UO}_{2}$ fueled lattices are dependent on the moderator-to-fuel ratio.

\section{Homogeneous Criticals}

The calculated values of $k_{\text {eff }}$ for the aqueous solution critical experiments are shown in Table 8. The calculated values of $k_{\text {eff }}$ are systematically lower than the measured values by $20.5 \%$ for the uranyl nitrate solutions. The calculated values of $k_{\text {eff }}$ for the $27.24 \mathrm{in}$. diameter sphere and the $48.04 \mathrm{in.} \mathrm{diameter} \mathrm{sphere} \mathrm{are} \mathrm{almost} \mathrm{identical;} \mathrm{therefore,} \mathrm{reactor} \mathrm{size}$ does not appear to be an influence on the calculation. When these results are compared to those obtained for the $\mathrm{UO}_{2}$ lattice criticals we note that the mean values are $20.5 \%$ different. However, if these points were plotted on the curve of $k_{e f f}$ as a function of hydrogen-to- ${ }^{235}$ uranium atom ratio (Figure 4) then the results are consistent with those for the $\mathrm{UO}_{2}$ lattices. That is, a $-0.5 \%$ discrepancy exists in calculated values of $\mathrm{k}_{\text {eff }}$ at $\mathrm{H} /{ }^{235} \mathrm{U}$ ratios $>500$. These solution criticals are at $\mathrm{H} /{ }^{235} \mathrm{U}$ ratios ranging from 972 to 1835 as shown in Table 3. Thus, a bias which is related to hydrogento-fuel ratio is evident in the theoretical methods. 


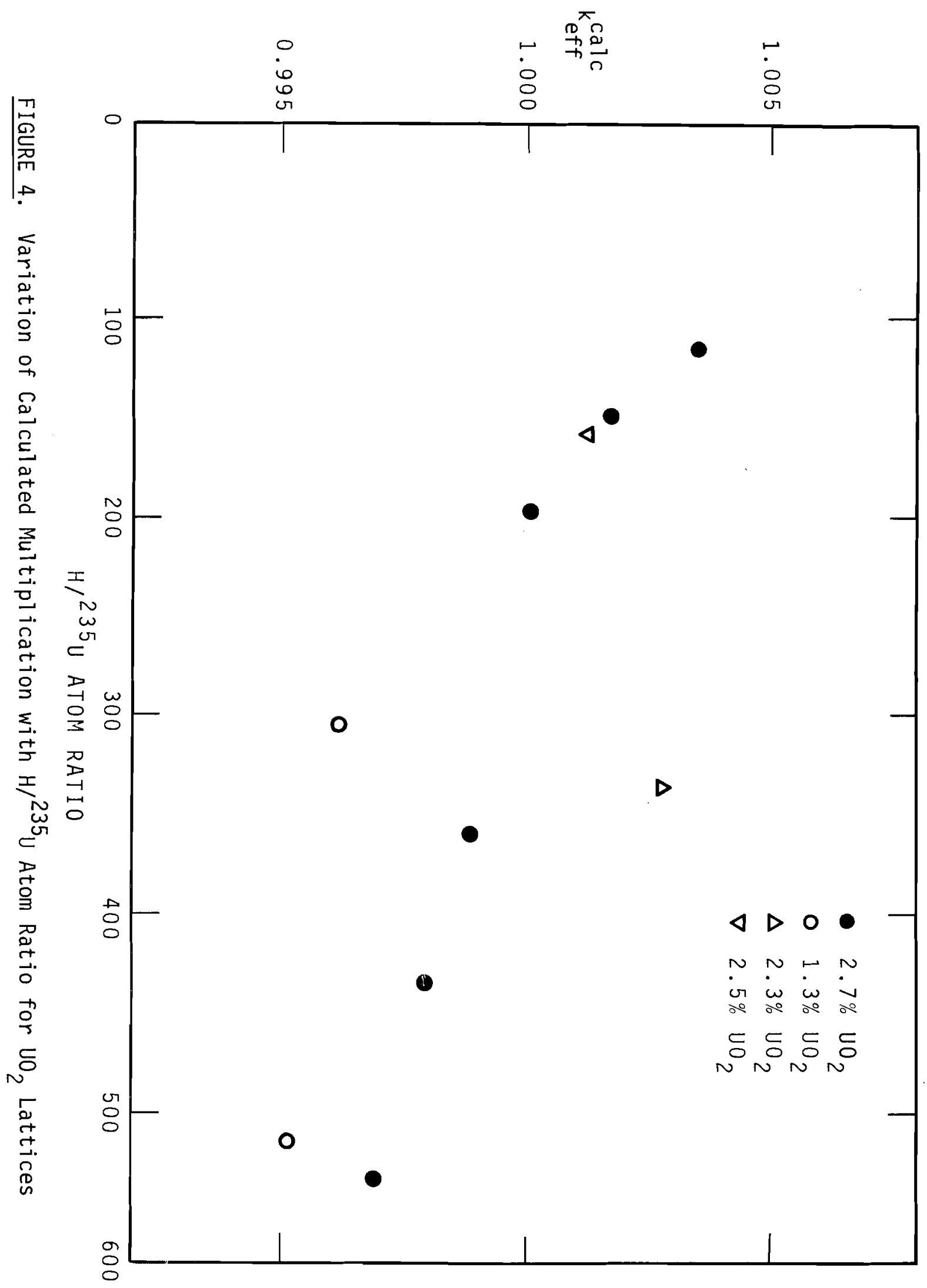


BNWL-1656

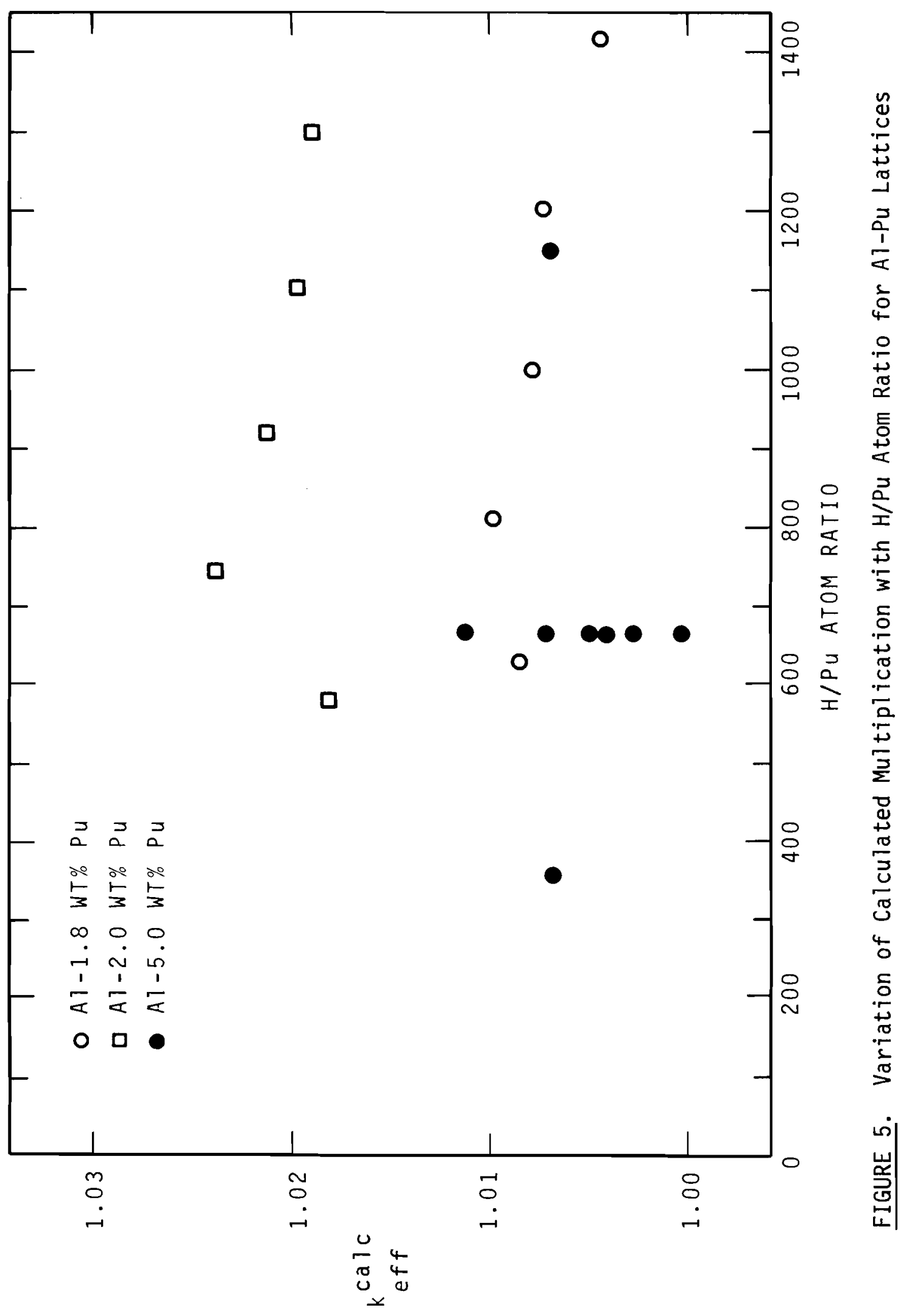


BNWL-1656

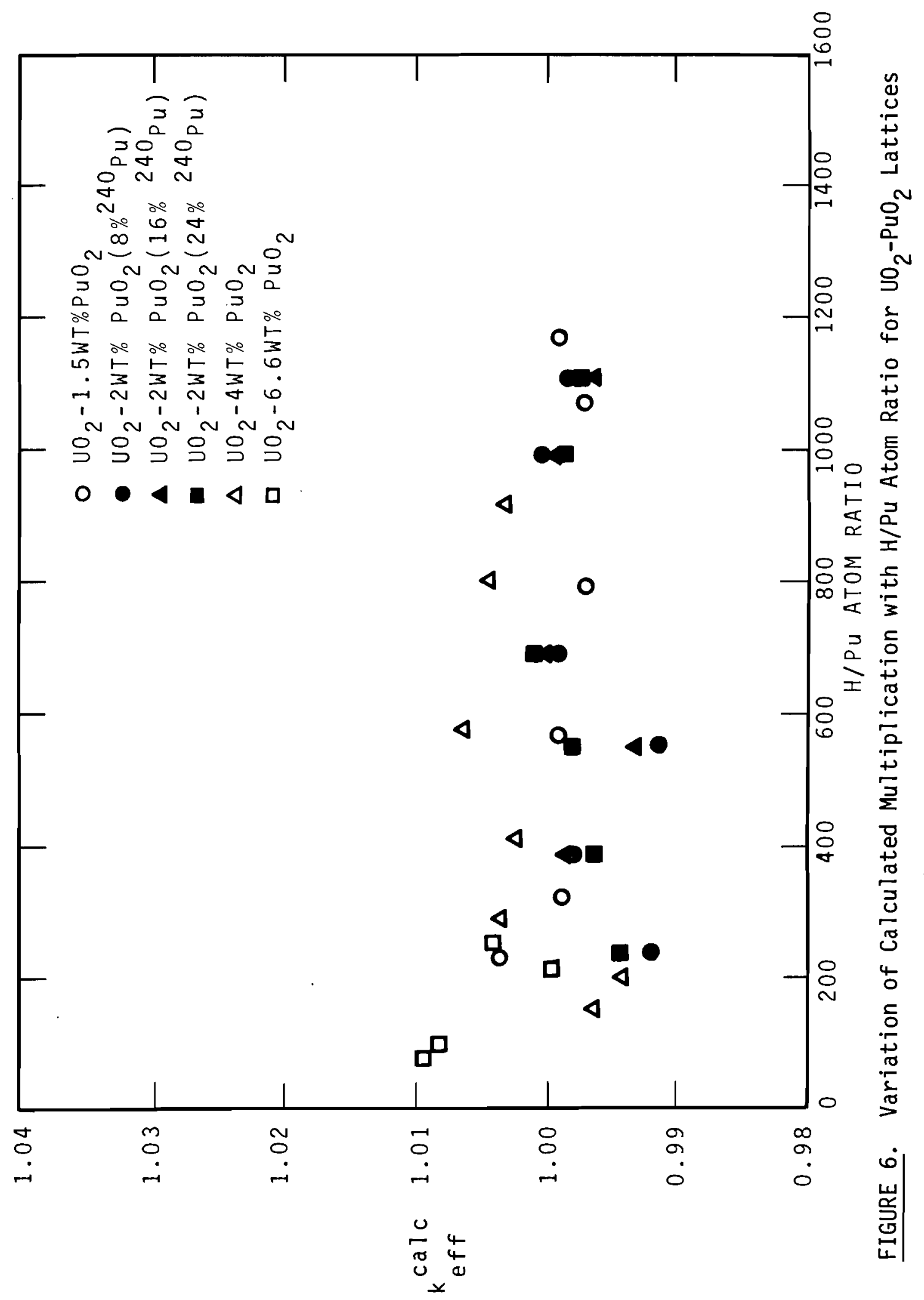


TABLE 8. Values of $k_{\text {eff }}$ for Aqueous Solution Criticals* Homogeneous Uranyl Nitrate Spheres

\begin{tabular}{|c|c|c|c|}
\hline Experiment \# & Sphere Diameter & Measured $k_{\text {eff }}$ & Calculated $k_{\text {eff }}$ \\
\hline 1 & $27.24 \mathrm{in.}$ & 1.00026 & 0.9955 \\
\hline 2 & $27.24 \mathrm{in.}$ & 0.99975 & 0.9959 \\
\hline 3 & $27.24 \mathrm{in.}$ & 0.99994 & 0.9936 \\
\hline 4 & 27.24 in. & 0.99924 & 0.9954 \\
\hline 10 & 48.04 in. & 1.00031 & 0.9944 \\
\hline
\end{tabular}

Homogeneous Plutonium Nitrate Spheres

(Measured Values $=1.0000$ )

$\mathrm{H} / \mathrm{Pu}$

Case \# Sphere Diameter Atom Ratio Calculated $k_{\text {eff }}$

1 (Reflected)

15.2 in.

553

1.0135

2 (Bare)

15.2 in.

668

1.0127

$$
\text { Mean }=1.013 \pm 0.001
$$

*The uncertainties assigned to the mean values are standard deviations for a typical value rather thun for the mean value. 
The values of $k_{\text {eff }}$ calculated for the plutonium nitrate systems are both high by $1.3 \% \Delta \mathrm{k} / \mathrm{k}$. Since the bare and fully water-reflected spheres have nearly the same calculated multiplication it does not appear that the reflector adds to the calculational problem. Richey's analysis ${ }^{(48)}$ gave calculated results using diffusion theory which were within $\pm 0.4 \%$ of experiment using the GAMTEC-II and HFN computer codes. Since we used the same diffusion theory code in this analysis, the reactivity difference between Richey's results and ours is due to the difference in spectrum average cross sections (GAMTEC-II versus HRG3/BRT-1) which is about $1.3 \% \Delta \mathrm{k} / \mathrm{k}$. The major difference between the spectrum average cross section is the result of using different basic cross sections for ${ }^{239} \mathrm{Pu}$ below $1.0 \mathrm{eV}$. Richey used data for ${ }^{239} \mathrm{Pu}$ which were normalized to a $2200 \mathrm{~m} / \mathrm{s} n$ value of $2.093(17)$ whereas the ${ }^{239} \mathrm{Pu}$ cross sections used in our analysis were normalized to the 1965 IAEA evaluated $\eta$ value of $2.114 .^{\text {(33) }}$ This difference in values for $239 \mathrm{n}$ at $2200 \mathrm{~m} / \mathrm{s}$ is about the order of the difference in the $k_{\text {eff }}$ values. Other slight differences in the calculated values of $k_{\text {eff }}$ are due to differences in calculational methods and cross sections, but these effects tend to cancel. Thus, our findings are consistent with Richey's when the calculational differences due to ${ }^{239} \mathrm{n}$ at $2200 \mathrm{~m} / \mathrm{s}$ are taken into account.

Superimposing the calculated values of $k_{\text {eff }}$ for these two plutonium nitrate criticals on the curve where $k_{\text {eff }}$ is plotted as a function of $\mathrm{H} / \mathrm{Pu}$ atom ratio (Figure 5) for the Al-Pu fueled systems, we note that they are consistent with those for the Al-Pu fueled lattices (i.e., biased values of $k_{\text {eff }}$ but no evident trend with H/Pu ratio).

\section{SUMMARY OF THE CORRELATION}

The mean value of $k_{\text {eff }}$ and the standard deviation of the mean for each series of experiments are shown in Table 9. With the exception of the A $1-2.0 \mathrm{wt} \%$ Pu fueled experiments and the plutonium nitrate experiments the calculations are all 1ess than $1 \%$ in error.

The discrepancy observed for the plutonium nitrate systems indicates probable calculational error. The discrepancy for the Al-2 wt\% Pu fueled 
TABLE 9. Mean Values and Standard Deviation for Lattice Multiplication Studies

\section{Loading}

Number of

Data Points Mean Value

\section{Lattice}

$$
\begin{aligned}
& \mathrm{Al}-1.8 \mathrm{Pu} \\
& \mathrm{A1}-2.0 \mathrm{Pu} \\
& \mathrm{A1}-5.0 \mathrm{Pu} \\
& \mathrm{UO}_{2}-1.5 \mathrm{PuO}_{2} \quad{ }^{2} \mathrm{Pu}_{2}-2.0 \mathrm{PuO}_{2}\left(8 \%{ }^{\mathrm{Pu}}\right) \\
& \mathrm{UO}_{2}-2.0 \mathrm{PuO}_{2}\left(16 \%{ }^{240} \mathrm{Pu}\right) \\
& \mathrm{UO}_{2}-2.0 \mathrm{PuO}_{2} \quad\left(24 \%{ }^{240} \mathrm{Pu}\right) \\
& \mathrm{UO}_{2}-4.0 \mathrm{PuO}_{2} \\
& \mathrm{UO}_{2}-6.6 \mathrm{PuO}_{2} \\
& \mathrm{UO}_{2}
\end{aligned}
$$

$\begin{array}{rl}5 & 1.008 \pm 0.002 \\ 5 & 1.020 \pm 0.003 \\ 8 & 1.006 \pm 0.003 \\ 6 & 0.999 \pm 0.001 \\ 6 & 0.996 \pm 0.004 \\ 5 & 0.997 \pm 0.002 \\ 6 & 0.998 \pm 0.002 \\ 7 & 1.002 \pm 0.004 \\ 4 & 1.005 \pm 0.005 \\ 10 & 1.000 \pm 0.003\end{array}$

Homogeneous

$\begin{array}{lll}\text { Large Uranyl Nitrate Spheres } & 5 & 0.995 \pm 0.001 \\ \text { Smal1 Plutonium Nitrate Spheres } & 2 & 1.013 \pm 0.001\end{array}$


systems is inconsistent relative to the results obtained for the other Al-Pu fueled systems. Two trends were observable in the results of this analysis. One being that systems fueled with plutonium only have calculated values of $k_{\text {eff }}$ which are consistently larger than experiment. The other is that the calculated values of $k_{\text {eff }}$ for the systems fueled with uranium only are dependent on the atom ratio $\mathrm{H} /{ }^{235} \mathrm{U}$.

The major components of $k_{\text {eff }}$ for the plutonium only systems are the neutron leakage and the thermal reaction rates ( $\bar{\eta} f$ ) because the values of the resonance escape probability $(p)$ and the fast fission factor $(\varepsilon)$ are near unity. Thus, there must be errors in the calculation of one or both of these components which are causing the discrepancies noted. The examination of the results in terms of buckling dependence did not point to probable errors in the leakage calculation. Thus, the prime candidate of error is the calculation of the thermal reaction rates.

The uranyl nitrate solution experiments are so well thermalized and physically large that the major component of $k_{\text {eff }}$ is the thermal reaction rates $(\bar{n} f)$. As noted, the calculated value of $k_{\text {eff }}$ is about $0.5 \%$ low which indicates an error of this magnitude exists in the thermalization calculation. All of the components of $k_{\text {eff }}$ are important contributions in the values for the $\mathrm{UO}_{2}$ fueled lattices. On the basis of the correlation for the aqueous solutions we cannot expect better agreement than $-0.5 \%$. The mean value for the $\mathrm{UO}_{2}$ lattices is $1.000 \pm 0.003$ which is better than we expected. Moreover, the comparison of measured and calculated values of

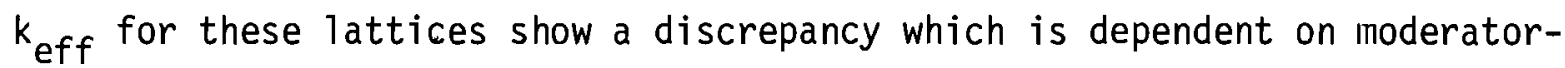
to-fuel ratios. Thus, we conclude that compensating errors are present in the analysis. The calculated values of $k_{\text {eff }}$ are not buckling dependent, which indicates that the neutron leakage calculations are adequate. Of the four factors of $k_{\infty}, \bar{n}, f, p$ and $\varepsilon$, we would expect to be able to calculate $\bar{\eta}$ and $f$ more accurately than $p$ and $\varepsilon$. The reason being that the value of $\eta$ for ${ }^{235} U$ is nearly constant in the thermal energy region such that errors in the spectrum calculation do not significantly affect the cell average value of $\eta$. Also, since most of the isotopes present in these lattices have cross sections which are $1 / v$ dependent, the only error in the 
calculation of $f$ is that propogated by errors in the calculation of the spatial flux within a lattice cell. Thus, we feel that the observed trend in $\mathrm{k}_{\text {eff }}$ with $\mathrm{H} /{ }^{235} \mathrm{U}$ ratio is the result of; an error in the calculation of the resonance escape probability, $p$, (principally the ${ }^{238} \mathrm{U}$ resonance absorption rate) and/or an error in the calculation of the fast fission factor, $\varepsilon$ (principally spatial flux considerations).

The calculated values of $k_{\text {eff }}$ are generally high for the plutonium systems and low for the uranium systems. It could be inferred that the calculated values of $k_{\text {eff }}$ for the mixed oxide systems would be in better agreement with experiment because these differences would tend to cancel. In fact, we note that, in general and contrary to these expectations, the calculated values of $k_{\text {eff }}$ for the mixed oxide lattices do not simply lie in-between the results obtained for the uranium only $\left(\mathrm{UO}_{2}\right)$ and plutonium only (Al-Pu) fueled assemblies. Cancellation of errors probably exists in the calculation of each different type of fueled assembly. Thus, the discrepancies for uranium and plutonium fueled systems do not linearly combine in the mixed oxide fueled systems. When we go back and delineate the approximations which we have made in the analysis, the shear number of these leads to further suspicion that cancellation of errors is present in the analysis. To gain additional insight regarding the accuracy of our analysis, we examine in the next section the potential sources of error and make estimates as to the magnitude of the errors. 


\section{EVALUATION OF SOME OF THE UNCERTAINTIES IN THE ANALYSIS}

Uncertainties always exist in a neutronic theoretical analysis. If the theoretical methods and the analysis procedures were exact, an uncertainty in a calculated value would still exist because of uncertainties in the cross sections. There are, however, approximations made in the theoretical methods, many of which are simply to make the mathematics tractable. In addition, assumptions are frequently made in the analysis to make the task less burdensome, (cost and/or time). Nevertheless, use of approximations can be a root of error and an understanding of the errors is vital to making valid judgments concerning the inherent accuracy of the theoretical methods.

The results of the analysis presented in the previous section have such associated uncertainties. Results are presented in this section of some studies which are aimed at determining the magnitude of the uncertainty on the calculated values of $k_{\text {eff }}$ due to approximations made in the analysis.

We delineate below the more obvious sources of potential error in the calculations.

Area of Calculation

A. Fuel \& Lattice Specification

B. Cell Calculations
Source of Potential Error

1. Particulate Fuel

2. Lattice Hardware

3. Manufacturing Tolerances

1. Uncertainties in neutron cross sections

- Effects of experimental uncertainties in cross sections

- Effect of changing basic cross sections

- Definition of diffusion coefficient

2. Slowing down calculation

- Experimental uncertainties in cross sections

- Spatial fast fission effects

- Spatial resonance absorption

- Resonance overlap effects 
Area of Calculation

B. Cell Calculations (contd)

C. Leakage Calculations
Source of Potential Error

3. Thermalization

- Reflecting cell boundary conditions

- Approximating anisotropy

- Energy groups

- Upper energy limit of $0.683 \mathrm{eV}$

1. Separating flux into radial and axial component

2. Axial leakage representation

- buckling

- streaming effects

3. Energy detai1

4. Spatial detai1

5. Transport theory

A. REPRESENTATION OF FUEL AND LATTICES

Uncertainties exist in the tolerance used for fabricating fuel rods and lattice structure (i.e., templates). In addition, mixed oxide fuels are fabricated from mixtures of plutonium dioxide and uranium dioxide which leads to particulate fuel structures. Some of the uncertainty associated with these effects are studied and estimates of their effect on the correlation results are made.

1. Particulate Fuel

Assuming that the fuel is a solid solution in the $\mathrm{UO}_{2}-\mathrm{PuO}_{2}$ fueled experiments is a known source of error in our calculations. It has been demonstrated experimentally (27) that the fuels used in these experiments contain $\mathrm{PuO}_{2}$ particles of average size, 25 microns, and that a reactivity defect occurs $(50)$ as a result of having these particles. Having the $\mathrm{PuO}_{2}$ in the form of finite size particles results in a reactivity change relative to homogeneous fuel mainly because of changes in ${ }^{239} \mathrm{Pu}$ fission, ${ }^{239} \mathrm{Pu}$ capture and ${ }^{240} \mathrm{Pu}$ absorption. The changes in ${ }^{239} \mathrm{Pu}$ fission and capture are mainly in the energy range below $0.683 \mathrm{eV}$ while the change in ${ }^{240} \mathrm{Pu}$ absorption is primarily in the range of the $1.056 \mathrm{eV}{ }^{240} \mathrm{Pu}$ resonance. As pointed out previously, ${ }^{(50)}$ self-shielding of ${ }^{239} \mathrm{Pu}$ with increasing $\mathrm{PuO}_{2}$ 
particle size reduces the ${ }^{239} \mathrm{Pu}$ fission reaction rate in the fuel, thus producing a negative reactivity effect. The thermal-spectrum-averaged value of the ${ }^{239} \mathrm{Pu}$ capture-to-fission ratio, $\bar{\alpha}^{239}$, is also reduced because of a larger proportionate increase in shielding of the $0.3 \mathrm{eV}$ resonance. A positive reactivity change is contributed by the increased shielding of the $1.0 \mathrm{eV}$ resonance of ${ }^{240} \mathrm{Pu}$. The magnitude of this positive reactivity contribution depends on the concentration of ${ }^{240} \mathrm{Pu}$ in the particle. The net reactivity effect due to shielding within the $\mathrm{PuO}_{2}$ particles can be negative or positive, depending on the spectrum, the isotopic composition of plutonium and the size of the $\mathrm{PuO}_{2}$ particle. We have made an assessment of the magnitude of the error incurred in our calculations because of neglecting the particulate nature of the fuel.

The codes GRANIT and EGGNIT, which are described in Appendix A, were used to calculate unit cell group constants for selected lattices assuming $\mathrm{PuO}_{2}$ grains with diameters of zero (i.e., solid solution fuel) and 25 microns. These four-group constants were then used in HFN to regenerate values of $k_{\text {eff }}$. The change* in calculated values of $k_{\text {eff }}$ between zero and 25 micron fuel cases is shown in Figure 7 for each fuel type.

The reactivity effect, because of neutron self-shielding in the particles, is seen to be dependent on; $\mathrm{H} / \mathrm{Pu}$ atom ratio or lattice pitch, plutonium content, plutonium composition and rod size. The largest effect occurs for the $\mathrm{UO}_{2}-1.5 \mathrm{wt} \% \mathrm{PuO}_{2}$ rods because these are smaller diameter rods than the others. The reactivity effect is in the range of 0.1 to $0.7 \% \Delta \mathrm{k} / \mathrm{k}$ and is negative for all the cases studied, but it can clearly be seen that at tighter pitches the effect would be expected to be positive. Also, for mixed oxide fuels containing higher concentrations of ${ }^{240} \mathrm{Pu}$, one would expect the entire curve to shift toward the positive direction. These results indicate that our calculated values of $k_{\text {eff }}$ presented in the previous section for the mixed oxide lattices are all too high. The smallest and largest calculational errors are for tight and loose lattices respectively.

* The experimental evidence shows a linear change in reactivity with particle size; therefore, we use simply the difference in $k_{\text {eff }}$ values. 
BNWL - 1656

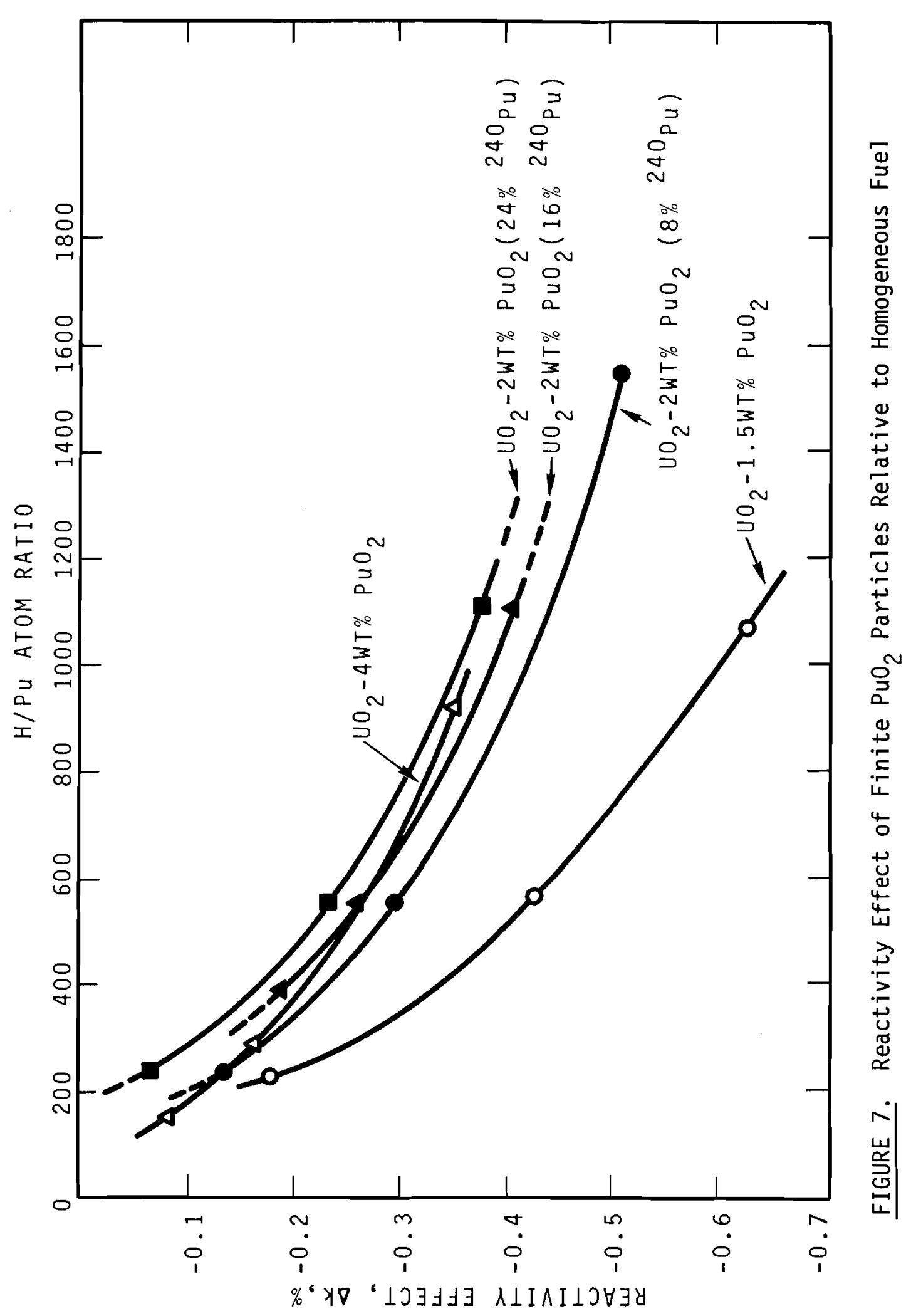




\section{Lattice Hardware Ignored}

In the calculations we have used the as-measured critical sizes for a11 lattices. No corrections were made to account for the presence of lattice grid plates and other hardware in the assemblies. The most significant of the neglected items are the lattice grid plates. In most of the lattices the grid plates were of Lucite $\left(\mathrm{C}_{5} \mathrm{H}_{8} \mathrm{O}_{2}\right) .{ }^{(51)}$ The presence of Lucite in the core produces an effect which is essentially a voiding effect. Thus, in tight lattices we would expect a slight negative reactivity effect and in loose lattices a slight positive reactivity effect due to the presence of the Lucite. The magnitude of the reactivity effect has been determined experimenta11 $\mathrm{y}^{(52)}$ for a few lattices and is of the order of $0.2 \% \Delta \mathrm{k}$ or less. In a few of the lattices some grid plates of aluminum were included and in these cases one would expect a slight negative reactivity effect. For the Hanford experiments using Al-1.8 wt\% Pu and A1-2.0 wt\% Pu rods, the rods were enclosed in Lucite sleeves. (41) Subsequent measurements $(53,54)$ indicated that the reactivity effect of the Lucite sleeves was of the order of $0.1-0.2 \%$ in $k_{\text {eff }}$.

\section{Manufacturing Tolerances}

As in all situations of having to manufacture something, the specimen to be manufactured is built to within certain tolerances. Usually, these tolerances are selected such that they represent a meaningful balance between cost of manufacturing and the effect of the tolerance on the predicted performance of the product. We have determined the effect these manufacturing constraints have on the accuracy of the calculations and whether they are of significance in terms of the accuracy of the correlation. Specifically, the reactivity effects due to variations in fuel density, fuel height, clad thickness and lattice spacing were studied using the $\mathrm{UO}_{2}-1.5 \mathrm{wt} \% \mathrm{PuO}_{2}$ fueled lattices as typifying the effect for the plutonium fueled systems. The sensitivity of multiplication values to changes in these quantities was determined by repeating the calculations using different input paramenters.

To determine how sensitive the calculated multiplication is to changes in transverse buckling (i.e., tolerances in the height of the fuel and the 
reflector savings value used to deduce an axial leakage), the multiplication factor, $\mathrm{k}_{\text {eff }}$, for the $\mathrm{UO}_{2}-1.5 \mathrm{wt} \% \mathrm{PuO}_{2}$ lattices has been recalculated assuming no axial leakage $\mathrm{B}_{\mathrm{Z}}^{2}=0$ in the HFN calculation. Correspondingly, the sensitivity of the nonthermal reaction rates of cell components to changes in neutron leakage were determined by reducing the geometrical buckling, $\mathrm{B}_{\mathrm{g}}^{2}$, used as input to the HRG3 code by a factor of 100 . The resulting few group cross sections from HRG 3 were used to obtain new multiplication values from HFN calculations.

The results are summarized in Table 10 as coefficients of reactivity. These coefficients were obtained by taking the differences in multiplication between the perturbed and the correlated cases and dividing by the change in the perturbed parameter (i.e., $B_{z}^{2}$ or $B_{g}^{2}$ ).

Also shown in Table 10 are coefficients for changes in fuel element density, cladding thickness and lattice spacing. To determine the effects on reactivity due to variations in fuel density all calculations were repeated for a uniform $2 \%$ decrease in fuel density.

The multiplication sensitivity to variations in cladding thickness was determined by repeating the calculations for rods with a 25 mil cladding thickness (i.e., 2 mils less).

The multiplication uncertainty due to lattice spacing variations was also calculated. An analytical expression for the best fit curve to the calculated critical mass was differentiated with respect to lattice spacing,

$$
B_{g}{ }^{2}=\left(\frac{2.4048}{\ell \sqrt{\frac{N_{C} \sqrt{3}}{2 \pi}}+\lambda}\right)^{2}+\left(\frac{3.1416}{H+2 \lambda}\right)^{2}
$$

where: $N_{c}=$ the calculated number of rods for critical

$\ell=$ the lattice spacing

$\lambda=$ the reflector-savings

$H=$ the height of the fuel column 


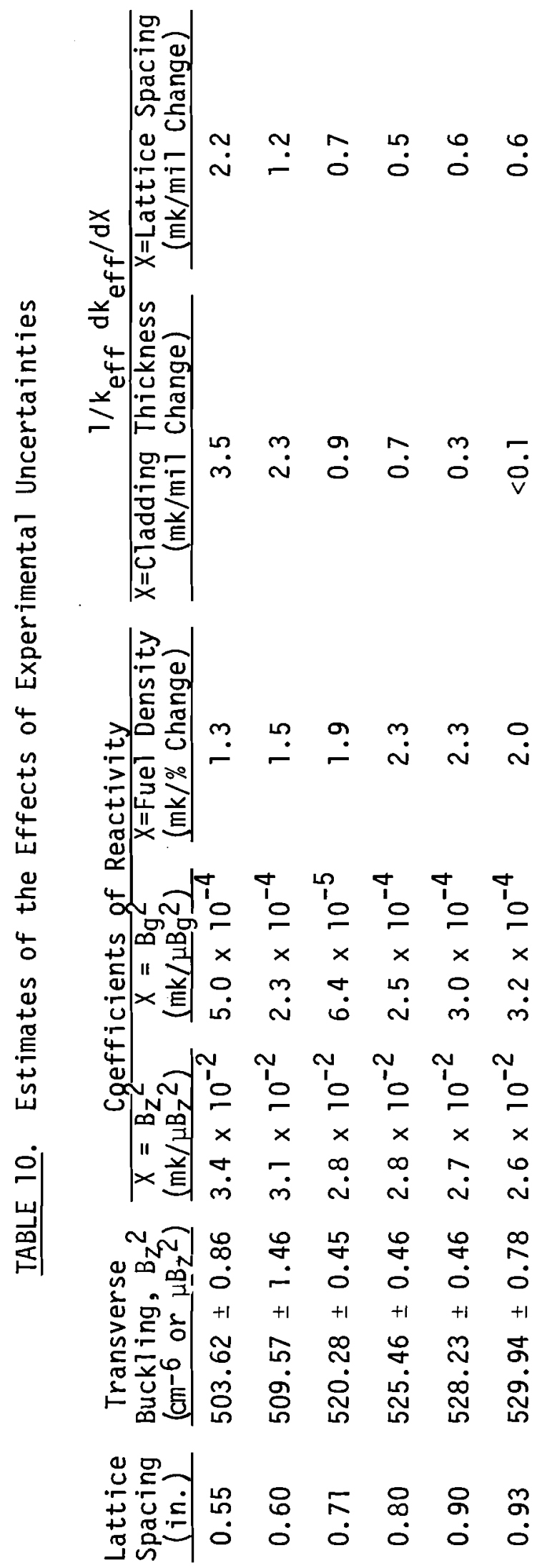


$\ell$, to obtain the slopes ( $\mathrm{dN} / \mathrm{dX}$ in rods/mil of lattice spacing) of the curve at each measured lattice spacing. The corresponding multiplication sensitivity was obtained by dividing these values for the slope by the calculated value of the number of rods/mk as determined from a criticality search calculation in HFN. The resulting perturbation coefficients are listed in Column 7 of Table 10.

The coefficients listed in Table 10 demonstrate how important geometrical considerations are in obtaining agreement between calculational and experimental results. As an example we can consider the importance of the uncertainties in the geometrical arrangement of the critical experiments. To do this, the errors of a given quantity will be used to determine such an effect on $k_{\text {eff }}$. This example, however, is not considered a realistic situation since each value considered is the best value for a core average and any individual values will be randomly distributed about the average.

The largest uncertainties in $k_{\text {eff }}$ due to uncertainties in $\mathrm{B}_{\mathrm{Z}}^{2}$ and $\mathrm{B}_{\mathrm{g}}^{2}$ occur for the $0.60 \mathrm{in}$. lattice. The values are the products of the quoted experimental uncertainties in each $\left(1.46 \mu \mathrm{B}_{\mathrm{z}}^{2}\right.$ and $\left.80 \mu \mathrm{B}_{\mathrm{g}}^{2}\right)$ and the buckling coefficients of reactivity, $1 / k_{\text {eff }} d k_{e f f} / \mathrm{dB}_{x}^{2}$. These values are 4.5 $\times 10^{-2} \mathrm{mk}$ for the uncertainty in $\mathrm{B}_{\mathrm{Z}}^{2}$ and $1.8 \times 10^{-2} \mathrm{mk}$ for the uncertainty in $\mathrm{B}_{\mathrm{g}}^{2}$. Uncertainties in multiplications caused by the experimental uncertainties in $\lambda$ and $\mathrm{B}_{\mathrm{g}}^{2}$ can be considered negligible for these lattices.

Variations in the lattice geometry occur tecause of variations in fuel length, cladding thickness and fuel rod positioning. A variation in fuel length reflects a variation in $B_{z}^{2}$ and subsequently a perturbation in the calculated values of $k_{\text {eff }}$. A variation of $\pm 1 / 16$ in. in fuel length corresponds to a maximum change of $1.2 \mu \mathrm{B}_{\mathrm{z}}^{2}$ in the transverse buckling, which occurs for the $0.55 \mathrm{in}$. lattice. Using the transverse buckling coefficient of reactivity from Table 10 and this $B_{z}^{2}$ variation results in a multiplication perturbation of $<0.04 \mathrm{mk}$.

The largest reactivity difference due to a uniform $1.5 \%$ change in fuel density occurs for the $0.90 \mathrm{in}$. lattice and is $<4 \mathrm{mk}$. 
A change in cladding thickness significantly changes the amount of moderator to be associated with a fuel rod at tight lattice spacings. The perturbation on multiplication for the 0.55 in. lattice is $7.0 \mathrm{mk}$. Thus, in this range of moderator-to-fuel volume ratios the multiplication (or critical mass) has a sizeable dependence on cladding thickness variations.

The perturbation on the multiplication because of lattice spacing variations is also due to the change in the moderator-to-fuel ratio. The largest perturbation due to a $1 \mathrm{mil}$ change in all lattice positions occurs for the $0.55 \mathrm{in}$. lattice and is $2.2 \mathrm{mk}$.

In summary, assuming that we can use these results as typical, the variations in multiplication due to variations in fuel density, cladding thickness and lattice position could represent a large uncertainty if these variations are not controlled and all acted in the same direction. In the example used, the tolerances associated with fuel and lattice fabrication do not necessarily evolve into an uncertainty in $k_{\text {eff }}$. For example, a 2 mil tolerance in cladding thickness is calculated as a $7 \mathrm{mk}$ uncertainty in keff for the $0.55 \mathrm{in}$. lattice. However, this variation in $k_{\text {eff }}$ represents every rod in the lattice being clad with tubing 25 mils thick instead of $27 \mathrm{mils}$ thick. Statistically, some rods are going to have cladding which is thicker in the other direction (i.e., 29 mils thick). To assign an uncertainty limit in $k_{\text {eff }}$ due to variations in these parameters (fuel density, cladding thickness, etc.) the exact value of each parameter for each fuel rod plus the location in the lattice would have to be known.

Thus, of all the variations discussed above, the only parameter for which an approximate uncertainty value in $\mathrm{k}_{\text {eff }}$ can be assigned is the particle size of $\mathrm{PuO}_{2}$, since a homogeneous fuel is assumed rather than a fuel based on an average particle size. The estimated bias in our correlated multiplications due to particle lumping is taken as the value for $25 \mu$ particles. Using the results shown in Figure 7 we correct the calculated values presented in Table 6 . The results are shown in Table 11 along with the uncorrected results for comparison. The effect of including neutron self shielding in the $\mathrm{PuO}_{2}$ particles in the calculation of $\mathrm{k}_{\text {eff }}$ is to uniformly 
TABLE 11. Corrected Values of keff for $\mathrm{UO}_{2}-\mathrm{Pu}_{2}$ Lattices to Account for $\mathrm{PuO}_{2}$ Particle Self Shielding

\begin{tabular}{|c|c|c|c|c|c|c|c|}
\hline \multirow[b]{2}{*}{ Fuel Type } & \multirow{2}{*}{$\begin{array}{c}\text { Lattice } \\
\text { Spacing } \\
\text { (in.) }\end{array}$} & \multicolumn{6}{|c|}{ Calculated Value of $k_{\text {eff }}$} \\
\hline & & \multicolumn{2}{|c|}{ Solid Solution } & Fuel & \multicolumn{3}{|c|}{$\begin{array}{c}\text { Corrected for } \\
25 \mu \text { Pu0 } \\
2\end{array}$} \\
\hline \multirow[t]{3}{*}{$\mathrm{UO}_{2}-1.5 \mathrm{wt} \% \mathrm{PuO}_{2}$} & $\begin{array}{l}0.55 \\
0.60 \\
0.71 \\
0.80 \\
0.90 \\
0.93\end{array}$ & & $\begin{array}{l}1.0035 \\
0.9988 \\
0.9988 \\
0.9968 \\
0.9971 \\
0.9989\end{array}$ & & & $\begin{array}{l}1.0017 \\
0.9960 \\
0.9945 \\
0.9916 \\
0.9908 \\
0.9923\end{array}$ & \\
\hline & & Mean & $\overline{0.9990}$ & & & $\overline{0.9945}$ & \\
\hline & & $8 \% \star$ & $16 \% \star$ & $24 \% \star$ & $8 \% \star$ & $16 \%$ * & $24 \% \star$ \\
\hline \multirow[t]{2}{*}{$\mathrm{UO}_{2}-2$ wt\% $\mathrm{PuO}_{2}$} & $\begin{array}{l}0.80 \\
0.93 \\
1.05 \\
1.143 \\
1.32 \\
1.386\end{array}$ & $\begin{array}{l}0.9920 \\
0.9979 \\
0.9913 \\
0.9992 \\
0.9999 \\
0.9979\end{array}$ & $\begin{array}{c}- \\
0.9982 \\
0.9931 \\
1.0000 \\
0.9995 \\
0.9964\end{array}$ & $\begin{array}{l}0.9942 \\
0.9963 \\
0.9981 \\
1.0007 \\
0.9985 \\
0.9971\end{array}$ & $\begin{array}{l}0.9907 \\
0.9956 \\
0.9983 \\
0.9958 \\
0.9958 \\
0.9935\end{array}$ & $\begin{array}{l}-\overline{-} \\
0.9963 \\
0.9905 \\
0.9969 \\
0.9957 \\
0.9924\end{array}$ & $\begin{array}{l}0.9935 \\
0.9947 \\
0.9958 \\
0.9979 \\
0.9950 \\
0.9933\end{array}$ \\
\hline & Mean & $\overline{0.9964}$ & $\overline{0.9974}$ & $\overline{0.9975}$ & $\overline{0.9933}$ & $\overline{0.9944}$ & $\overline{0.9950}$ \\
\hline \multirow[t]{2}{*}{$\mathrm{UO}_{2}-4 \mathrm{wt} \% \mathrm{PuO}_{2}$} & $\begin{array}{l}0.85 \\
0.93 \\
1.05 \\
1.143 \\
1.386 \\
1.60 \\
1.70\end{array}$ & & $\begin{array}{l}0.9964 \\
0.9940 \\
1.0035 \\
1.0024 \\
1.0062 \\
1.0047 \\
1.0031\end{array}$ & & & $\begin{array}{l}0.9956 \\
0.9929 \\
1.0019 \\
1.0003 \\
1.0035 \\
1.0014 \\
0.9996\end{array}$ & \\
\hline & & Mean & $\overline{1.0015}$ & & & $\overline{0.9993}$ & \\
\hline
\end{tabular}


lower the calculated value as shown by comparing the mean values in Table 11. We noted previously that discrepancies between calculated and measured values of $\mathrm{k}_{\text {eff }}$ for the $\mathrm{UO}_{2}-\mathrm{PuO}_{2}$ fuels did not appear to be functions of $\mathrm{Pu}$ content, $240 \mathrm{Pu}$ content, leakage $\left(\mathrm{B}_{\mathrm{g}}^{2}\right)$, or moderator-to-fuel ratio ( $\left.\mathrm{H} / \mathrm{Pu}\right)$. Though the calculated values change when neutron self shielding in the $\mathrm{PuO}_{2}$ particles is included in the calculations, the evidence of trends is still absent. Calculations of $\mathrm{k}_{\text {eff }}$ for particles of $\mathrm{PuO}_{2}$ were not made for the $\mathrm{UO}_{2}-6.6 \mathrm{wt} \% \mathrm{PuO}_{2}$ fuel. However, using the results we do have, and extrapolating, we estimate the effect to be similar in that the calculated values of $k_{\text {eff }}$ would be lower for each lattice and that the largest change would occur for the lattice with the largest pitch.

\section{B. CELL CALCULATIONS}

Many approximations have been made in the representation of the unit cell and the calculation of the multigroup neutron-spectrum in the lattice cell. These include the basic cross sections, the cell transport theory methods, and the manner in which they are applied. The uncertainty stemming from these is estimated here.

1. Uncertainties in Neutron Cross Sections

In considering what effects uncertainties in basic neutron cross sections have on calculated values of $k_{e f f}$, two approaches are taken. The first approach is to consider the actual experimental uncertainties associated with the best evaluated measured cross-section data, and to calculate the changes in $k_{\text {eff }}$ that come about when the cross sections are varied within their limits of uncertainty. In this approach one attempts to determine how accurately one should legitimately expect to be able to calculate $k_{\text {eff }}$, knowing the quoted precisions of the basic cross sections. The second approach is to consider the latest cross-section set to be "exact," and then calculate changes in $k$ that come about when the latest set of cross sections is substituted for some earlier set. This then is a measure of the "uncertainty" in the earlier set. 


\section{Effects of Experimental Uncertainties in Cross Sections}

Uncertainties in the nuclear data propagate through the calculational procedures and lead to uncertainties in calculated values of $k_{\text {eff }}$. Calculations have been performed to determine the sensitivity of $k_{e f f}$ to changes in the cross sections of uranium and plutonium isotopes. $(55,56)$ The results of these earlier studies are summarized in Table 12. Estimated uncertainties in the "best" evaluated cross sections have been reduced somewhat throughout the years, but the results shown in Table 12 are still representative. The uncertainties 1 isted in Table 12 are for the lattice of each type of fuel which exhibits the largest sensitivity to the cross section uncertainty.

TABLE 12. Uncertainties in Neutron Multiplication of Lattice Experiments due to Uncertainties in Isotopic Cross Sections

\begin{tabular}{|c|c|c|c|c|}
\hline $\begin{array}{l}\text { Isotope and Type } \\
\text { of Integral } \\
\end{array}$ & $\begin{array}{l}\text { Estimated Uncertainty } \\
\text { in } I_{\infty}, \%\end{array}$ & \multicolumn{3}{|c|}{ 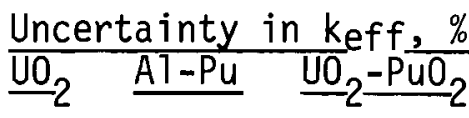 } \\
\hline${ }^{235} U$ fission & 6.0 & 0.8 & - & 0.3 \\
\hline${ }^{235} U$ absorption & 10.0 & 0.9 & - & 0.3 \\
\hline $238 \mathrm{U}$ absorption & 5.0 & 0.9 & - & 1.0 \\
\hline${ }^{239} \mathrm{Pu}$ fission & 10.0 & - & 0.6 & 1.2 \\
\hline${ }^{239} \mathrm{Pu}$ absorption & 12.0 & - & 0.6 & 0.8 \\
\hline${ }^{240} \mathrm{Pu}$ absorption & 8.0 & - & 0.3 & 0.4 \\
\hline
\end{tabular}

Isotope and Type Estimated Uncertainty of Cross Section in $2200 \mathrm{~m} / \mathrm{sec}$ Values, \%

$\begin{array}{llccr}{ }^{235} \mathrm{U} \text { fission } & 0.4 & 0.4 & - & <0.1 \\ 235 \mathrm{U} \text { absorption } & 0.4 & 0.2 & - & <0.1 \\ 238 \mathrm{U} \text { absorption } & 2.0 & 0.2 & - & 0.1 \\ 239 \mathrm{Pu} \text { fission } & 0.5 & - & 0.5 & 0.5 \\ { }^{239} \mathrm{Pu} \text { absorption } & 0.5 & - & 0.4 & 0.4 \\ 240 \mathrm{Pu} \text { absorption } & 7.0 & - & 0.2 & 0.2\end{array}$


Since the largest uncertainties are in the non-thermal data, the uncertainty in calculated values of $k_{e f f}$ is greatest for the tight lattices which have a greater proportion of non-thermal neutrons and is reduced as the assemblies become more thermal, i.e., as the moderator-to-fuel volume ratio increases. Uncertainties for fission and absorption cross sections are expected to be correlated but no effort has been made to evaluate the correlation effects.

The thermal data for ${ }^{239} \mathrm{Pu}$ contains a large resonance at $0.3 \mathrm{eV}$ in which the capture-to-fission ratio varies as a function of energy. Reference 57 contains results of calculations utilizing two sets of ${ }^{239} \mathrm{Pu}$ data with different shapes for the cross-section curve in this energy region. One shape was that given by Schmidt in Reference 58 and the other shape was that suggested by Leonard and given in Reference 59. The two different shapes can be taken as representative of the uncertainty in the exact shape of the cross-section curves. The values of $k_{\text {eff }}$ calculated using the different shapes differ by $20.5 \%$ for plutonium lattices.

In summary, our estimates of the uncertainties in calculated values of $k_{\text {eff }}$ due to experimental uncertainties in the cross sections are the following: For the A1-Pu lattices the uncertainty in $k_{\text {eff }}$ is about $\pm 1 \%$. For the $\mathrm{UO}_{2}$ lattices the uncertainty in $\mathrm{k}_{\text {eff }}$ ranges from about $\pm 1.5 \%$ for tight lattices to about \pm 0.5 for loose lattices. For the $\mathrm{UO}_{2}-\mathrm{PuO}_{2}$ lattices the uncertainty in $k_{\text {eff }}$ ranges from about $\pm 2.0 \%$ for tight lattices to about $\pm 1.0 \%$ for loose lattices. These numbers are estimates of how accurately one should legitimately expect to be able to calculate the reactivities of light water lattices using "exact" methods and knowing the quoted precisions of the basic cross sections.

\section{Effect of Changing Basic Cross Sections}

Some of the calculations were repeated using cross sections derived from ENDF/B-II. If ENDF/B-II data were not available for a particular isotope, the BNWML data were used. Thus, differences in results can be ascribed to differences between the cross sections for certain isotopes from ENDF/B-II and the BNWML. The source of the data for these calculations is summarized in Table 13. Water cross sections were not available 
TABLE 13. Source of Cross-Section Data for Cross

Section Sensitivity Calculations

\begin{tabular}{|c|c|c|}
\hline Isotope & HRG3 & BRT-I \\
\hline Oxygen & BNWML & BNWML \\
\hline Water & & ENDF/B-I I \\
\hline Zirconium & & BNWML \\
\hline Aluminum & $\downarrow$ & ENDF/B-II $22 p 0 \mathrm{~m} / \mathrm{s}$ Value \\
\hline Iron & ENDF/B-II & \\
\hline Nickel & & \\
\hline Chromium & & \\
\hline $235_{U}$ & & ENDF/B-II \\
\hline $238 \mathrm{U}$ & & \\
\hline${ }^{238} \mathrm{pu}$ & & BNWML \\
\hline${ }^{239} \mathrm{Pu}$ & & ENDF/B-II \\
\hline${ }^{240} \mathrm{Pu}$ & & \\
\hline${ }^{241} \mathrm{Pu}$ & & \\
\hline${ }^{242} \mathrm{Pu}$ & & $\downarrow$ \\
\hline${ }^{241} \mathrm{Am}$ & $\downarrow$ & BNWML \\
\hline
\end{tabular}

for HRG3 calculations because of library processing code problems. There are also no zirconium cross sections available on ENDF/B-II, so the BNWML data was used for both HRG 3 and BRT-I calculations. Aluminum, iron, nickel and chromium thermal absorption cross sections were used as $1 / v$ and norma $1-$ ized to ENDF/B-II values at $2200 \mathrm{~m} / \mathrm{sec}$. The most important fissile and fertile isotopes are from ENDF/B-II.

The results of these calculations are shown in Table 14, along with the corresponding calculations based upon the BNWML. Except for the Al-PU fueled systems, the results are drastically different. The calculated 
BNWL-1656

TABLE 14. Effect of Changing Cross Sections on Calculated Values of $k_{\text {eff }}$

\begin{tabular}{|c|c|c|c|}
\hline \multirow[b]{2}{*}{ Fuel Type } & \multirow{2}{*}{$\begin{array}{c}\text { Lattice } \\
\text { Spacing } \\
\text { (in.) }\end{array}$} & \multicolumn{2}{|c|}{$\begin{array}{c}\text { Calculated Value } \\
\text { keff }\end{array}$} \\
\hline & & BNWML & ENDF/B-II \\
\hline $2.734 \mathrm{wt} \% \mathrm{UO}_{2}$ & $\begin{array}{l}0.405 \\
0.470 \\
0.573 \\
0.665\end{array}$ & $\begin{array}{l}1.0035 \\
1.0002 \\
0.9989 \\
0.9969\end{array}$ & $\begin{array}{l}0.9658 \\
0.9770 \\
0.9850 \\
0.9861\end{array}$ \\
\hline $\mathrm{Al}-1.8$ wt\% Pu & $\begin{array}{l}0.75 \\
0.85 \\
0.95\end{array}$ & $\begin{array}{l}1.0086 \\
1.0079 \\
1.0045\end{array}$ & $\begin{array}{l}1.0113 \\
1.0112 \\
1.0083\end{array}$ \\
\hline $\mathrm{Al}-2 \mathrm{wt} \% \mathrm{Pu}$ & $\begin{array}{l}0.75 \\
0.85 \\
0.95\end{array}$ & $\begin{array}{l}1.0182 \\
1.0213 \\
1.0189\end{array}$ & $\begin{array}{l}1.0214 \\
1.0249 \\
1.0226\end{array}$ \\
\hline Al-5 wt\% Pu & $\begin{array}{l}0.85 \\
1.05 \\
1.30\end{array}$ & $\begin{array}{l}1.0067 \\
1.0113 \\
1.0069\end{array}$ & $\begin{array}{l}1.0065 \\
1.0119 \\
1.0074\end{array}$ \\
\hline $\mathrm{UO}_{2}-1.5 \mathrm{wt} \% \mathrm{PuO}_{2}$ & $\begin{array}{l}0.55 \\
0.71 \\
0.93\end{array}$ & $\begin{array}{l}1.0035 \\
0.9988 \\
0.9989\end{array}$ & $\begin{array}{l}0.9654 \\
0.9823 \\
0.9914\end{array}$ \\
\hline $\mathrm{UO}_{2}-2 \mathrm{wt} \% \mathrm{PuO}_{2}\left(8 \%{ }^{240} \mathrm{Pu}\right)$ & $\begin{array}{l}0.80 \\
1.05 \\
1.386\end{array}$ & $\begin{array}{l}0.9920 \\
0.9913 \\
0.9979\end{array}$ & $\begin{array}{l}0.9634 \\
0.9778 \\
0.9898\end{array}$ \\
\hline $\mathrm{UO}_{2}-2 \mathrm{wt} \% \mathrm{PuO}_{2}\left(16 \%{ }^{240} \mathrm{Pu}\right)$ & $\begin{array}{l}1.05 \\
1.386\end{array}$ & $\begin{array}{l}0.9931 \\
0.9964\end{array}$ & $\begin{array}{l}0.9799 \\
0.9884\end{array}$ \\
\hline $\mathrm{UO}_{2}-2 \mathrm{wt} \% \mathrm{PuO}_{2}\left(24 \%{ }^{240} \mathrm{Pu}\right)$ & $\begin{array}{l}0.80 \\
1.05 \\
1.386\end{array}$ & $\begin{array}{l}0.9942 \\
0.9981 \\
0.9971\end{array}$ & $\begin{array}{l}0.9676 \\
0.9855 \\
0.9893\end{array}$ \\
\hline $\mathrm{UO}_{2}-4 \mathrm{wt} \% \mathrm{PuO}_{2}$ & $\begin{array}{l}1.05 \\
1.386\end{array}$ & $\begin{array}{l}1.0035 \\
1.0062\end{array}$ & $\begin{array}{l}0.9920 \\
0.9991\end{array}$ \\
\hline
\end{tabular}

values of $k_{\text {eff }}$ are systematically lower using ENDF/B-II data for the $\mathrm{UO}_{2}$ and the $\mathrm{UO}_{2}-\mathrm{PuO}_{2}$ fueled systems. Moreover, a substantial trend is evident with changes in lattice spacing. The largest discrepancies occur for the smallest lattice spacings with the differences being approximately $3.5 \% \Delta k$. 
Considering the thermal cross sections for the fissile nuclides, we did not expect large differences in $k_{\text {eff }}$ in switching from BNWML to ENDF/B-II cross sections. The BNWML values at $2200 \mathrm{~m} / \mathrm{s}$ are the 1965 IAEA evaluation. (33) The corresponding ENDF/B-II values are the 1969 IAEA evaluation. (60) The differences between these two evaluations in parameters which have the most effect in these calculations are sma11. The principal parameters are $\sigma_{a}$ and $\eta$ for ${ }^{235} U$ and ${ }^{239} \mathrm{Pu}$, and the change in values at $2200 \mathrm{~m} / \mathrm{s}$ are not large enough to affect the calculation of $\bar{\eta} f$. Likewise, the differences in the shapes of the cross sections in the BNWML and ENDF/B-II are not large enough to cause a significant change in calculated values of $\bar{\eta} f$. Therefore, any observable differences were expected to come from above the thermal region for the fissile nuclides and from differences in the other cross sections.

It is instructive to resort to the two group buckling representation of $k_{\text {eff }}$ to examine in more detail what changed. This expression is:

$$
k_{e f f}=\frac{\bar{n}_{1}\left(1-p_{1}\right)}{\left(1+B_{g}^{2} \tau\right)}+\frac{\bar{n}_{2}\left(p_{1}\right)}{\left(1+B_{g}^{2} \tau\right)\left(1+B_{g}^{2} L^{2}\right)}
$$

where subscripts 1 and 2 refer to nonthermal and thermal energy groups and

$$
\begin{aligned}
& \bar{n} f=\left(\nu \bar{\Sigma}_{f} / \bar{\Sigma}_{\mathrm{a}}\right) \text { group } 1 \text { or } 2, \quad \mathrm{p}_{1}=\left(\frac{\bar{\Sigma}_{\text {scatter from group } 1}}{\bar{\Sigma}_{\text {removal from group } 1}}\right) \\
& \mathrm{B}_{\mathrm{g}}^{2}=\text { geometrical buckling, } \tau=\left(\mathrm{D} / \bar{\Sigma}_{\text {remova } 1}\right) \text { group } 1, \\
& \mathrm{~L}^{2}=\left(\mathrm{D} / \bar{\Sigma}_{\mathrm{a}}\right) \text { group } 2 \text { and a11 cross sections are cell average values. }
\end{aligned}
$$

According to this expression, when the system is infinite in size, $\mathrm{B}_{\mathrm{g}}^{2}$ becomes zero and $\mathrm{k}_{\text {eff }}$ becomes the infinite system multiplication factor, $k_{\infty}$. 
The values of the parameters for this equation were taken from the BRT-I and HRG3 calculations and are shown in Tables 15, 16 and 17 for two $\mathrm{UO}_{2}$, two $\mathrm{UO}_{2}-\mathrm{PuO}_{2}$ and two $\mathrm{Al}-\mathrm{Pu}$ lattices respectively. Also shown are the the values of $k_{\infty}$ and $k_{\text {eff }}$ as calculated using Equation 1 and the values of $k_{\text {eff }}$ calculated using HFN.

The leakage effects for the Al-Pu lattices are essentially the same for both sets of cross sections because $\tau$ and $L^{2}$ are essentially the same. In addition, $\bar{n} f$ and $p$ for the nonthermal energy group are also nearly the same. For the more open lattices, $p$ is so close to 1.0 that differences in $\bar{n} f_{1}$ do not affect $k_{\text {eff }}$ significantly. The increase in $k_{\text {eff }}$ and $k_{\infty}$ of about $0.3 \%$ is related solely to differences in $\bar{n} f_{2}$. This difference is primarily due to a change in $f$ which stems from differences in the aluminum cross sections ( $0.235 \mathrm{~b}$ on the BNWML and $0.230 \mathrm{~b}$ on ENDF/B-II).

In the $\mathrm{UO}_{2}-\mathrm{PuO}_{2}$ systems, $\tau$ increases when the ENDF/B-II data is used. For the 0.80 in. lattice the difference is about $1 \%$. The increased value in $\tau$ corresponds to the decreased value in $\bar{n} f_{1}$. For both lattices, the decrease in $\bar{n} f_{1}$ is about $8 \%$. It is due primarily to a larger spectrum average ${ }^{238} U$ cross section and this larger cross section leads to a significant reduction in $p$. As lattice spacing increases, the ${ }^{238} U$ cross section has a diminishing effect on $p$. In addition, since $p$ approaches 1.0 the nonthermal energy group is relatively less important.

The thermal value of $\bar{n} f$ is virtually identical for both sets of cross sections for the three types of lattices. The increase of $0.3 \%$ in $\mathrm{nf}_{2}$ observed for the A1-Pu systems does not show up in the $\mathrm{UO}_{2}-\mathrm{PuO}_{2}$ systems because of the absence of aluminum in these fuels. The change in $k_{\infty}$ and $k_{\text {eff }}$ for the $\mathrm{UO}_{2}$ and the $\mathrm{UO}_{2}-\mathrm{PuO}_{2}$ fueled lattices is due to the change in $238 \mathrm{U}$ resonance absorption rates as seen by comparing values of $p_{1}$ in Tables 15 and 16.

Thus the large changes in $\mathrm{k}_{\text {eff }}(1-3 \%)$ for the $\mathrm{UO}_{2}$ and $\mathrm{UO}_{2}-\mathrm{PuO}_{2}$ systems observed in Table 14 are basically due to nonthermal absorptions by ${ }^{238} \mathrm{U}$. Effects of changes in leakage and thermal neutron reactivity are much less than effects of changes in the nonthermal reactivity. 
TABLE 15. Comparison of Multiplication Parameters for Yankee $\mathrm{UO}_{2}$ Lattices

\begin{tabular}{|c|c|c|c|c|}
\hline \multirow[b]{2}{*}{ Parameter } & \multicolumn{2}{|c|}{$\begin{array}{c}\text { Lattice Spacing } \\
0.405 \text { in. }\end{array}$} & \multicolumn{2}{|c|}{$\begin{array}{c}\text { Lattice Spacing } \\
0.665 \text { in. }\end{array}$} \\
\hline & BNWML & ENDF/B-II & BNWML & ENDF/B-II \\
\hline $\bar{n} f_{1}$ (nontherma 1$)$ & 0.7068 & 0.6453 & 0.6531 & 0.6041 \\
\hline$p_{1}$ & 0.5897 & 0.5672 & 0.8687 & 0.8614 \\
\hline $\bar{n} f_{2}$ (therma1) & 1.4885 & 1.4843 & 1.2540 & 1.2509 \\
\hline$\tau, \mathrm{cm}^{2}$ & 35.83 & 35.47 & 28.09 & 27.94 \\
\hline $\mathrm{L}^{2}, \mathrm{~cm}^{2}$ & 1.64 & 1.69 & 2.19 & 2.11 \\
\hline $\mathrm{B}_{\mathrm{g}}^{2}$ (measured), $\mathrm{m}^{-2}$ & 40.75 & 40.75 & 52.92 & 52.92 \\
\hline $\mathrm{k}_{\infty}\left(\right.$ Eq. 1 with $\left.\mathrm{B}_{\mathrm{g}}^{2}=0\right)$ & 1.1678 & 1.1212 & 1.1751 & 1.1613 \\
\hline$k_{e f f}(E q \cdot 1)$ & 1.0139 & 0.9745 & 1.0121 & 1.0013 \\
\hline$k_{\text {eff }}(4$ group HFN $)$ & 1.0035 & 0.9658 & 0.9969 & 0.9861 \\
\hline
\end{tabular}

TABLE 16. Comparison of Multiplication Parameters for $\mathrm{UO}_{2}-2 \mathrm{wt} \% \mathrm{PuO}_{2}$ (8\% 240Pu) Lattices

Lattice Spacing Lattice Spacing

Parameter

0.80 in. 1.386 in. BNWML ENDF/B-II BNWML ENDF/B-II

$\begin{array}{lllll}\bar{n} f_{1} \text { (nontherma1) } & 0.7009 & 0.6431 & 0.6498 & 0.6014 \\ \mathrm{p}_{1} & 0.6676 & 0.6505 & 0.9032 & 0.8985 \\ \bar{n} f_{2} \text { (therma1) } & 1.6662 & 1.6658 & 1.2817 & 1.2798 \\ \tau, \mathrm{cm}^{2} & 35.97 & 36.36 & 28.30 & 28.38 \\ \mathrm{~L}^{2}, \mathrm{~cm}^{2} & 1.54 & 1.50 & 2.93 & 2.78 \\ \mathrm{~B}_{\mathrm{g}}^{2} \text { (measured), } \mathrm{m}^{-2} & 88.0 & 88.0 & 70.0 & 70.0 \\ \left.\mathrm{k}_{\infty} \text { (Eq. 1 with } \mathrm{B}_{\mathrm{g}}^{2}=0\right) & 1.3453 & 1.3084 & 1.2205 & 1.2109 \\ \mathrm{k}_{\text {eff }} \text { (Eq. 1) } & 1.0106 & 0.9805 & 0.9993 & 0.9919 \\ \mathrm{k}_{\text {eff }} \text { (4 group HFN) } & 0.9920 & 0.9634 & 0.9979 & 0.9898\end{array}$


TABLE 17. Comparison of Multiplication Parameters for $\mathrm{A} 1-1.8$ wt\% Pu Lattices

\begin{tabular}{|c|c|c|c|c|}
\hline \multirow[b]{2}{*}{ Parameter } & \multicolumn{2}{|c|}{$\begin{array}{c}\text { Lattice Spacing } \\
0.75 \text { in. } \\
\end{array}$} & \multicolumn{2}{|c|}{$\begin{array}{c}\text { Lattice Spacing } \\
0.95 \text { in } \\
\end{array}$} \\
\hline & $\overline{B N W M L}$ & ENDF/B-II & BNWML & ENDF/B-II \\
\hline $\bar{\eta} f_{1}$ (nonthermal) & 0.6839 & 0.6817 & 0.6190 & 0.5944 \\
\hline$P_{1}$ & 0.9136 & 0.9140 & 0.9488 & 0.9552 \\
\hline $\bar{\eta} f_{2}($ thermal) & 1.5054 & 1.5097 & 1.2573 & 1.2615 \\
\hline$\tau, \mathrm{cm}^{2}$ & 60.80 & 60.78 & 40.85 & 40.84 \\
\hline $\mathrm{L}^{2}, \mathrm{~cm}^{2}$ & 4.67 & 4.49 & 4.61 & 4.38 \\
\hline $\mathrm{B}_{\mathrm{g}}^{2} \quad$ (measured), $\mathrm{m}^{-2}$ & 60.2 & 60.2 & 47.3 & 47.3 \\
\hline $\mathrm{k}_{\infty}$ (Eq. 1 with $\mathrm{B}_{\mathrm{g}}^{2}=0$ ) & 1.4344 & 1.4385 & 1.2246 & 1.2316 \\
\hline$k_{\text {eff }}($ Eq. 1) & 1.0225 & 1.0266 & 1.0050 & 1.0117 \\
\hline$k_{\text {eff }}$ ( 4 group HFN) & 1.0086 & 1.0113 & 1.0045 & 1.0083 \\
\hline
\end{tabular}

When the HRG3 cases are compared with each other, one finds that the differences are due primarily to ${ }^{238} U$ cross sections. ${ }^{(61)}$ we examine the calculations for the $\mathrm{UO}_{2}-2$ wt\% $\mathrm{PuO}_{2}\left(8 \%{ }^{240} \mathrm{Pu}\right)$ fuel, $0.80 \mathrm{in}$. lattice in more detail to illustrate. The macroscopic parameters over the range 0.683 to $10^{7} \mathrm{eV}$ for the two cases are summarized ir Table 18. The cell-average parameters are also separated into the contribution from ${ }^{238} U$ and the contribution of all the other isotopes. In going from BNWML to ENDF/B-II cross sections, the cell-average macroscopic absorption cross section $\left(\bar{\Sigma}_{a}\right)$ increases $4.0 \%$ while the production cross section $\left(\nu \bar{\Sigma}_{f}\right)$ decreases $4.6 \%$. These changes give a net decrease in $\bar{\eta}_{f}\left(\nu \bar{\Sigma}_{f} / \bar{\Sigma}_{a}\right)$ of $8.2 \%$. About $60 \%$ of the absorptions occur in ${ }^{238} U$ while $30 \%$ of the fissions occur in ${ }^{238} U$. If we look at the column headed $\Delta$ Change, we see that the increase in $\bar{\Sigma}_{a}^{238}$ is about 4 times as much as the decrease in $\bar{\Sigma}_{a}$ of the other isotopes. In addition, the decrease in $\bar{\Sigma}_{a}$ of the other isotopes is nearly offset by a decrease in $\nu \bar{\Sigma}_{f}$ due to the other isotopes. Thus, $\bar{n} f$ is decreased only $1.2 \%$ if ${ }^{238} \mathrm{U}$ reactions are not included. 
TABLE 18. Nonthermal Parameters for the 0.80 in. Lattice of $\mathrm{UO}_{2}-2$ wt $\% \mathrm{PuO}_{2}(8 \% 2 \dot{4} 0 \mathrm{Pu})$ Fuel

\begin{tabular}{|c|c|c|c|c|}
\hline Parameter & BNWML & ENDF/B-II & $\triangle$ Change & $\%$ Change \\
\hline \multicolumn{5}{|l|}{ Macroscopic } \\
\hline $\bar{\Sigma}_{\mathrm{a}}^{\mathrm{cell}}$ & 0.010486 & 0.010904 & +0.000418 & +4.0 \\
\hline $\bar{\Sigma}_{a}^{238}$ & 0.006152 & 0.006711 & +0.000559 & +9.1 \\
\hline $\bar{\Sigma}_{a}^{c e l l}-\bar{\Sigma}_{a}^{238}$ & 0.004334 & 0.004192 & -0.000141 & -3.3 \\
\hline$v \bar{\Sigma}_{f}^{c e l 1}$ & 0.007349 & 0.007013 & -0.000337 & -4.6 \\
\hline$v \Sigma_{f}^{238}$ & 0.002457 & 0.002285 & -0.000171 & -7.0 \\
\hline$v \Sigma_{f}^{c e 11}-v \Sigma_{f}^{238}$ & 0.004893 & 0.004727 & -0.000166 & -3.4 \\
\hline $\bar{\eta} f(c e 11-238)$ * & 1.1290 & 1.1276 & -0.0014 & -1.2 \\
\hline $\bar{n} f(\operatorname{cel1})$ & 0.7009 & 0.6431 & -0.0578 & -8.2 \\
\hline
\end{tabular}

Microscopic for ${ }^{238} \mathrm{U}$

$\begin{array}{llllr}\sigma_{f_{1}}\left(10^{7}-1.17 \times 10^{4} \mathrm{eV}\right) & 0.181 & 0.165 & -0.016 & -8.9 \\ \sigma_{a_{1}}\left(10^{7}-1.17 \times 10^{4} \mathrm{eV}\right) & 0.346 & 0.321 & -0.025 & -7.2 \\ \sigma_{a_{2}}\left(1.17 \times 10^{4}-2.38 \mathrm{eV}\right) & 1.858 & 2.187 & +0.329 & +17.7 \\ \sigma_{a_{3}}(2.38-0.683 \mathrm{eV}) & 0.414 & 0.512 & +0.098 & +23.9 \\ \text { RI }_{a} \text { eff }\left(10^{7}-0.683 \mathrm{eV}\right) & 15.237 & 15.530 & +0.293 & +1.9\end{array}$

$\overline{\bar{n}_{f}(\mathrm{cel1}-238)}=\frac{v \bar{\Sigma}_{f}^{\mathrm{cel1}}-v \bar{\Sigma}_{f}^{238}}{\bar{\Sigma}_{\mathrm{a}}^{\mathrm{cel1}}-\bar{\Sigma}_{\mathrm{a}}^{238}}$

The effect on $p$, the resonance escape probability, is essentially proportional to the change in $\Sigma_{a}^{c e l l}$. In principle, one cannot separate fluxes and cross sections, but Table 18 and the discussion in the previous paragraph do show the major differences between the two sets of cross sections. 
The last section of Table 18 shows that the largest contribution to $\bar{\Sigma}_{a}^{c e l 1}$ is in the second energy group (2.38 eV to $\left.11.7 \mathrm{keV}\right)$. The microscopic absorption cross section increases by $17.7 \%$ in group 2. Since most of the absorptions in this energy range occur in the resonances, a comparison of the effective resonance integrals was made. The effective resonance integral excluding the floor, $\mathrm{RI}_{\mathrm{a}}^{\mathrm{eff}}$, using ENDF/B-II data ${ }^{(62)}$ is only $1.9 \%$ higher than the value using BNWML data. Thus, the difference in $\sigma_{a_{2}}$ must come from differences in cross sections not subject to self-shielding, i.e., the floor.

In order to understand the ${ }^{238} \mathrm{U}$ cross-section differences more clearly, the infinite dilute resonance integral was looked at in detail. Values are summarized in Table 19. The processing codes BARNS ${ }^{(63)}$ and ETOG ${ }^{(64)}$ give values of 270.8 for BNWML data and 278.1 for ENDF/B-II data, respectively, for the infinite dilute resonance integrals. HRG3 runs were made using a 1/E flux and resonance parameters which should give infintely dilute values. The "infinitely dilute" resonance integrals calculated in this manner are 3.8 and 3.2 barns smaller than the values from BARNS and ETOG, respectively. Nevertheless, the HRG3 values are adequate for this discussion. The resonance integral calculated using HRG3 is broken down into components representing five energy groups. Group 3 in Table 19 covers the same energy range as group 2 in Table $18(2.38 \mathrm{eV}$ to $11.7 \mathrm{keV})$. It contains all of the resonance integral subject to shielding.

The portion of the resonance integral subject to shielding in HRG3 is 261.8 and 267.5 barns for BNWML and ENDF/B-II data, respectively. Thus, the floor or non-shielded portion of the resonance integral is 5.15 barns' $^{\prime}$ for BNWML data and 7.39 barns for ENDF/B-II data. This difference is smal1 when compared to the infinite dilute resonance integral; however, when it is added to an effective resonance integral of about 15 barns, the resulting cross section differs by $210 \%$. The floor in the resonance region (Group 3) increases from 1.36 barns to 3.85 barns. Adding this floor to an effective resonance integral of 15 barns would increase the spectrum average cross section in this group by $15 \%$. This is in good agreement with the observed increase in $\sigma_{a_{2}}$ (Table 18) of $17.7 \%$. 
TABLE 19. Components of the Infinite Dilute Resonance Integrals used in HRG3

\begin{tabular}{|c|c|c|}
\hline Component, b. & BNWML & ENDF/B-II \\
\hline $\mathrm{RI}_{\mathrm{a}}$ (processing codes) & 270.8 & 278.1 \\
\hline $\mathrm{RI}_{f}$ (processing codes) & 1.25 & 1.18 \\
\hline $\mathrm{RI}_{\mathrm{a}_{1}}(10 \mathrm{MeV}-0.18 \mathrm{MeV})$ & 1.59 & 1.52 \\
\hline $\mathrm{RI}_{\mathrm{a}_{2}}(0.18 \mathrm{MeV}-11.7 \mathrm{keV})$ & 1.15 & 1.05 \\
\hline $\mathrm{RI}_{\mathrm{a}_{3}}(11.7 \mathrm{keV}-2.38 \mathrm{eV})$ & 263.21 & 271.39 \\
\hline $\mathrm{RI}_{\mathrm{a}_{4}}(2.38 \mathrm{eV}-0.683 \mathrm{eV})$ & 0.52 & 0.64 \\
\hline $\mathrm{RI}_{\mathrm{a}_{5}}(0.683 \mathrm{eV}-0.414 \mathrm{eV})$ & 0.53 & 0.33 \\
\hline$R I_{a}=\sum_{i} R I_{a_{i}}(H R G 3)$ & 267.00 & 274.92 \\
\hline $\mathrm{RI}_{\mathrm{a}}$ (subject to shielding in HRG3) & 261.85 & 267.53 \\
\hline $\mathrm{RI}_{\mathrm{a}}(\mathrm{HRG} 3$ floor $)$ & 5.15 & 7.39 \\
\hline $\mathrm{RI}_{\mathrm{a}_{3}}$ (HRG3 floor) & 1.36 & 3.85 \\
\hline
\end{tabular}

The contributions to the floor of the ENDF/B-II data used in HRG3 are summarized in Table 20. Since HRG3 can handle only 99 resonances, the other 150 are put in the floor as infinite dilute values. This amounts to only about 0.45 barns. The floor under the resolved resonances is also added to the floor of the data file. It has a resonance integral of 0.21 barns. The $p$-wave resolved resonances contribute 1.06 barns to the total resonance integral while the $p$-wave and $s$-wave unresolved resonances contribute 1.65 barns to resonance integral. The smooth $(n, \gamma)$ ENDF/B-II file adds 2.80 barns to the floor. It contains 1.27 barns of $p$-wave cross section in the resolved region. The components listed above are $(n, \gamma)$ 
reactions. If 1.18 barns is added for $(n, f)$ reactions, the total is the portion of the absorption resonance integral which is not subject to selfshielding. It agrees very well with the floor in the HRG3 library.

TABLE 20. Cross Section Components of the $\begin{gathered}238 \mathrm{U} \text { Floor in HRG3 } \\ \text { Component }\end{gathered}$
$\begin{array}{lc}\mathrm{RI} \text { from } \\ \text { ENDF/B-II, b. }\end{array}$
$\begin{array}{ll}150 \text { excess resonances } & 0.45 \\ \text { l/v portion under the resonances } & 0.21 \\ \text { p-wave resolved resonances } & 1.06 \\ \text { unresolved resonances } & 1.65 \\ \text { smooth }(n, \gamma) & 2.80 \\ \text { smooth }(n, f) & 1.18 \\ \text { Total Floor } & 7.34\end{array}$

The BNWML resolved resonance region is from $1 \mathrm{eV}$ to $1.8 \mathrm{keV}$ and the unresolved region covers the energy range from $1.8 \mathrm{keV}$ to $2.5 \mathrm{keV}$ for ${ }^{238} \mathrm{U}$. The resolved resonance region on the ENDF/B-II data file is from $5 \mathrm{eV}$ to $3.9 \mathrm{keV}$ while the unresolved region extends up to $45 \mathrm{keV}$. The BNWML data does not contain any p-wave cross sections in either the resolved or unresolved resonance regions (from $1 \mathrm{eV}$ to $2.5 \mathrm{keV}$ ). From the previous paragraph and Table 20 we note that the $p$-wave resolved resonances and the p-wave cross section on the smooth file add up to about 2.3 barns. Thus, the difference between the HRG3 floors using BNWML and ENDF/B-II crosssection data appears to be due to the p-wave cross-section data in the resonance region. Group 3 in Table 19 essentially covers the resonance region. The floor in this group shows a difference of about 2.5 barns which is consistent with the previous discussion.

In principle, the ENDF/B-II cross-section data is better than BNWML cross-sction data because it represents newer experimental data and evaluations. Since $k_{\text {eff }}$ values calculated with ENDF/B-II data are as much 
as $3.8 \%$ low, we expect that the calculation of resonance absorption in ${ }^{238} \mathrm{U}$ is in error. This could be the result of; 1 ) the ${ }^{238} \mathrm{U}$ cross sections in ENDF/B-II, 2) the way that it is processed to multigroup format for HRG3, 3 ) the HRG3 resonance calculation itself, 4) all of these.

\section{Definition of Diffusion Coefficient}

Two types of transport cross sections are calculated in HRG3. The consistent definition is obtained by equating the second of the $\mathrm{P}_{1}$ or $\mathrm{B}_{1}$ equations to Fick's law. In terms of cross sections, the definition for group $g$ is:

$$
\Sigma_{\text {tr,g }} \text { (consistent) }=\alpha_{g} \Sigma_{t, g}-\Sigma_{1, g}^{\text {in }}
$$

where $\Sigma_{t, g}$ is the current weighted total cross section, $\Sigma_{1, g}^{i n}$ is the current weighted $\mathrm{P}_{1}$ component of the scattering cross section from all energies into energy group $g$, and $\alpha_{g}$ is a parameter in the second $B_{1}$ equation:

$$
a_{g}=x^{2} A_{0} / 3\left(1-A_{0}\right)
$$

where $x=K / \Sigma_{t, g}, A_{0}=\tan ^{-1} x / X$, and $K$ is the square root of the buckling. $\alpha_{g}$ approaches 1.0 as leakage approaches zero. Our analysis above was based upon using this definition of $\Sigma_{t r}$.

The standard transport cross section is defined as:

$$
\left.\Sigma_{\text {tr,g }} \text { (Standard }\right)=\alpha_{g} \Sigma_{t, g}-\Sigma_{1, g}^{\text {out }}
$$

where $\Sigma_{1, g}^{\text {out }}$ is the current weighted $P_{1}$ component of the scattering cross section from group $g$ into all other energy groups, and the other parameters are as above. In the limit of a single energy group solution, these two definitions yield identical values for the transport cross section. However, in a multigroup solution the values may differ considerably.

Diffusion coefficients, $D$, can be calculated with either type of transport cross section as $1 / 3 \Sigma_{\mathrm{tr}}$. Values for one of the mixed oxide lattices are shown in Table 21. The standard $D$ is $5 \%$ higher than the consistent $D$ in the fast energy group, but is 5\% lower in group 2 and $10 \%$ lower in group 3. The one-group value is only $1.3 \%$ higher. 
TABLE 21. Comparison of Diffusion Coefficient Definitions in HRG3 for 0.80 in. Lattice of $\mathrm{UO}_{2}-2 \mathrm{wt} \% \mathrm{PuO}_{2}(8 \% 240 \mathrm{Pu})$

\begin{tabular}{cccccc} 
& & & & \multicolumn{2}{c}{ Type of Definition } \\
\cline { 1 - 2 } \cline { 5 - 6 } $\mathrm{D}_{1}$ & $10 \mathrm{MeV}$ to $11.7 \mathrm{keV}$ & & 1.4190 & 1.4923 \\
$\mathrm{D}_{2}$ & $11.7 \mathrm{keV}$ to $2.38 \mathrm{eV}$ & 0.6044 & 0.5766 \\
$\mathrm{D}_{3}$ & $2.38 \mathrm{eV}$ to $0.683 \mathrm{eV}$ & 0.6394 & 0.5754 \\
$\mathrm{D}$ & $10 \mathrm{MeV}$ to $0.683 \mathrm{eV}$ & & 1.1345 & 1.1489
\end{tabular}

Calculated values of $k_{\text {eff }}$ using the two different definitions of the transport cross sections are shown in Table 22 for this lattice. The value of $D$ from BRT-I for the single thermal group was used for all the calculations shown in Table 22. The 2-group buckling equation gives values of $k_{\text {eff }}$ about $1 \%$ high. The difference of $1.3 \%$ in the nonthermal diffusion coefficient results in values of $k_{\text {eff }}$ which are $0.30 \% \Delta k$ different. When the leakage calculation is performed with HFN in 4 energy groups, the values of $\mathrm{k}_{\text {eff }}$ are about $1 \%$ low. The three nonthermal groups correspond to the energies shown in Table 21. The results shown on line 2 of Table 22 utilize consistent $D$ 's for the reflector for both calculations. The results on line 3 are similar to the results on line 2 except the HRG 3 calculation was performed with no leakage. With no leakige, values of $k_{\text {eff }}$ increase about $1.5 \mathrm{mk}$ primarily because absorption, fission, and scattering cross sections change ( $k_{\infty}$ is $0.19 \% \Delta k / k$ higher). The effect of the diffusion coefficient definition on $k_{\text {eff }}$ is about $0.40 \%$ whether or not leakage is put into the HRG3 calculation.

To properly determine the effect of the diffusion coefficient definition on $k_{\text {eff }}$, the diffusion coefficients in the reflector should also be changed. The results on the last two lines of Table 22 show the effect of changing $D$ in both the core and reflector. The reflector cross sections were recalculated, but the only significant change was in the thermal $D$ $(0.1185$ to 0.1350$)$. The new reflector cross sections increase $k_{\text {eff }}$ 
by $1.6 \mathrm{mk}$ as shown by comparing the results using consistent D's with the values on lines 2 and 3 . Calculated values of $k_{\text {eff }}$ are decreased by $0.65 \%$ when consistent D's are replaced by standard D's in both the core and reflector. Thus, the reflector $D$ 's have an effect $(2.5 \mathrm{mk})$ nearly as large as the core D's $(4.0 \mathrm{mk})$.

TABLE 22. Diffusion Theory Results for $0,80 \mathrm{in}$. Lattice of $\mathrm{UO}_{2}-2 \mathrm{wt} \% \mathrm{PuO}_{2}(8 \% 240 \mathrm{Pu})$

\begin{tabular}{|c|c|c|c|c|}
\hline $\begin{array}{c}\mathrm{k} \text { in HRG3, } \\
\mathrm{cm}^{-1}\end{array}$ & $\mathrm{k}_{\infty}$ & $\frac{k}{\text { Consistent D }}$ & $f f \overline{\text { Standard D }}$ & $\begin{array}{r}\text { Differer } \\
\% \Delta k \\
\end{array}$ \\
\hline \multicolumn{5}{|c|}{ 2-Group Buckling Equation } \\
\hline 0.09322 & 1.3453 & 1.0137 & 1.0107 & -0.30 \\
\hline \multicolumn{5}{|c|}{ HFN (4 Groups)* } \\
\hline 0.09322 & 1.3453 & 0.9920 & 0.9881 & -0.39 \\
\hline $1.0-10$ & 1.3479 & 0.9935 & 0.9894 & -0.41 \\
\hline \multicolumn{5}{|c|}{ HFN (4 Groups)** } \\
\hline 0.09322 & 1.3453 & 0.9936 & 0.9874 & -0.62 \\
\hline $1.0-10$ & 1.3479 & 0.9952 & 0.9886 & -0.66 \\
\hline
\end{tabular}

* 01d water with consistent D's for the reflector; $\mathrm{D}_{4}^{\mathrm{H}} 2 \mathrm{O}=0.11848 \mathrm{~cm}$.

** New water with appropriate $D$ 's for the reflector: $\mathrm{D}_{4}^{\mathrm{H} 2 \mathrm{O}}=0.13504 \mathrm{~cm}$.

Reactivity calculations for a number of other lattices were performed with HFN in 4 energy groups using the two types of diffusion coefficients. Results are shown in Table 23. The reflector diffusion coefficients were not changed so the results indicate a smaller effect than actually exists (analogous to line 2 of Table 22). The few-group parameters were obtained using ENDF/B-II data in HRG3 and BRT-1 for the heavy isotopes. The D's in Table 21 and $k_{\infty}$ 's in Table 22 utilized BNWML data. The primary difference 
TABLE 23. Effect of Changing the Diffusion Coefficient on Calculated Values of $k_{\text {eff }}$

\begin{tabular}{|c|c|c|c|c|c|}
\hline Fuel Type & $\begin{array}{l}\text { Lattice } \\
\text { Spacing } \\
\text { (in.) } \\
\end{array}$ & $\begin{array}{l}\text { Calculate } \\
\text { of keff with } \\
\text { Consistent D }\end{array}$ & $\begin{array}{l}\text { ed Value } \\
\text { ENDF/B-II Data } \\
\text { D } \frac{\text { Standard D }}{\text { Stard }}\end{array}$ & $\begin{array}{c}\text { Difference } \\
\% \Delta \mathrm{k} \\
\end{array}$ & $\begin{array}{l}\mathrm{B}^{2} \text { in } \mathrm{HRG} 3 \text {, } \\
\mathrm{m}-2\end{array}$ \\
\hline $2.734 \mathrm{wt} \% \mathrm{UO}_{2}$ & $\begin{array}{l}0.405 \\
0.470 \\
0.573 \\
0.665\end{array}$ & $\begin{array}{l}0.9658 \\
0.9770 \\
0.9850 \\
0.9861\end{array}$ & $\begin{array}{l}0.9637 \\
0.9736 \\
0.9809 \\
0.9821\end{array}$ & $\begin{array}{l}-0.21 \\
-0.34 \\
-0.41 \\
-0.40\end{array}$ & $\begin{array}{l}40.7 \\
63.4 \\
59.4 \\
51.0\end{array}$ \\
\hline $\mathrm{A} 1-1.8 \mathrm{wt} \% \mathrm{Pu}$ & $\begin{array}{l}0.75 \\
0.85 \\
0.95\end{array}$ & $\begin{array}{l}1.0113 \\
1.0112 \\
1.0083\end{array}$ & $\begin{array}{l}1.0067 \\
1.0064 \\
1.0037\end{array}$ & $\begin{array}{l}-0.46 \\
-0.48 \\
-0.46\end{array}$ & $\begin{array}{l}60.2 \\
60.1 \\
47.3\end{array}$ \\
\hline $\mathrm{A} 1-2$ wt\% Pu & $\begin{array}{l}0.75 \\
0.85 \\
0.95\end{array}$ & $\begin{array}{l}1.0214 \\
1.0249 \\
1.0226\end{array}$ & $\begin{array}{l}1.0168 \\
1.0202 \\
1.0186\end{array}$ & $\begin{array}{l}-0.46 \\
-0.47 \\
-0.40\end{array}$ & $\begin{array}{l}48.5 \\
45.4 \\
36.3\end{array}$ \\
\hline $\mathrm{A} 1-5 \mathrm{wt} \% \mathrm{Pu}$ & $\begin{array}{l}0.85 \\
1.05 \\
1.30\end{array}$ & $\begin{array}{l}1.0065 \\
1.0119 \\
1.0074\end{array}$ & $\begin{array}{l}1.0008 \\
1.0050 \\
1.0010\end{array}$ & $\begin{array}{l}-0.57 \\
-0.69 \\
-0.64\end{array}$ & $\begin{array}{r}102.8 \\
79.8 \\
105.8\end{array}$ \\
\hline $\mathrm{UO}_{2}-1.5$ wt\% $\mathrm{PuO}_{2}$ & $\begin{array}{l}0.55 \\
0.71 \\
0.93\end{array}$ & $\begin{array}{l}0.9654 \\
0.9823 \\
0.9914\end{array}$ & $\begin{array}{l}0.9629 \\
0.9780 \\
0.9870\end{array}$ & $\begin{array}{l}-0.25 \\
-0.43 \\
-0.44\end{array}$ & $\begin{array}{l}48.0 \\
78.5 \\
55.2\end{array}$ \\
\hline $\mathrm{UO}_{2}-2 \mathrm{wt} \% \mathrm{PuO}_{2}\left(8 \%{ }^{240} \mathrm{Pu}\right)$ & $\begin{array}{l}0.80 \\
1.05 \\
1.386\end{array}$ & $\begin{array}{l}0.9634 \\
0.9778 \\
0.9898\end{array}$ & $\begin{array}{l}0.9597 \\
0.9726 \\
0.9846\end{array}$ & $\begin{array}{l}-0.37 \\
-0.52 \\
-0.52\end{array}$ & $\begin{array}{r}86.9 \\
108.2 \\
66.4\end{array}$ \\
\hline $\mathrm{UO}_{2}-2 \mathrm{wt} \% \mathrm{PuO}_{2}\left(16 \%{ }^{240} \mathrm{Pu}\right)$ & $\begin{array}{l}1.05 \\
1.386\end{array}$ & $\begin{array}{l}0.9799 \\
0.9884\end{array}$ & $\begin{array}{l}0.9749 \\
0.9839\end{array}$ & $\begin{array}{l}-0.50 \\
-0.45\end{array}$ & $\begin{array}{l}86.2 \\
59.6\end{array}$ \\
\hline $\mathrm{UO}_{2}-2 \mathrm{wt} \% \mathrm{PuO}_{2}\left(24 \%{ }^{240} \mathrm{Pu}\right)$ & $\begin{array}{l}0.80 \\
1.05 \\
1.386\end{array}$ & $\begin{array}{l}0.9676 \\
0.9855 \\
0.9893\end{array}$ & $\begin{array}{l}0.9642 \\
0.9806 \\
0.9853\end{array}$ & $\begin{array}{l}-0.34 \\
-0.49 \\
-0.40\end{array}$ & $\begin{array}{l}63.3 \\
75.7 \\
44.4\end{array}$ \\
\hline $\mathrm{UO}_{2}-4 \mathrm{wt} \% \mathrm{PuO}_{2}$ & $\begin{array}{l}1.05 \\
1.386\end{array}$ & $\begin{array}{l}0.9920 \\
0.9991\end{array}$ & $\begin{array}{l}0.9869 \\
0.9934\end{array}$ & $\begin{array}{l}-0.51 \\
-0.57\end{array}$ & $\begin{array}{r}108.7 \\
88.4\end{array}$ \\
\hline
\end{tabular}


in results using the two sets of data is in the $k_{\infty}$ calculation rather than the leakage calculation. For example, the diffusion coefficient effect for the 0.80 in. lattice of $\mathrm{UO}_{2}-2 \mathrm{wt} \% \mathrm{PuO}_{2}(8 \% 240 \mathrm{Pu})$ is $-0.37 \% \Delta \mathrm{k}$ with ENDF/B-II data whereas it is $-0.39 \% \triangle k$ with BNWML data. $k_{\infty}$ for this lattice using ENDF/B-II data is 1.3084 which is $2.75 \%$ lower than the value calculated with BNWML data (1.3453). The differences in $k_{\text {eff }}$ shown as $\% \Delta k$ in Table 23 range from $-0.2 \%$ to $-0.7 \%$. The difference should be proportional to the geometrical buckling because it is a leakage effect only. However, there does not seem to be much of a correlation between the differences and the geometrical bucklings shown in Table 23 .

To aid in evaluating which definition of the diffusion coefficient to use, the age of fission neutrons in water was calculated and is compared to the measured age to indium resonance in Table 24. The indium resonance is at $1.46 \mathrm{eV}$ whereas the few-group parameters for the reflector were calculated for a boundary of $0.683 \mathrm{eV}$. HRG3 calculates a quantity called "Age" at each energy group. Comparing lines 2 and 3 of Table 24, the two different boundaries affect the value by only $0.3 \mathrm{~cm}^{2}$. The value printed out by HRG3 is midway between the values calculated with the equation: $\tau=D / \Sigma_{r}$ where $\Sigma_{r}$ is the removal cross section and the two definitions of $D$ are used. The calculated values utilized a ${ }^{239} \mathrm{Pu}$ fission spectrum while the measured value is for ${ }^{235} U$ fission neutrons. The effect of differences in fission spectra for ${ }^{235} U$ and ${ }^{239} \mathrm{Pu}$ in HRG3 on the calculated age is sma11. Using the last two values in Table 24 and correcting for the different energy cutoff, the age calculated with the consistent $D$ would be slightly closer to the measured age than the age calculated with the standard D. However, on this basis alone, stating that one definition of the diffusion coefficient is better than the other would be difficult. 
BNWL-1656

TABLE 24. Neutron Age in Water

$\begin{array}{lll}\frac{\text { Description }}{\text { Measured (to Indium Resonance) }} & & \text { Age, } \mathrm{cm}^{2} \\ \text { Age as calculated by HRG3 }(1.44 \mathrm{eV}) & 26.48 \pm 0.32 \text { (Ref. 65) } \\ \text { Age as calculated by HRG3 }(0.683 \mathrm{eV}) & 26.92 \\ D / \Sigma_{r}(0.683 \mathrm{eV}) \text { consistent } D & 26.59 \\ D / \Sigma_{r}(0.683 \mathrm{eV}) \text { standard } D & 27.29\end{array}$

\section{Slowing Down Calculation}

Fast Fission. In the calculational method described above, the fast fission from ${ }^{235} \mathrm{U},{ }^{238} \mathrm{U},{ }^{239} \mathrm{Pu}$ and ${ }^{240} \mathrm{Pu}$ is computed assuming a finite homogenized lattice. However, the fuel rods are in a regular array throughout the moderator. Thus, in describing the lattice as a homogeneous mixture of fuel, cladding and moderator, the fast neutron flux is assumed to be spatially flat throughout the unit lattice cell. In reality, the fast neutron flux is peaked in the fuel rod and depressed in the moderator (i.e., the reciprocal of the thermal neutron flux distribution in the lattice ce11). Thus a correction to the fast cross sections due to lattice heterogeneity should have been made. The effects on criticality due to approximating the lattice cell in a homogeneous fashion have been investigated by Dwivedi ${ }^{(66)}$ for the $\mathrm{UO}_{2}$ fueled lattices studied here. The results of his study show that the lattice multiplications increase when a heterogeneous correction is made to the fast fission factor. The correction to the lattice multiplications ranges from approximately 0.22 to $0.45 \%$. These results are consistent with the findings of other investigations of the spatial effects of fast fission events in ${ }^{238} U .(67,68)$ The mixed oxide fuels and the $\mathrm{UO}_{2}$ fuels in our study are similar from the standpoint of fast fission events because of ${ }^{238} \mathrm{U}$ contents in the fuels. The magnitude of the correction is a function of lattice spacing ${ }^{(67)}$ with the largest effect expected at the more open lattices. On this basis we would estimate the error in our calculated values of $k_{\text {eff }}$ to be of the order $-0.5 \%$ because spatial effects were neglected in calculating fast fission events. 
Resonance Absorption. Just as in calculating fast fission events using the HRG3 code, spatial flux considerations are neglected in calculating resonance absorption events. Also, the effect of one resonance shielding another is neglected. These assumptions may not be valid and may be the cause of errors in our calculated values of $k_{\text {eff. }}$. Other investigators have studied the effect of resonance overlap. $(69,70,71)$ The results of these investigations show that a definite effect exists. Hellens (71) has made an estimate of the magnitude of the resonance overlap of ${ }^{239} \mathrm{Pu}$ and ${ }^{238} \mathrm{U}$ in terms of $\mathrm{k}_{\text {eff }}$ for the $\mathrm{UO}_{2}-2 \mathrm{wt} \% \mathrm{PuO}_{2}\left(8 \%{ }^{240} \mathrm{Pu}\right)$ fuel. His results indicate a correction ranging from 0.1 to $0.4 \% \Delta \mathrm{k}$ can be attributed to neglecting this effect. The largest effect is in the tightest lattice. On the basis of this limited information, we assume an error exists in our calculated values of $\mathrm{k}_{\text {eff }}$ for the $\mathrm{UO}_{2}$ and $\mathrm{UO}_{2}-\mathrm{PuO}_{2}$ fueled lattices. We estimate this error is of the magnitude $-0.5 \% \Delta \mathrm{k} / \mathrm{k}$.

\section{Thermalization Calculation}

Boundary Conditions. In our thermal model, reflecting boundary conditions were used in the one dimensional cylindrical cells. Others have $(72,73)$ shown that these boundary conditions could lead to serious errors in the spatial flux for tightly packed uranium-water lattices. Honeck showed that disadvantage factors obtained from the one dimensional cell calculation agree favorably with two dimensional calculations when the outer boundary of the one dimensional cell has a pure heavy srattering material surrounding it (i.e., neutrons returned isotropically). Subsequent investigations on the effects of cell boundary approximations have shown that a so-called white boundary leads to significant improvements in the description of thermal neutron distributions in space and energy. (74) A white boundary condition was incorporated in the BRT-I code after most of our calculations were completed. To assess whether the use of reflecting boundary conditions causes errors in our calculated values of $k_{\text {eff }}$, some of the BRT-I problems were rerun using the white boundary condition incorporated in the BRT-I code. The tight lattices were studied since the largest effect is expected for these cases. The results are compared in Table 25 to those obtained using reflecting boundary conditions. Calculated values of thermal 
utilization, $f$, thermal disadvantage factor, $\Phi$ Moderator/ $\Phi$ Fuel, and the thermal component of $k_{\infty}, \bar{n} f$, are presented. The use of a white boundary condition leads to a larger calculated value of $f$ mainly because of the smaller value of the disadvantage factor. The change in $\bar{n} f$ follows the change in $f$. The magnitude of the effect ranges from $0.2 \% \Delta n f$ for the $2.35 \mathrm{wt} \% \mathrm{UO}_{2}$ fueled system to $0.5 \%$ for the $\mathrm{Al}-2 \mathrm{wt} \%$ Pu fueled system. For the plutonium fueled systems, the change in $\bar{n} f$ is smaller than the change in $f$ because $\bar{n}$ is decreasing to offset some of the change in $f$. Assuming that the white boundary condition is exact and the change in $\bar{n} f$ propagates directly to a change in $k_{\text {eff }}$, we state that our calculated values of $k_{\text {eff }}$ are in error because we used reflecting cell boundary conditions in the thermalization calculation. The magnitude of the error is expected to be lattice spacing dependent but no larger than $0.5 \% \frac{\Delta k}{k}$ for the lattices studied.

TABLE 25. Comparison of Thermal Utilization, Disadvantage Factor and Thermal Value of $\bar{n} f$ for Reflecting and White Boundary Conditions in the Thermalization Calculation $\frac{\text { Thermal Utilization, } f}{\text { Reflecting White }}$ $\underline{2.35 \mathrm{wt} \% \mathrm{UO}} 2=0.75 \mathrm{in}$. lattice

0.847

0.849

1.206

1.1 .81

1.476 $\frac{\bar{n} f=v \bar{\Sigma}_{f} / \bar{\Sigma}_{a} \text { (Thermal) }}{\text { Reflecting White }}$

A1-2 wt\% Pu-0.75 in. lattice

0.844

0.849

1.123

1.090

1.463

Al-2 wt\% Pu-0.95 in. lattice
0.701
0.703
1.117
1.108
1.218
1.222

$\left.\underline{\mathrm{U}}_{2}-2 \mathrm{wt} \% \mathrm{PuO}_{2}-8 \%^{240} \mathrm{Pu}\right)-0.75 \mathrm{in.}$ lattice

0.930

0.934

1.446

1.359

1.665

1.670

$\underline{\mathrm{UO}}_{2}-4 \mathrm{wt} \% \mathrm{PuO}_{2}-0.80 \mathrm{in.}$ lattice

0.948

0.953

1.723

1.572

1.687

1.690 
Resonance Overlap. In our computational mode1, the $1.054 \mathrm{eV}$ resonance of $24 \overline{\mathrm{Pu}}$ is assumed to not shield the $0.296 \mathrm{eV}$ resonance of ${ }^{239} \mathrm{Pu}$ (i.e., flux recovers to $1 / E$ in shape between the resonances). To determine if the ${ }^{240} \mathrm{Pu}$ resonance does indeed self-shield the ${ }^{239} \mathrm{Pu}$ resonance, a calculation using an early version of the THERMOS code was made, whereby, both resonances are included in the cell calculation. A 40 energy group mesh covering the range from 0.0 to $1.4 \mathrm{eV}$ was utilized with the Brown-St. John model for $\mathrm{H}_{2} \mathrm{O} .{ }^{(75)}$ The Brown-St. John model was used rather than the Nelkin model $(76)$ because numerical problems were encountered in the latter when stretched over this energy range. ${ }^{(77)}$ An edit from the problem provided cell averaged cross sections for the thermal range $(0.0$ to $0.683 \mathrm{eV})$ and these results are compared in Table 26 to the corresponding values obtained from calculations in which the self-shielding was neglected. The problem studied was the $0.55 \mathrm{in}$. lattice using $\mathrm{UO}_{2}-1.5 \mathrm{wt} \% \mathrm{PuO}_{2}$ fuel. The cell averaged cross sections, $v \bar{\Sigma}_{f}$ and $\bar{\Sigma}_{\mathrm{a}}$ both decrease when the ${ }^{240} \mathrm{Pu}$ resonance is included in the calculation. The net effect of these changes is to increase the value of $\bar{\eta} f$ by about $0.5 \%$. The increase is shown to be the result of a change in $\bar{\eta}$ rather than $f$. Again assuming $\bar{\eta} f$ changes propagate directly to changes in $k_{\text {eff }}$, we estimate that not including the $240 \mathrm{Pu}$ resonance in the thermalization calculation results in an error of about $0.5 \%$. Since a gas model was used for these calculations, molecular binding effects due to $\mathrm{H}_{2} \mathrm{O}$ are not included which may lead to additional error or compensate for the effect noted here.

TABLE 26. Comparison of Ce11 Averaged Thermal Cross Sections, and the Effects on Criticality for the $\mathrm{U0}_{2}-1.5 \mathrm{wt} \% \mathrm{PuO}_{2} 0.55$ in. Lattice Which Include and Neglect Resonance Shielding
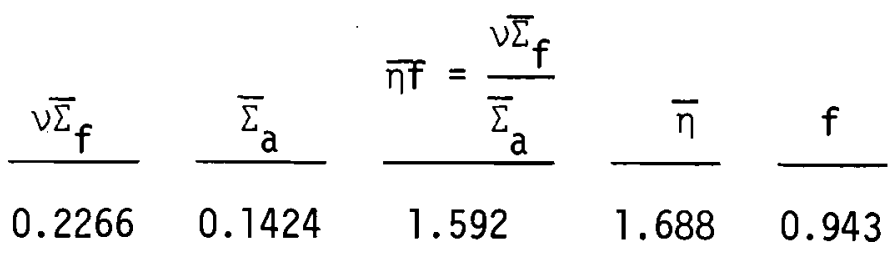
No Shielding
0.1424
1.592
1.688
0.943
Shielding
0.2254
0.1408
1.601
1.697
0.943 
Energy Detail. We have used 30 groups to span the energy region from 0.0 to $0.683 \mathrm{eV}$. To check if this provided enough detail for the reaction rate calculation, the thermalization problems for the 0.55 in. lattice using $\mathrm{UO}_{2}-1.5 \mathrm{wt}_{2} \mathrm{PuO}_{2}$ fuel and the $0.75 \mathrm{in}$. lattice using $\mathrm{Al}-2 \mathrm{wt} \%$ Pu fuel were run using 40 energy groups. Most of the extra detail provided by the 10 additional groups was concentrated in the mesh covering the $20.3 \mathrm{eV}{ }^{239} \mathrm{Pu}$ resonance. Comparison of calculated values of $\bar{\eta} f\left(\frac{\nu \bar{\Sigma}_{f}}{\bar{\Sigma}_{a}}\right)$ cel1 from the 30 and 40 energy group problems showed differences of the magnitude of $0.1 \% \Delta k / k$.

We also have assumed that the thermalization region extends to only $0.683 \mathrm{eV}$ and that neutron upscattering to energies above this in water systems can be accounted for by an approximate correction to the hydrogen cross section in HRG3. Evidence of molecular binding in the neutron energy region above $0.683 \mathrm{eV}$ which was assumed in our calculations is well founded. One of our early attempts was to include the region from 0.683 to $\sim 2 \mathrm{eV}$ in our thermalization calculation using the THERMOS type code. Though we were not limited as to the number of energy groups, the results of studies we made ${ }^{(77)}$ showed that extending the Nelkin kernel for $\mathrm{H}_{2} \mathrm{O}$ to energies above $0.683 \mathrm{eV}$ resulted in oscillating behavior in the calculated water cross sections and the flux in media comprised of only $\mathrm{H}_{2} \mathrm{O}$. Attempts to "connect" a gas model to account for downscattering with a Nelkin model to account for upscattering were unsuccessful. Therefore, considering the circumstances it was decided that the most prudent approach was to try to account for this effect by an approximation which could be accommodated in the slowing down calculation in the HRG 3 code. Determinations of the magnitude of the effect of the approximation which is included in the HRG3 code ${ }^{(79)}$ were made for purposes of evaluation and the results are presented in Table 27.

The change in $\mathrm{k}_{\text {eff }}$ is negligible when $\mathrm{H}_{2} \mathrm{O}$ upscattering is introduced into the $\mathrm{UO}_{2}$ lattice calculations. For the lattices containing plutonium, the effect is significant ranging up to $0.7 \% \Delta k / k$. The change in $k_{\text {eff }}$ is due primarily to the increased absorption rate in the ${ }^{240} \mathrm{Pu} 1.056 \mathrm{eV}$ resonance. The effect is largest for the tightest lattices. It also increases 
as the ${ }^{240} \mathrm{Pu}$ content in the plutonium increases. The base calculations reported in this paper utilized the approximation for $\mathrm{H}_{2} \mathrm{O}$ upscattering in HRG3. No estimate on the accuracy of this approximation has been made. The results shown in Table 27 give an indication of the significance of $\mathrm{H}_{2} \mathrm{O}$ upscattering in the various lattices.

TABLE 27. Reactivity Effect of Using Water Upscattering in HRG3

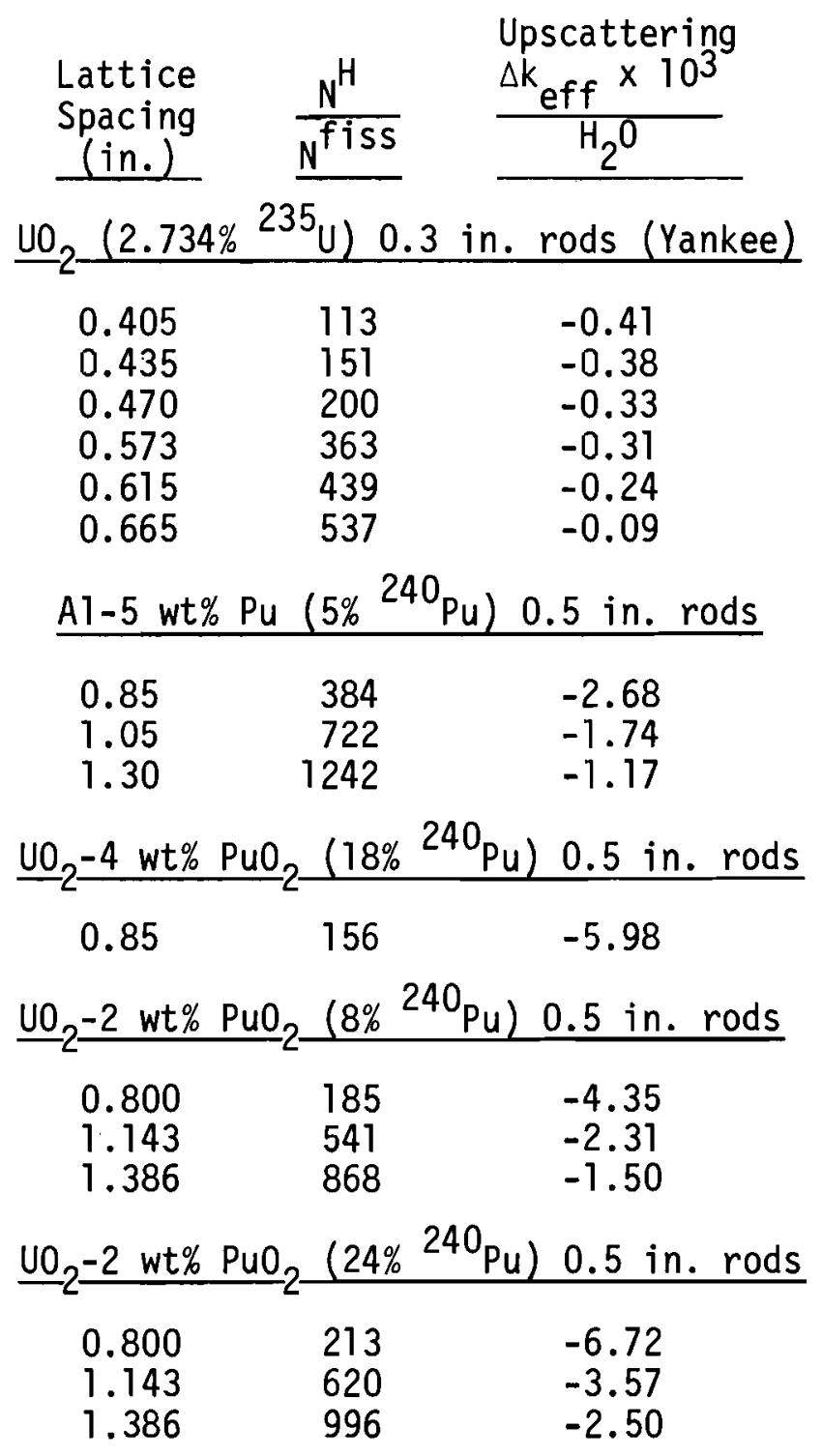


Neill and Prezbindowski ${ }^{(80)}$ made a study of the effects of different group structures and $\mathrm{H}_{2} \mathrm{O}$ scattering kernels for the $\mathrm{Al}-5$ wt\% Pu fueled 1.30 in. lattice. The results of their study showed that the calculated value of $k_{\text {eff }}$ was insensitive $( \pm 0.1 \% \Delta k / k)$ to scattering models (Haywood-II, McMurray-Russell and Nelkin) or to including more groups than 30 below $0.683 \mathrm{eV}$. The study does show that a change in $k_{\text {eff }}$ of somewhere in the neighborhood of +0.3 to $+0.7 \% \Delta \mathrm{k} / \mathrm{k}$ occurs when the thermal cutoff is increased from 0.683 to $3.059 \mathrm{eV}$. In Table 27 we show that the upscattering correction incorporated in the HRG3 code leads to a reduction in $k_{\text {eff }}$ of $0.117 \%$. Thus, the results of Neill's and Prezbindowski's study show an opposite effect from our results.

Anisotropy. We also approximate the effects of anisotropy in the thermalization calculation by altering the scattering kernels. Previous studies $(81)$ have shown that the approximation of substituting the transport cross section for the total cross section is a significant effect for certain lattices. The question remains: is the approximate correction an accurate method to account for the effect of anisotropy in the scattering? Lacking more definitive evidence, we simply state that the results of our analysis are correct in this regard by assuming the anisotropy effect has been accounted for in our calculations.

\section{LEAKAGE CALCULATIONS}

This area of the analysis is perhaps most susceptible to error because of the relatively high leakage components of the assembly multiplication value. Some of the effects of various approximations made in this area are studied to determine if systematic errors are introduced in the analysis.

1. Separability of Flux in Axial and Radial Components

We assumed that the radial and axial components of the flux in the critical assembly are separable. Moreover, we assumed that axial leakage can be adequately described by an axial buckling representation in HFN. To test this approximation a two-dimensional diffusion theory solution was obtained using the EXTERMINATOR-2 code ${ }^{(82)}$ and the results compared to the 
one-dimensional HFN solution with axial buckling. The problem selected was the 1.05 in. lattice containing A1-5 wt\% Pu fuel because this lattice has the largest axial leakage. To make certain that the evaluation was actually physical and not numerical, comparisons were made between the results from the HFN code and corresponding solutions using the EXTERMINATOR-2 code in one dimension. The results are shown in Table 28.

TABLE 28. One and Two Dimensional Diffusion Theory Solutions for the 1.05 in. Al-5 wt\% Pu Fueled Lattice

\begin{tabular}{|c|c|c|c|c|}
\hline & & $\# M_{\epsilon}$ & 1 Points & \\
\hline Code & \# Dimensions & Core & Reflector & keff \\
\hline HFN & 1 & 30 & 30 & 1.02725 \\
\hline HFN & 1 & 50 & 50 & 1.02721 \\
\hline HFN & 1 & 70 & 70 & 1.02721 \\
\hline Exterminator-2 & 1 & 30 & 30 & 1.02696 \\
\hline Exterminator-2 & 1 & 50 & 50 & 1.02692 \\
\hline Exterminator-2 & 1 & 15 & 15 & 1.02350 \\
\hline Exterminator-2 & 2 & $15 R$ & ial 15 & \\
\hline & & 25 & ial 10 & 1.02025 \\
\hline
\end{tabular}

We first note that the two codes produce nearly identical results when mesh points are changed from $30 / 30$ to $50 / 50$ in core/reflector, with the absolute difference in $k_{\text {eff }}$ between codes being $0.029 \% \Delta k_{\text {eff }}$. Due to limitations in spatial representation of the core, the two-dimensional calculation was made using 15 points in both core and reflector in the radial direction, with 25 points in the core and 10 in the reflector axially. The results are compared to the corresponding one-dimensional radial solution with axial buckling to evaluate the combined effect of flux separability and use of axial buckling, since they cannot be separated in this problem. The difference in $k_{\text {eff }}$ values is seen to be $0.00325 \Delta k_{\text {eff }}$. Thus, a 
one-dimensional diffusion theory solution using axial buckling can result in errors of $0.2 \% \Delta k_{e f f} / k_{e f f}$, since this lattice should represent the extreme case.

The results in Table 28 also show that the use of 50 points in the core and reflector regions, respectively, is an adequate representation since the value of $k_{\text {eff }}$ does not change upon adding 20 points to each region.

2. Axial Leakage Representation

The representation of the axial leakage in our calculations is uncertain because of the buckling representation and the possibility of neutrons streaming in the fuel rods. The results of the investigations presented in the subsection above show that the uncertainty stemming from the use of a $\mathrm{DB}^{2}$ representation of axial leakage is about $\leq 0.2 \% \Delta \mathrm{K} / \mathrm{k}$.

We have represented axial leakage as that emerging from the top and bottom of a cylindrical homogeneous core which is fully reflected with $\mathrm{H}_{2} \mathrm{O}$. This representation does not account for the possibility of neutrons leaking from the assembly via streaming in the fuel and moderator channels in the lattices. For the systems we have studied, the largest probability for calculational errors from this source occurs in the case of the A1-Pu fueled lattices because the fuel rods are mainly aluminum. We have not made an analysis of the existence or the magnitude of this effect. However, other investigations have studied this phenomenon both experimentally and analytically. $(83,84)$ Based upon their findings, we state that this effect is real and unaccounted for in our analysis. We arbitrarily assign an error in our analysis of the Al-Pu fueled systems of $0.5 \% \Delta k / k$. The sign of the correction for this effect is negative because we would underestimate the fast neutron leakage from the core with our homogeneous model which would lead to overpredicting $k_{\text {eff }}$. We likewise arbitrarily assume an error of $-0.25 \% \Delta \mathrm{k} / \mathrm{k}$ for the $\mathrm{UO}_{2}$ and $\mathrm{UO}_{2}-\mathrm{PuO}_{2}$ fueled lattices. We use a smaller error because these fuel rods are longer than the A1-Pu rods and less susceptible to streaming. 


\section{Number of Energy Groups}

Our analysis also assumed that four groups of neutrons were sufficient in describing the neutron leakage from the assemblies. To test the validity of the assumption, we performed some calculations using 18 groups of neutrons in the HFN code. The groups were selected such that extra energy detail was provided in the region above $11.7 \mathrm{keV}$, the one fast group in the four-group analysis. The problems selected for the evaluation were the two highest leakage systems; the 1.05 in. Al-5 wt\% Pu fueled lattice and a plutonium nitrate critical. The results are shown in Table 29.

TABLE 29. Effect on Calculated keff of Increasing the Number of Energy Groups

$\begin{array}{lcc}\begin{array}{l}\text { Al-5 wt\% Pu }-1.05 \text { in. Lattice } \\ \text { Case \# }\end{array} \frac{\text { Number of Groups }}{2} \frac{\text { Calculated k eff }}{1} & 2\left(\mathrm{Bg}^{2}\right) & 1.0466 \\ 2 & 2 & 1.0282 \\ 3 & 4 & 1.0234 \\ 4 & 18 & 1.0284\end{array}$

Pu Nitrate Systems

$\begin{array}{rrr}5 & 4 \text { (Bare) } & 1.01332 \\ 6 & 18 \text { (Bare) } & 1.01401 \\ 7 & 4 \text { (Reflected) } & 1.01918 \\ 8 & 18 \text { (Reflected) } & 1.01936\end{array}$

For interest, we also show two-group results for the A1-5 wt\% lattice. Case 1 is using the measured value of the buckling in Equation 1 and Case 2 is a two-group HFN solution with axial buckling where the range from 0.683 to $10^{7} \mathrm{eV}$ is described by a single group. We note results similar to those shown in Table 17, whereby the buckling representation of total leakage consistently underpredicts the leakage and therefore overpredicts $k_{\text {eff }}$. 
The effect of increasing the number of groups from 4 to 18 is to increase the calculated value of $k_{\text {eff }}$. The magnitude of the effect is $0.5 \%$ for the A1-5 wt\% Pu fueled lattice as shown by the differences between Cases 3 and 4 , and less than $0.1 \%$ for the plutonium nitrate criticals for both the bare and reflected systems. Thus, we conclude the maximum error incurred in our four-group model using diffusion theory is $0.5 \%$ in $k_{\text {eff }}$. 4. Two Region Model of the Assembly

A11 of the analyses have been made using a two region radial model of the assembly, namely, a homogeneous core and a reflector. In reality, there is a spectral shift which occurs as the boundary between core and reflector is approached. A calculation was made to assess the sensitivity of the calculated value of $k_{\text {eff }}$ when some accounting for the shift is accommodated in the model. This was accomplished by using two discrete reflector regions: a one-unit-lattice thick region near the core and a region outside of this region which represented the balance of the reflector. The cross sections for hydrogen and oxygen in the interim reflector region were taken directly from the HRG3 and BRT-I cell calculations. The nonthermal constants were cell average values and the thermal constants were averages over the moderator portion of the three region unit cel1. The calculation was made for the $\mathrm{UO}_{2}-2 \mathrm{wt} \% \mathrm{PuO}_{2}\left(8 \%{ }^{240} \mathrm{Pu}\right.$ ) lattice with a $0.85 \mathrm{in}$. lattice spacing. The calculated $k_{\text {eff }}$ increased from 0.9954 for the two-region reactor to 1.0062 for the throe-region reactor. We conclude from this that if we were to change from a two-region model to a more detailed description we could expect changes in calculated values of $k_{\text {eff }}$ at least as large as 1\%. The three-region calculational method gives much better agreement between measured and calculated radial power density distributions. (85) In the study reported in Reference 38 , the value of $k_{\text {eff }}$ obtained for a $\mathrm{UO}_{2}-\mathrm{PuO}_{2}$ lattice (0.75 in. square), using the three-region reactor model was $21 \%$ greater than that obtained using a two-region model. For a $\mathrm{UO}_{2}$ lattice the three-region model yielded a $k_{\text {eff }} \sim 0.5 \%$ greater than that given by the two-region model. 
BNWL -1656

5. Transport Theory Solution

Diffusion theory solutions of neutron leakage from typically high leakage assemblies may be introducing errors in the analysis. To determine if this is so, some calculations were repeated using a transport theory code. Based upon the studies presented above, a one-dimensional solution appears to be adequate and therefore the $1 \mathrm{D}$ transport code ${ }^{(87)}$ DTF-IV was used for these studies. The code is briefly described in Appendix A. The same problems run in the sensitivity to energy groups, Table 29, were run using the DTF-IV code, since these represent the highest leakage systems. The calculations were made using both the 4-group and 18-group structures. The results of these calculations are shown in Table 30 along with the diffusion theory results.

TABLE 30. Comparison of Diffusion and Transport Theory Solutions

\begin{tabular}{|c|c|c|c|}
\hline Solution & $\begin{array}{c}\text { Number of } \\
\text { Energy Groups } \\
\end{array}$ & \multicolumn{2}{|c|}{ Calculated $k_{\text {eff }}$} \\
\hline \multicolumn{4}{|c|}{ Al-5wt\% Pu -1.05 in. lattice } \\
\hline $\begin{array}{l}\text { Diffusion } \\
\text { Diffusion }\end{array}$ & $\begin{array}{r}4 \\
18\end{array}$ & \multicolumn{2}{|c|}{$\begin{array}{l}1.0234 \\
1.0284\end{array}$} \\
\hline $\begin{array}{l}\text { Transport (S4) } \\
\text { Transport (S4) }\end{array}$ & $\begin{array}{r}4 \\
18\end{array}$ & \multicolumn{2}{|c|}{$\begin{array}{l}1.0960 \\
1.0322\end{array}$} \\
\hline \multicolumn{2}{|c|}{ Plutonium Nitrate Criticals } & Bare System & Reflected System \\
\hline $\begin{array}{l}\text { Diffusion } \\
\text { Diffusion }\end{array}$ & $\begin{array}{r}4 \\
18\end{array}$ & $\begin{array}{l}1.0133 \\
1.0140\end{array}$ & $\begin{array}{l}1.0192 \\
1.0194\end{array}$ \\
\hline $\begin{array}{l}\text { Transport (S4) } \\
\text { Transport (S4) }\end{array}$ & $\begin{array}{r}4 \\
18\end{array}$ & $\begin{array}{l}1.0839 \\
1.0211\end{array}$ & $\begin{array}{l}1.1059 \\
1.0373\end{array}$ \\
\hline
\end{tabular}

The comparison shows substantial differences between values of $k_{\text {eff }}$ calculated using diffusion and transport theory, particularly for the fourgroup comparisons. Increasing the number of groups in diffusion theory does not have near the effect on calculated $k_{\text {eff }}$ as it does in transport 
theory. The differences in $k_{\text {eff }}$ values for the 18-group comparisons of diffusion theory with transport theory range from approximately $0.5 \%$ for the A1-5 wt\% Pu cases to slightly more than $2 \%$ for the reflected nitrate system. Dwivedi ${ }^{(87)}$ has made an analysis to determine the dependence of calculated $k_{\text {eff }}$ on energy and angular detail for the two nitrate systems shown in Table 30. He concludes that 10 energy groups and an S-8 order approximation is sufficiently accurate for DTF-IV calculations. The effect of going from S-4 to S-8 would be to decrease slightly (approximately $0.2 \% \Delta \mathrm{k} / \mathrm{k}$ ) the calculated values presented in Table 30 .

As stated previously Richey ${ }^{(48)}$ made an extensive analysis of plutonium homogeneous critical experiments. His results were all based upon an 18-group model and they showed similar trends when going from diffusion theory to transport theory solutions. The trends observed when transport theory is used rather than diffusion theory for the leakage calculations are confirmed in a study performed by Neill and Prezbindowski. ${ }^{(80)}$ They observed differences of $3.4 \%$ in the calculated value of $k_{\text {eff }}$ for the Al-5 wt\% Pu - 1.30 in. lattice. These results cast suspicion on the validity of the use of diffusion theory to calculate neutron leakage from these assemblies.

Multitable Definitions. The transport theory calculations reported above were made a few years ago with older versions of HRG. Transport theory calculations were recently performed with DTF-IV for the $0.80 \mathrm{in}$. lattice of $\mathrm{UO}_{2}-2$ wt $\% \mathrm{PuO}_{2}\left(8 \%{ }^{240} \mathrm{Pu}\right)$ using BNWML data. Values of $\mathrm{k}_{\text {eff }}$ with 4 and 10 energy groups using various definitions of multitable cross sections for transport codes from HRG3 are presented in Table 31. Conditions for the calculations are summarized at the bottom of Table 31. The water cross sections correspond to the values used for the calculations in the last part of Table 22. The group structure for 4 energy groups is the same as the structure used in the HFN calculations. The 10-group structure (Table 32 ) is the same as was used in previous calculations, ${ }^{(87)}$ and found to be detailed enough at that time. When WOIN $=1.0$ in HRG3, only one table of cross sections is punched and an isotropic calculation is done in DTF-IV. When WOIN $=2.0$ or 4.0 , two tables of cross sections are punched for each material. The latter set $($ WOIN $=4.0)$ represents the extended transport 
TABLE 31. Transport Theory (DTF-IV) Results for 0.80 in. Lattice of $\mathrm{UO}_{2}-2 \mathrm{wt} \% \mathrm{PuO}_{2}(8 \% 240 \mathrm{Pu})$

\begin{tabular}{lccccc}
\multicolumn{1}{c}{ Description* } & & WOIN & $\begin{array}{c}\text { Number of } \\
\text { Groups }\end{array}$ & & $k_{\text {eff }}$ \\
\cline { 1 - 1 } Isotropic & & & 4 & & 1.0015 \\
Normal Transport & 2 & & 4 & 0.9969 \\
Extended Transport & 4 & & 4 & 1.0021 \\
Isotropic & & 1 & 10 & 1.0033 \\
Normal Transport & 2 & & 10 & 1.0056 \\
Extended Transport & 4 & & 10 & & 1.0067
\end{tabular}

*BNWML Cross-Section Data

$k$ (Buckling) $=0.09322$ in HRG3

WCTP $=4.0$ in HRG3

$\varepsilon=10^{-4}$ in DTF-IV

$\mathrm{S}_{4}$ Quadrature Set

New Water in the Reflector (See Table 22.)

50 Space Points in Fuel +50 Space Points in Reflector

TABLE 32. Energy Boundaries for 10-Group Structure

\begin{tabular}{|c|c|}
\hline Group \# & Lower Energy, el \\
\hline 1 & $4.72 \times 10^{6}$ \\
\hline 2 & $2.87 \times 10^{6}$ \\
\hline 3 & $1.74 \times 10^{6}$ \\
\hline 4 & $1.35 \times 10^{6}$ \\
\hline 5 & $4.98 \times 10^{5}$ \\
\hline 6 & $1.83 \times 10^{5}$ \\
\hline 7 & $1.17 \times 10^{4}$ \\
\hline 8 & 2.38 \\
\hline 9 & 0.683 \\
\hline 10 & 0.0 \\
\hline
\end{tabular}


approximation which contains second moment weighted cross sections. The cross sections for WOIN $=2.0$ are basically the same as cross sections punched with older versions of HRG. The main difference is in the definition of the self-scatter entry in the first table. The 4-group values of $k_{\text {eff }}$ with DTF-IV are all higher than the HFN values (ranging from $0.5 \%$ to $1.5 \%)$. Of the three 4-group values of $k_{\text {eff }}$, the extended transport calculation in DTF-IV is most sophisticated. This value is $1 \%$ larger than obtained with HFN.

In going from 4 groups to 10 groups in DTF-IV, the calculated values of $k_{\text {eff }}$ increase for all values of WOIN. The normal and extended transport calculations give values of $\mathrm{k}_{\text {eff }}$ within $1 \mathrm{mk}$ of each other. The isotropic calculation is only 2 to $3 \mathrm{mk}$ lower. The sensitivity of $k_{\text {eff }}$ to group structure is much less pronounced than noted in the calculations presented above. (87)

From all of the analyses of leakage presented in this report, it seems reasonable to assume that the 10-group DTF-IV calculations with HRG3 punched cards for the extended multitable definition is an accurate calculation of the leakage from lattices of small critical systems such as these.

\section{SUMMARY OF THE ERRORS AND/OR UNCERTAINTIES IN THE ANALYSIS}

We have attempted to identify the sources of error in our theoretical analysis of these critical assemblies. Many potential sources of error have been shown to exist and estimates were made as to the magnitude of the associated errors. For some sources such as manufacturing tolerances it is perhaps more accurate to state the effects as uncertainties rather than errors because the variations are controlled and therefore are not expected to act in the same direction. Therefore we have not associated any uncertainty to our calculated values of $k_{\text {eff }}$ which is ascribable to such sources.

We view it reasonable to assume that there are two major sources of error in our analysis and we attempt to correct for these in the following sections. The first is that particle self shielding cannot be neglected 
for mixed oxide fuels. Second, a diffusion theory calculation overpredicts the leakage as compared to a transport theory solution. Another source which could be debated as to error or uncertainty is the use of BNWML cross sections in 1 ieu of ENDF/B-II cross sections. We choose to treat this as an error simply because ENDF/B-II represents newer experimental data and evaluations than the BNWML data.

It is obvious that we cannot provide an estimate of the uncertainty in the calculated value of $k_{\text {eff }}$ for each individual lattice studied because we have not made a detailed analysis of all the individual effects for each lattice. Taking the simplest approach we try to estimate the overall uncertainty in our calculation of $k_{\text {eff }}$ for each of the major fuel types studied (namely plutonium only, uranium only and mixed oxide) by making extrapolations from the limited amount of data that we do have.

Errors in Our Analysis. As mentioned, it is difficult to predict precisely the values of $k_{\text {eff }}$ if we had used ENDF/B-II cross sections, and a 10-group transport theory solution of neutron leakage from each assembly. Nevertheless, we estimate how the mean values presented in Table 9 would change were these errors not incurred, and these are given in Table 33. Included is a gross correction value for particle self shielding as presented in Table 11 . The corrected calculated values of $k_{\text {eff }}$ all become more discrepant with experiment except for the $U$ nitrate systems. The plutonium only systems have high values of $\mathrm{k}_{\text {eff }}$, and the $\mathrm{UO}_{2}$ and mixed oxide systems have low values of $k_{\text {eff }}$. As noted in Table 33 , we expect a significant trend in $k_{\text {eff }}$ with lattice pitch for these latter two systems.

Uncertainties in Our Analysis. Some of the sources of uncertainty discussed in the previous subsection are present in the analysis for these systems. We list the estimate of the magnitude of uncertainties in Table 34 for certain areas of our calculation. We neglected including certain hardware, such as lattice templates, in our calculations. We estimate this results in an uncertainty of around 0.1 to $0.3 \% \Delta \mathrm{k} / \mathrm{k}$. The slowing-down calculation is an important source of uncertainty, particularly for the systems containing large amounts of ${ }^{238} \mathrm{U}$. We assign a slightly higher uncertainty for the mixed oxide lattices compared to $\mathrm{UO}_{2}$ lattices because of resonance 
TABLE 33. Estimated Corrections to the Analys is to Account for Errors

\begin{tabular}{|c|c|c|c|c|c|}
\hline \multirow[b]{2}{*}{ System } & \multirow{2}{*}{$\begin{array}{c}\text { Mean Value } \\
\text { of } k_{\text {eff }}(\text { Table 9) }\end{array}$} & \multicolumn{3}{|c|}{ Gross Corrections $(\Delta k / k, \%)$} & \multirow{2}{*}{$\begin{array}{c}\text { Corrected } \\
\mathrm{k}_{\text {eff }} \\
\end{array}$} \\
\hline & & Leakage & $\begin{array}{c}\text { Particle } \\
\text { Self Shielding }\end{array}$ & ENDF/B-II & \\
\hline $\mathrm{Al}-\mathrm{Pu}$ & 1.007 & +1.5 & 0.0 & +0.4 & 21.03 \\
\hline Pu Nitrate & 1.013 & +1.5 & 0.0 & +0.4 & 21.03 \\
\hline $\mathrm{UO}_{2}$ & 1.000 & +0.8 & 0.0 & $-1.8^{*}$ & $20.99 *$ \\
\hline U Nitrate & 0.995 & +0.5 & 0.0 & -0.2 & 21.00 \\
\hline $\mathrm{UO}_{2}-\mathrm{PuO}_{2}$ & 0.995 & +1.0 & -0.3 & $-1.5^{\star}$ & 20.99* \\
\hline
\end{tabular}

* It is estimated that these lattices would have a significant discrepancy in keff as a function of lattice pitch with the largest discrepancy appearing for the tightest lattices (as illustrated in Table 14).

TABLE 34. Estimated Uncertainties in Our Analyses

\begin{tabular}{|c|c|c|c|c|c|}
\hline & \multicolumn{5}{|c|}{ Magnitude of Uncertainty, $(\Delta k / k, \%)$} \\
\hline Area & $\overline{\mathrm{A} 1-\mathrm{Pu}}$ & Pu Nitrate & $\underline{\mathrm{U}} \mathrm{Z}$ & U Nitrate & $\mathrm{UO}_{2}-\mathrm{PuO}$ \\
\hline Lattice Hardware, etc. & \pm 0.3 & \pm 0.2 & \pm 0.3 & \pm 0.1 & \pm 0.3 \\
\hline Slowing-Down Calculation & \pm 0.5 & \pm 0.5 & \pm 0.8 & \pm 0.2 & \pm 1.0 \\
\hline Thermalization Calculation & \pm 0.8 & \pm 0.5 & \pm 0.5 & \pm 0.3 & \pm 0.8 \\
\hline Basic Cross Sections & \pm 0.6 & \pm 0.6 & \pm 0.8 & \pm 0.4 & \pm 1.0 \\
\hline Standard Deviation $\simeq$ & \pm 1.2 & \pm 0.95 & \pm 7.3 & $\pm 0.55 /$ & \pm 1.7 \\
\hline
\end{tabular}


overlap effects. The thermalization calculation represents an area of uncertainty which has many individual sources. These are energy detail (number of groups and what region should represent thermalization), boundary description and anisotropy. We assign an uncertainty ranging from 0.3 to $0.8 \%$ to the collection of these depending on the system. Finally, the degree of uncertainty in the experimental knowledge of basic cross sections is still a significant source of uncertainty, as shown in Table 34 . We assign values ranging from 0.4 to $1.0 \%$ depending on the particular system. Combining these uncertainties statistically, we obtain the standard deviations shown in Table 34. The values are larger for the lattices than for the homogeneous systems, as would be expected.

The following qualitative judgments can be made by comparing the corrected values of $\mathrm{k}_{\text {eff }}$ in Table 33 with the standard deviations in Table 34:

1. For the $\mathrm{Al}-\mathrm{Pu}$ and $\mathrm{Pu}$ nitrate systems, if the uncertainties all acted in the same direction (i.e., be of same sign) they would not account for the magnitude of the discrepancies in calculated $k_{\text {eff }}$ 's.

2. For the $\mathrm{UO}_{2}$ and $\mathrm{UO}_{2}-\mathrm{PuO}_{2}$ systems, the uncertainties would a 11 have to have the same sign to come close to accounting for the magnitude of the discrepancies. It is doubtful that they could account for it entirely at tight lattices. 


\section{SUMMARY OF OTHER CORRELATIONS}

An important consideration when choosing a calculational scheme for design purposes is that its range of applicability covers all conditions which the design must meet. Therefore it is important to know the limits within which the particular calculational scheme can be reliably applied. We have already addressed ourselves to this problem with regard to the parameter $k_{\text {eff }}$ in terms of the range of enrichments, the range of bucklings, and the range of hydrogen-to-plutonium ratios.

When evaluating the range of validity of a calculational scheme one should also apply the scheme to other parameters which can be obtained from various experiments. This is recommended because it is possible that a fortuitous cancellation of errors results in good theory-experiment agreement for one particular parameter and not for another. In this section we address ourselves to this problem by considering additional information that is available from several other studies.

\section{A. CORRELATIONS OF $k_{\infty}$}

Measurements and calculations of $k_{\infty}$ have been made by Newman and Gordon. (50) These experiments have the advantage of eliminating leakage and core-reflector spectrum problems associated with small critical experiments.

The calculated value of $\mathrm{k}_{\infty}$ for a $\mathrm{UO}_{2}-2 \mathrm{wt} \% \mathrm{PuO}_{2}$ water lattice is about $3 \%$ high. It was also found in their study that the thermal disadvantage factor in mixed oxide, 1ight-water moderated lattices is consistently overestimated by about $14 \%$ using the BRT-I code. This overestimation of the thermal disadvantage factor has the effect of underestimating the thermal utilization by $2 \%$ to $6 \%$.

The discrepancy between the calculated and measured thermal utilization increases with boron concentration in the water moderator. There is evidence that the flux depression around the $0.3 \mathrm{eV}$ resonance of ${ }^{239} \mathrm{Pu}$ is overestimated in the thermalization calculation. The fission ratio 
of ${ }^{235} \mathrm{U}$ to ${ }^{239} \mathrm{Pu}$ and the spectrum average value of eta, $\bar{\eta}$, for ${ }^{239} \mathrm{Pu}$ are both overestimated in the calculation. Calculational errors in $\bar{\eta}$ and $f$ tend to cancel for lattices poisoned with boron in the water to $k_{\infty}$ of unity. Calculational errors in $\bar{n}$ and $f$ for unpoisoned lattices only partially compensate.

The conclusion was reached that there appears to be a basic discrepancy in the space and energy-dependent thermal neutron spectrum as calculated using the BRT-1 code. Nevertheless, the calculational scheme yields "better" agreement in $k_{\text {eff }}$ than $3 \%$ for the high leakage systems. This correlation of $k_{\infty}$ values makes any agreement between measured and calculated $k_{\text {eff }}$ values for the clean critical lattices appear dubious.

B. CORRELATIONS OF $\rho^{28}$ and $\delta^{28}$

A study has been made at Pacific Northwest Laboratory to evaluate theory-experiment correlations of $\rho^{28^{*}}$ and $\delta^{28 * \star}$ for 26 lattices of $\mathrm{UO}_{2}$ rods in light-water moderator. ${ }^{(88)}$ In mixed oxide rods there is a large amount of ${ }^{238} \mathrm{U}$ present and neutron capture and fission rates in ${ }^{238} \mathrm{U}$ strongly influence the physics characteristics in these lattices. Thermal neutron capture in ${ }^{238} U$ typically represents 5 to $15 \%$ of the total thermal neutron captures in power reactors. However, the resonance neutron capture rate in ${ }^{238} \mathrm{U}$ represents most of the nonthermal neutron captures in these lattices and is typically one to four times the thermal capture rate in ${ }^{238} U$. An accurate knowledge of the capture rate in ${ }^{238} U$ is also important for predicting fuel economy since the obtainable fuel burnup is sensitive to the initial conversion ratio which is defined as the number of neutrons captured in ${ }^{238} \mathrm{U}$ per neutron absorbed in ${ }^{235} \mathrm{U}$.

Detailed fine structure measurements within the fuel have not been made in the plutonium enriched systems. One reason for this omission has been the toxic nature of plutonium which dictates handling precautions that increase the cost of such measurements by factors of five to ten and which

$* \mathrm{P}^{28}=1 / \mathrm{CdR}-1$ where $\mathrm{CdR}$ is the ${ }^{238} \mathrm{U}$ cadmium ratio in the fuel rod. $\star \star \delta^{28}=$ Total fission rate in ${ }^{238} U /$ Total fission rate in ${ }^{235} U$. 
require additional confining materials that in some cases increase the experimental level of uncertainty. Other reasons have been the very sma 11 supply and the high cost of highly purified plutonium isotopes for use in studies of individual reaction rates. However, when it comes to testing the adequacy of calculational methods in predicting ${ }^{238} U$ reaction rates, we can rely upon the information that has been gathered along these lines for $\mathrm{UO}_{2}$ lattices. We can use this information because there is essentially the same amount of ${ }^{238} \mathrm{U}$ in mixed oxide lattices as in slightly enriched $\mathrm{UO}_{2}$ lattices.

A group of 26 lattice experiments from four different laboratories, covering a wide range of $235 U$ enrichments, fuel rod diameters and lattice pitches were chosen for this study. The results of this theory-experiment correlation of $\rho^{28}$ and $\delta^{28}$ for 26 lattices of $\mathrm{UO}_{2}$ rods indicate 1 arge discrepancies between theory and experiment. Calculations in general yield values of $\rho^{28}$ higher than measured values, and values of $\delta^{28}$ lower than measured values. The net effect of overestimating $\rho^{28}$ and underestimating $\delta^{28}$ should result in a consistent underestimate of $k_{\infty}$ and $k_{\text {eff }}$ in the absence of other errors. For a typical light-water reactor, one would expect the error in calculated $k_{\text {eff }}$ values to be of the order of $1 \%$ due to the incorrect calculations of $\rho^{28}$ and $\delta 28$.

The incorrect calculation of $\rho^{28}$ would also be expected to have an effect on calculations of burnup. If one consistently overestimates $\rho^{28}$, which is the ratio of the epi-cadmium capture in ${ }^{238} U$ to the sub-cadmium capture rate in ${ }^{238} \mathrm{U}$, one should not expect to be able to calculate the burnup accurately using these same calculational methods. Thus, this study brings to light several additional inconsistencies in the calculational methods. These particular inconsistencies apply to the calculation of mixed oxide lattices as well as to $\mathrm{UO}_{2}$ lattices. 
A search was made to determine if there is any systematic variation in the discrepancy between calculated and measured temperature coefficients as a function of the buckling or of some calculated cell parameter. The only parameters for which there seems to be any systematic variation of the discrepancy are the thermal group parameters; the cell average values of thermal $\Sigma_{a}$ and $\nu \Sigma_{f}$. Thus, there seems to be some evidence that the discrepancies observed between calculated and measured temperature coefficients are related to the thermalization calculation. This tends to support the conclusion reached in the $k_{\infty}$ study that there appears to be some basic discrepancy in the space and energy dependent thermal neutron spectrum as calculated using the THERMOS method. 
BNWL-1656

\section{CONCLUSIONS AND RECOMMENDATIONS}

The results of the analysis presented in this report have demonstrated the importance of detail. Given only the summary of results presented in Table 9, it could be concluded that the cross sections, theoretical methods and analysis procedures are adequate and that sound technical bases and design criteria could be established using these results. However, keff is an integral parameter which is made up of many components. Subsequent study of the underlying uncertainties in calculating these components uncovers many potential sources of error. We have attempted to identify what we think are the major errors/uncertainties and have provided an estimate of the magnitude of these in our calculations. Our estimates of the best calculated values of $k_{\text {eff }}$ (i.e., the corrected values in Table 33) show:

- For Al-Pu lattices, the calculated values are $\sim 3 \% 1$ arger than measured values.

- For $\mathrm{UO}_{2}$ and $\mathrm{UO}_{2}-\mathrm{PuO}_{2}$ lattices the calculated values are smaller than measured values ( $1 \%$ or more).

We combined the uncertainties in a gross manner to assign a standard deviation to the calculation of $k_{\text {eff }}$ for the lattices considered. The values arrived at were $\pm 1.2, \pm 1.3$ and $\pm 1.7 \% \Delta k / k$ for the $A 1-\mathrm{Pu}, \mathrm{UO}_{2}$ and $\mathrm{UO}_{2}-\mathrm{PuO}_{2}$ fueled lattices respectively (Table 34 ). The standard deviation quoted for the Al-Pu lattices of $\pm 1.2 \% \Delta \mathrm{k} / \mathrm{k}$ is $\sim 2 \%$ smaller than the discrepancy noted $(23 \%)$. We used the uncertainty in cross sections quoted by the evaluators ${ }^{(61)}$ which perhaps is an underestimate. Concerning the magnitude of the efforts expended in attempting to improve the basic reactor physics technology, the size of the discrepancies is rather large. However, the analysis of so-called simple systems such as clean-uniform lattice criticals is not simple, but rather requires a complex analysis.

According to our analysis, the calculation of the neutron leakage is of prime importance in correlating these lattices. The use of sophisticated theoretical methods (transport theory) yields systematically larger values of $k_{\text {eff }}$ than the less exact methods such as diffusion theory. 
We assume, a priori, that transport theory is exact and conclude that high leakage lattices, such as analyzed in this study, require the utilization of a one-dimensional transport theory code to calculate the leakage properly.

In summary, the results of the theory-experiment correlation of lattice criticals lead us to conclude that two principal areas of the unit cell calculations are in error. These are: (1) the calculation of resonance absorption events in systems containing ${ }^{238} \mathrm{U}$, and (2) the calculation of thermalization events in systems containing plutonium. The use of a more recent cross-section evaluation, ENDF/B-II, yields calculated values of $k_{\text {eff }}$ which deviate more significantly from measured values than when the BNWML values were used. The major effect comes from the different values for nonthermal $238_{U}$ data. The use of ENDF/B-II data results in significant discrepancies between calculated and measured values of $k_{\text {eff }}$ for $\mathrm{UO}_{2}$ and $\mathrm{UO}_{2}-\mathrm{PuO}_{2}$ fueled lattices. On the basis of the magnitude and sign of the discrepancies, we conclude that the calculation of ${ }^{238} \mathrm{U}$ resonance absorption is in error. The error could be due to the basic cross sections for ${ }^{238} \mathrm{U}$, the processing to multigroup values, or the theoretical description of resonance absorption, or perhaps a 11 of these. The utilization of better cross-section data or more sophisticated theories does not necessarily result in better agreement between calculation and measurement.

The error in the calculation of thermalization events could be in (1) the cross sections for ${ }^{239} \mathrm{Pu},(2)$ the scattering kernel for $\mathrm{H}_{2} \mathrm{O}$, (3) the theory in THERMOS, or (4) perhaps all of these. Regarding the ${ }^{239} \mathrm{Pu}$ cross sections, either the $2200 \mathrm{~m} / \mathrm{sec}$ value of $\mathrm{n}$ for ${ }^{239} \mathrm{Pu}$ is too large (current1y, 2.1085), ${ }^{(61)}$ or the shape of the ${ }^{239} \mathrm{Pu}$ cross sections in the thermal energy region is wrong, or both. The scattering kernel for $\mathrm{H}_{2} \mathrm{O}$ does not appear to be a sensitive parameter in calculating $\mathrm{k}_{\text {eff }}$. The calculated values of $k_{\text {eff }}$ are not much different ${ }^{(80)}$ when using the Nelkin mode? ${ }^{(76)}$ (as embodied in the GAKER code ${ }^{(5)}$ ) or the Haywood kernel (as embodied in the ENDF/B system and the FLANGE code ${ }^{(94)}$ ). The use of integral transport theory to calculate thermalization has, in our estimation, 
never been conclusively proven as being correct, and therefore could be the cause of the error. A rigorous comparison between multigroup integral and differential transport theory codes on a well defined thermalization problem backed up by a continuous (space, energy, angular) Monte Carlo solution would be very helpful to evaluating whether or not a problem exists in THERMOS.

Relating the results of correlations of other parameters, given in SectionVI, to the lattice critical correlations, supports the general conclusions drawn from the latter. The correlation of measured and calculated values of $\mathrm{k}_{\infty}$ for a $\mathrm{UO}_{2}-\mathrm{PuO}_{2}-\mathrm{H}_{2} \mathrm{O}$ unit cell shows discrepancies which are due primarily to the thermal utilization calculation. The correlations of experiments which test the accuracy of calculating resonance absorption in ${ }^{238} U$ ( $\rho^{28}$, and burnup of Yankee-Rowe fuel) support the conclusion of errors in the calculation of ${ }^{238} U$ resonance absorption events. The correlations of power distributions and temperature coefficients indicate that the problem of accurately calculating these parameters resides in the leakage calculation and the thermalization calculation.

The results of our analysis are disturbing when considering the needs of the reactor designer. Exact theoretical methods and analysis procedures demand substantial amounts of computer storage capacity and are usually very costly. Therefore, the designer must rely on the development of practical methods and utilize these methods knowledegably to make accurate economic predictions while simultaneously making conservative safety predictions. Critical experiments, such as we have analyzed, have historically been used as a basis for normalizing design methods to bring calculated and measured parameters into agreement. In most cases, either the theoretical methods and/or the basic cross sections are changed to bring about the agreement. Our analysis shows that a major problem is encountered in adequately calculating the leakage in critical experiments and therein lies a potential pitfall.

The relationship between the correlation of critical experiments and the design problem rests in the bundle design calculation. Being able to 
calculate criticals after adjustment of cross sections and/or unit cell theory gives the designer confidence in his ability to accurately predict bundle parameters such as $k_{\infty}$, local power distribution, control worth, etc. Since the bundle problem does not contain leakage, the solution eigenvalue of this problem is the infinite multiplication value, $k_{\infty}$, for the bundle. The lattice critical problem contains leakage and its solution eigenvalue is in the effective multiplication $k_{\text {eff }}$; where $k_{\text {eff }} \simeq k_{\infty} /$ leakage. As a result of the lattice critical correlations the design engineer might adjust the calculation of $k_{\infty}$ (through theory or cross sections in the unit cell calculation) to compensate for errors in the calculation of leakage to normalize $k_{\text {eff }}$. Therefore he has compromised on his ability to calculate the correct value of $k_{\infty}$ for the bundle and is falsely confi ent of his ability to predict bundle parameters accurately.

One of the many lessons we have learned in the course of these studies is that calculating a large number of experiments is not a necessary and sufficient condition to judging where errors lie in calculations. Rather, a few well-determined cases are much more valuable. Ideally, a critical experiment which includes measurement of: $k_{\text {eff }}$, axial and radial flux and power distributions, and fine structure parameters such thermal utilization, resonance absorption rate, etc., provides the data needed to evaluate all components of the calculation important in design analysis. We do however, realize the difficulties inherent in obtaining the ideal set of data. Nevertheless, the test of adequacy of design methods must include experiments which test the various parts of the calculation of $k_{\text {eff }}$.

We offer the following as fruitful areas for further investigation. First, there are those questions on the cross sections and methods used in cell spectra calculations which must be resolved prior to performing an extensive number of calculations of $k_{\text {eff }}$ for the critical assemblies. Secondly, the calculation of $k_{\text {eff }}$ means coming to grips with the problem of calculating the neutron leakage accurately. We briefly outline below the subsets of each of these areas which we feel would warrant further study. 
BNWL-1656

\section{A. CROSS SECTIONS}

The expected uncertainty in $k_{\text {eff }}$ due to experimental uncertainties in the cross sections is significant. For $\mathrm{UO}_{2}$ lattices this uncertainty in $k_{\text {eff }}$ ranges from about $\pm 1.5 \%$ for tight lattices to about $\pm 0.5 \%$ for 100 se lattices. For A1-Pu lattices the uncertainty in $k_{\text {eff }}$ is about $\pm 1 \%$. For the $\mathrm{UO}_{2}-\mathrm{PuO}_{2}$ lattices the uncertainty in $\mathrm{k}_{\text {eff }}$ ranges from about $\pm 2 \%$ for tight lattices to about $\pm 1 \%$ for loose lattices. Thus, if the theoretical methods and analytical procedures used in a calculation were "exact," these uncertainties are estimates of how accurately one can legitimately expect to be able to calculate $k_{\text {eff }}$.

The cross sections making the largest contribution to the uncertainty in $k_{\text {eff }}$ are the nonthermal data for ${ }^{238} \mathrm{U}$, and ${ }^{239} \mathrm{Pu}$. Since ${ }^{238} \mathrm{U}$ is present in such high concentrations, it would be desirable to know the background (floor) cross section data, as well as the resonance parameters, more precisely than they are known at present. Attention should be given to the processing of the ENDF/B file to produce the multigroup values required by slowing down codes to insure that this is being done correctly. The thermal cross sections for ${ }^{239} \mathrm{Pu}$ should be reevaluated (and perhaps remeasured) to determine if the small experimental errors quoted for the integral measurements are not biasing the evaluation.

\section{B. CELL METHODS}

Exact theoretical methods and analysis procedures generally are not used in reactor design because they would demand an excessive amount of computer storage capacity and running time. In practice, various assumptions and approximations are made to simplify the calculation of cel1average parameters, and this should be expected to result in a bias in the calculated results. When designing reactor cores, it is important to estimate the net bias that one would expect from the particular assumptions and approximations that he has made in his cell methods. However, the scope of this paper has not included an evaluation of the effect of every assumption and approximation on the calculated result for every lattice. 
BNWL-1656

Rather, the purpose of the studies presented in Section $V$ has been to illustrate the importance of various assumptions and approximations for a few selected lattices.

Some of the important assumptions which result in a bias in our results are neglecting resonance overlap effects, fast fission effects, streaming, the grain size of $\mathrm{PuO}_{2}$ particles, assuming a reflecting boundary condition in BRT-I, and a thermal energy group upper boundary of $0.683 \mathrm{eV}$ instead of an energy above the $1.056 \mathrm{eV}$ resonance of ${ }^{240} \mathrm{Pu}$. It may not be necessary for the reactor designer to include all of these items in his calculation; however, they all need to be evaluated so that the designer can apply a correction to his calculated results to account for the neglected items.

\section{LEAKAGE CALCULATION}

In our base analysis we used a one-dimensional, four energy group, diffusion theory calculation to predict the leakage. Increasing the number of energy groups to 18 has a smal1 effect $(20.5 \% \Delta k / k)$. A tworegion reactor model yields values of $k_{\text {eff }}$ which are somewhat lower than a three-region model. The use of transport theory in lieu of diffusion theory changes (increases) the calculated values of $k_{\text {eff }}$ significantly.

Historically, critical experiment correlations have been used to evaluate either cross sections or cell methods or both. The problem of calculating the leakage, although it has been pointed out as a problem area, has usually been ignored. That is, it has been assumed generally that the leakage can be predicted adequately by a zero or one dimensional diffusion theory calculation. It is our opinion that a detailed analysis must be made of the leakage from these small assemblies if one is to have confidence in the use of these lattices as benchmarks for testing design methods. On the basis of our analysis it appear that diffusion theory is definitely questionable as is the use of a two-region assembly model (a homogeneous core and a reflector). In the absence of proof, we 
conclude that a higher order calculation (perhaps even Monte Carlo) is necessary to assure a proper calculation of the leakage. We recommend that a study be conducted to prove conclusively, what theory(ies) and reactor model(s) are adequate to accurately calculate the leakage from critical assemblies $( \pm .2 \% \Delta k / k)$. 
BNWL-1656

\section{REFERENCES}

1. R. C. Liikala, "Updated R. B. U. Basic Library," HW-75716, Hanford Laboratories, May 1963.

2. R. C. Liikala, "R.B.U. Basic Library, Updating Methods \& Data," HW-83160, Hanford Laboratories, July 1964.

3. K. B. Stewart, "BNW Master Library," BNWL-CC-325, Pacific Northwest Laboratory, (September 1965, and subsequent revisions).

4. H. C. Honeck, "ENDF/B Specifications for an Evaluated Nuclear Data File for Reactor Applications," BNL-50066(T-467), Brookhaven National Laboratory, May 1966, Revised Ju1y 1967.

5. H. C. Honeck, "THERMOS, A Thermalization Transport Theory Code for Reactor Lattice Calculations," BNL-5826, Brookhaven National Laboratory, September 1961.

6. G. D. Joanou and J. S. Dudek, "GAM-1: A Consistent P1 Multigroup Code for the Evaluation of Fast Neutron Spectra and Multigroup Constants," GA-1850, June 28, 1961 and G. D. Joanou and J. S. Dudek, "GAM-II: A $\mathrm{B}_{3}$ Code for the Calculation of Fast Neutron Spectra and Associated Constants," GA-4265, (September 1963).

7. C. L. Bennett and W. L. Purce11, "BRT-1: Battelle-Revised-THERMOS," BNWL-1434, Pacific Northwest Laboratory, (1970).

8. J. L. Carter, "HRG3: A Code for Calculating the Slowing-Down Spectrum in the $P_{1}$ or $B_{1}$ Approximation," BNWL-1432, Pacific Northwest Laboratory, (1970).

9. J. R. Lilley, "Computer Code HFN-Multigroup, Multiregion Neutron Diffusion Theory in One Space Dimension," HW-71545, Hanford Laboratories, November 1961 .

10. V. I. Neeley et al., "Neutron Multiplication Measurement with Pu-A1 A110y Rods in Light Water," USAEC Report HW-70944, August 1961.

11. W. P. Stinson and L. C. Schmid, "Subcritical Measurements with 1.8 wt\% Pu-A1. Rods in Light Water," Physics Research Quarterly Report, July, August, September 1963, USAEC Report HW-79054, pp. 17-24, July 1962.

12. W. P. Stinson et a1., "Subcritical Measurements With 2.0 wt\% Pu-A1 Rods in Light Water," Physics Research Quarterly Report, July, August, September 1963, USAEC Report HW-79054, pp. 43-46, October 1963. 
BNWL-1656

13. P. F. Gast, "Reactor Physics of Plutonium," Report of a Panel on Light Water Lattices Held in Vienna May 25-June 1, 1962, International Atomic Energy Agency-Vienna 1962, and P. F. Gast, "Physics of Plutonium in Thermal Reactors," Proceedings of an ANS Topical Meeting on Plutonium As a Power Reactor Fuel, Richland, Washington, September 13 and 14, 1962, HW-75007, December 1962.

14. J. J. Regimbal, Trans. Am. Nucl. Soc. 5, 369 (1962).

15. P. G. Aline and R. J. McWhorter, Trans. Am. Nucl, Soc., 5, 369 (1962).

16. B. R. Leonard, Jr., "Survey of the Status of Low Energy Cross Sections of Fissile Nuclides," Neutron Physics, Proceedings of Symposium held at Rensselaer Polytechnic Institute, 1961, pp. 3-33, edited by M. L. Yeater, Academic Press, New York, New York, 1962, also HW-69342, Apri1 $22,1961$.

17. R. Sher and J. Felberbaum, "Least Squares Analysis of the $2200 \mathrm{~m} / \mathrm{sec}$ Parameters of U-233, U-235 and Pu-239," BNL-722, Brookhaven National Laboratory, 1962.

18. B. J. Toppel et a1., "Safety Analysis Associated with the Plutonium Recycle Experiment in EBWR," ANL-6841, Argonne National Laboratory, November 1964.

19. B. J. Toppel and R. Avery, "Some Physics Aspects of the Plutonium Experiment in EBWR," ANL-7019, Argonne National Laboratory, Apri1 1965.

20. R. C. Liikala et al., "The $\mathrm{PuO}_{2}-\mathrm{UO}_{2}$ Experiment in the EBWR," $\mathrm{BNWL}-126$, Pacific Northwest Laboratory, June 1965.

21. P. W. Davison et a1., "Yankee Critical Experiments - Measurements on Lattices of Stainless Steel Clad Slightly Enriched Uranium Dioxide Fuel Rods in Light Water," USAEC Report YAEC-94, Westinghouse Electric Corporation, Apri1 1959.

22. V. E. Grob et a1., "Results of Critical Experiments in Loose Lattices of $\mathrm{UO}_{2}$ Rods in $\mathrm{H}_{2} \mathrm{O}$," USAEC Report WCAP-1412, Westinghouse Electric Corporation, March 1960.

23. R. C. Liikala et al., "An Analysis of Uranium Fueled-Light Water Moderated Critical Experiments," Physics Research Quarterly Report, January-March, 1964, HW-81659, Apri1 1964.

24. J. R. Worden et a1., "An Analysis of Plutonium Light Water Critical Experiments," Physics Research Quarterly Report, January-March, 1964, HW-81639, Apri1 1964. 
25. L. C. Schmid et al., "Experiments with $\mathrm{PuO}_{2}-\mathrm{UO}_{2}$ Fuel Elements in Light Water," Physics Research Quarterly Report, January-March 1964, HW-81639, Apri1 1964.

26. L. C. Schmid et al., "Critical Masses and Bucklings of PuO2-UO $\mathrm{O}_{2}-\mathrm{H}_{2} \mathrm{O}$ Systems," Physics Research Quarterly Report, Apri1-June 1964, HW-83187, July 1964.

27. L. C. Schmid et al., "Critical Masses and Bucklings of $\mathrm{PuO}_{2}-\mathrm{UO}-\mathrm{H}_{2} \mathrm{O}$ Systems," Trans. Am. Nuc. Soc. 7, 2: 216 (1964).

28. F. G. Dawson, "Physics Design Aspects of Plutonium Recycle," Presented at the Commercial Plutonium Fuels Conference, Washington, D.C., March $1-2,19 \overline{66}$, CONF-660308.

29. R. C. Liikala and W. P. Stinson, "Experimental and Analytical Results for $\mathrm{PuO}_{2}-\mathrm{UO}_{2}-\mathrm{H}_{2} \mathrm{O}$ Lattices," Trans. Am. Nuc. Soc. 9, 1: 127, (1966).

30. F. G. Dawson et a1., "Analysis of Plutonium-Fueled Light Water Reactors," IAEA Symposium on the Use of Plutonium as a Reactor Fuel, Brussels, Belgium, March 13-17, 1967.

31. J. L. Carter, Jr., "Effective Cross Sections for Resonances in HRG," and "Computer Code Abstracts," Technical Activities Quarterly Report, July, August, September 1966, BNWL-340, Pacific Northwest Laboratory, October 15, 1966.

32. J. L. Carter, Jr., "HRG Data Tape," Reactor Physics Department Quarterly Report, October-December 1966, BNWL-400, Pacific Northwest Laboratory, Apri1 1967.

33. C. H. Westcott et a1., Atomic Energy Review, 3, 2 (1965) 3.

34. F. G. Dawson et a1., "Results From USAEC Plutonium Utilization Programs Conducted by Battelle-Northwest," IAEA Panel on Plutonium Utilization, Vienna, Austria (1968).

35. W. P. Stinson and J. H. Lauby, "CAF Measurements With A1-5 wt\% Pu Fuel in $\mathrm{H}_{2} \mathrm{O}$ Moderation," Plutonium Utilization Program Technical Activities Quarter ly Report, June-August 1968, BNWL-907, Pacific Northwest Laboratory, November 1968.

36. R. C. Liikala and G. L. Gelhaus, "Calculated Results For Al-5 wt\% Pu Fueled $\mathrm{H}_{2} \mathrm{O}$ Moderated Uniform Lattices," Plutonium Utilization Program Technical Activities Quarterly Report, June-August 1968, BNWL-907, Pacific Northwest Laboratory, November 1968.

37. R. C. Liikala et a1., "Uncertainties in the Analysis of Plutonium Fueled Assemblies," Trans. Am. Nucl. Soc., 1, 227 (1969). 
38. F. G. Dawson et a1., "Plutonium Utilization in Light Water Reactors," A/Conf 49/P-Fourth International Conference on the Peaceful Uses of Atomic Energy, Geneva, (1971).

39. J. R. Stehn et a1., "Neutron Cross Sections," BNL-325, 2nd Ed., Supplement No. 2, Vol. III, February 1965.

40. W. A. Wittkopf et a1., "U-238 Neutron Cross-Section Data for the ENDF/B," ENDF-103, BAW-316, The Babcock \& Wilcox Company (1967).

41. L. C. Schmid et a1., "Reactor Physics Data for the Utilization of Plutonium in Thermal Power Reactors," BNWL-801 (1968).

42. P. Loizzo et a1., "Experimental and Calculated Results for $\mathrm{UO}_{2}$ and $\mathrm{UO}_{2}-\mathrm{PuO}_{2}$, Fueled $\mathrm{H}_{2} \mathrm{O}$ Moderated Loadings, "BNWL-1379, Pacific Northwest Laboratory, (1970).

43. T. C. Engelder et a1., "Measurement and Analysis of Uniform Lattices of Slightly Enriched $\mathrm{UO}_{2}$ Moderated by $\mathrm{D}_{2} \mathrm{O}-\mathrm{H}_{2} \mathrm{O}$ Mixtures," BAW-1273, Babcock \& Wi1cox Company, (1963).

44. J. R. Brown and D. R. Harris, "Kinetic and Buckling Measurements on Lattices Slightly Enriched Uranium and $\mathrm{UO}_{2}$ Rods in Light Water," WAPD-176, Westinghouse Electric Corporation, (1958).

45. R. Gwin and D. W. Magnuson, Nuc1. Sci. Eng., 12, 364 (1962).

46. R. C. Lloyd et a1., Nuc1. Sci. Eng., 25, 165 (1966).

47. Alan Staub et a1., Nuc1. Sci. Eng., 34, 263 (1968).

48. C. R. Richey, Nuc1. Sci. Eng., 31, 32 (1968).

49. W. P. Stinson and V. 0. Uotinen, "Destructive and Nondestructive Analysis of Plutonium Fuels Used in Lattice Experiments," BNWL-1627, Pacific Northwest Laboratory, (1971).

50. D. F. Newman and C. R. Gordon, "Measurement and Analytical Correlation of Neutronic Parameters for a Water-Moderated Lattice Containing $\mathrm{UO}_{2}-\mathrm{PuO}_{2}$ Particulate Fuels," BNWL-1603, Pacific Northwest Laboratory, $(1971)$.

51. L. R. Heintze, Nucleonics, 41: No. 5, 108 (May 1966).

52. V. 0. Uotinen and L. D. Williams, "Experiments and Calculations for $\mathrm{H}_{2} \mathrm{O}$ Moderated Assemblies Containing U0, 2 wt\% PuO 2 Fuel Rods," BNWL-SA-1107, Pacific Northwest Laboratory, (1967). 
53. J. H. Lauby, "Summary of Water Moderated Experiments with 1.8 wt\% Pu-Al Fuel in the PRCF," Physics Research Quarterly Report, April, May, June 1965, BNWL-149, Pacific Northwest Laboratory, (1965).

54. V. 0. Uotinen, "Clean Critical Loading of A1-2 wt\% Pu Fuel in an $\mathrm{H}_{2} \mathrm{O}$ Moderated Core," Plutonium Utilization Program Annual Report, Fiscal Year 1967, BNWL-624, Pacific Northwest Laboratory, (1968).

55. R. C. Liikala et al., "Sensitivity of Reactor Multiplication Values to Cross Section Uncertainties for Thermal Systems," Proceedings of the Conference on Neutron Cross Section Technology, Conf-660303. Washington, D.C., (1966).

56. F. G. Dawson et al., "Analys is of Plutonium Fueled Light Water Reactors," Proceedings Plutonium as a Reactor Fuel, IAEA Symposium, Brussels, Belgium, March 13-17, 1967.

57. U. P. Jenquin et a1., "Sensitivity of Reactivity Characteristics to Cross-Section Uncertainties for Plutonium-Fueled Thermal Systems," Proceedings of Conference on Neutron Cross Sections and Technology, NBS Special Publication, 299, Washington, D.C., (1968).

58. J. J. Schmidt, "Neutron Cross Sections for Fast Reactor Materials, Part 1: Evaluation," KFK-120 (E ANDC-E-35U), (1966).

59. B. R. Leonard, Jr., "A Review of the Neutron Cross Sections of Pu-239 Below 1 eV," TNCC(US)-58, August 1959.

60. C. H. Westcott et al., "Revision of Values for the $2200 \mathrm{~m} / \mathrm{sec}$ Neutron Constants for Four Fissile Nuclides," Atomic Energy Review VII, 3 , (1969).

61. U. P. Jenquin et a1., "Effect of ENDF/B-II Data for ${ }^{238} U$ on Critical Experiments," Trans. Am. Nucl. Soc. 15, 461 (1972).

62. T. A. Pitterle, "Evaluation of $238 \mathrm{U}$ Neutron Cross Sections for the ENDF/B VERSION II File," WARD-4181-1, Westinghouse Elec. Corp. (1971).

63. J. E. Schlosser, "BARNS: A Program to Obtain Cross Sections from the R. B. U. Basic Library," HW-72117, Hanford Laboratories (1961), and J. L. Carter, "Revisions in BARNS-II," Reactor Physics Department Technical Activities Quarterly Report, Apri1, May, June, 1967, BNWL-534, Pacific Northwest Laboratory, (1969).

64. D. E. Kusner et a1., "ETOG-1, A FORTRAN IV Program to Process Data from the ENDF/B File to the MUFT, GAM, and ANISIN Formats," WCAP-3845-1/ENDF 114, Westinghouse Electric Corporation, December 1969.

65. R. K. Pascha11, Nucl. Sci. Eng., 20, 436 (1964). 
66. S. R. Dwivedi, "Heterogeneity Correction to Fast Fissions," Plutonium Utilization Program Technical Activities Quarterly Report June, July August 1969, BNWL-1224, Pacific Northwest Laboratory, (1969).

67. R. L. Hellens and H. C. Honeck, "A Summary and Preliminary Analysis of the BNL-Slightly Enriched Uranium Water Moderated Lattice Measurements," Report of a Panel held in Vienna, May 28-June 1, 1962 on Light Water Lattices, International Atomic Energy Agency, Vienna, (1962).

68. H. A. Risti, "Unit Cell Homogenization for Reactor Depletion Studies," WCAP-6060, Westinghouse Electric Corp., (1964).

69. D. H. Carter and J. E. Sanders, "U-238 Resonance Shielding of Epicadmium Reactions in U-235, Pu-239, and Mn-55 Detectors," AEEW-R 483, (1966).

70. H. Häegblom, Nucleonic Band 12, Heft 5, 189, (1969).

71. R. L. Hellens, Trans. Am. Nucl. Soc. 14, 820, (1971).

72. D. Newmarch, "Errors Due to the Cylindrical Cell Approximation in Lattice Calculations," AEEW R-34, (1960).

73. H. C. Honeck, Nucl. Sci. Eng., 18, 49, (1964).

74. J. R. Askew and R. J. Brissenden, "Some Improvements in the Discrete Ordinates Methods of B. G. Carlson for Solving the Neutron Transport Equation," AEEW R-161, (1963).

75. H. Brown and D. St. John, "Neutron Energy Spectrum in Water," Savannah River Report DP-64, (1956), and "Neutron Energy Spectrum in $\mathrm{D}_{2} \mathrm{O}$, Savannah River Report, DP-35, (1954).

76. M. S. Ne1kin, Phys. Rev., 119, 741, (1960).

77. M. A. Robkin, Private Communication, (Apri1 1967).

78. J. M. Neill et a1., Nucl. Sci. Eng., 33, 265, (1968).

79. J. L. Carter, "Upscattering Corrections to $\mathrm{H}_{2} \mathrm{O}$ in HRG Group Structure," Plutonium Utilization Program Technical Activities Quarterly Report, December 1968, January, February 1969, BNWL-1039. Battel1e-Northwest, Richland, Washington, April 1969.

80. J. M. Neill and D. L. Prezbindowski, "Uncertainties in Predicting Thermal Neutron Spectra and Lattice Multiplications for A1-5 wt\% Pu Fueled Light Water Systems," Proceedings of the Third Conference on Neutron Cross Sections and Technology, CONF-710301. University of Tennessee, (1971). 
BNWL-1656

APPENDICES 
BNWL-1656

APPENDIX A 
APPENDIX A

DESCRIPTION OF THE CROSS SECTIONS, THEORETICAL METHODS AND ANALYSIS PROCEDURES

The theoretical methods that we have used for this analysis are based upon a combination of transport and diffusion theory methods. Transport theory methods are used for performing unit cell spectrum calculations. Diffusion theory is used for performing reactor neutron balance calculations to obtain multiplication values. In some instances, transport theory is also used for the latter type calculation to evaluate the differences between diffusion theory and transport theory solutions. The source of the basic cross sections is the Battelle-Northwest Master Library, BNWML. (3) These cross sections are, with some exceptions, nearly identical to those contained in version I of ENDF/B. ${ }^{(4)}$ The following is a summary of the more important cross-section values and a brief description of each of the codes used.

\section{A. CROSS SECTIONS}

The BNWPIL (its genesis is the R. B. U. Basic Library) $(1,2)$ is a compilation of isotopic partial cross sections represented as point values covering the energy range from zero to $10 \mathrm{MeV}$. A computer code ${ }^{(63)}$ was developed to read and interpret this basic file and provide cross-section values at specific energy points or group averages using the appropriate flux weighting. The cell codes described below derive their multigroup 1 ibraries from the BNWML by this means. The most important cross sections in these calculations are summarized in Tables A-1 and A-2.

\section{Resonance Cross Sections}

Age measurements have been used extensively to assist in determining the adequacy of the cross sections for the common moderating materials. Using the cross sections on the BNWML for hydrogen and oxygen we calculated the age from a fission source to indium resonance of neutrons in $\mathrm{H}_{2} \mathrm{O}$. The 
calculated value is compared to what we consider the best measured value in Table A-1. As shown, the agreement is excellent between the calculated value and the experimental value.

TABLE A-1. Summary of Resonance Cross Sections

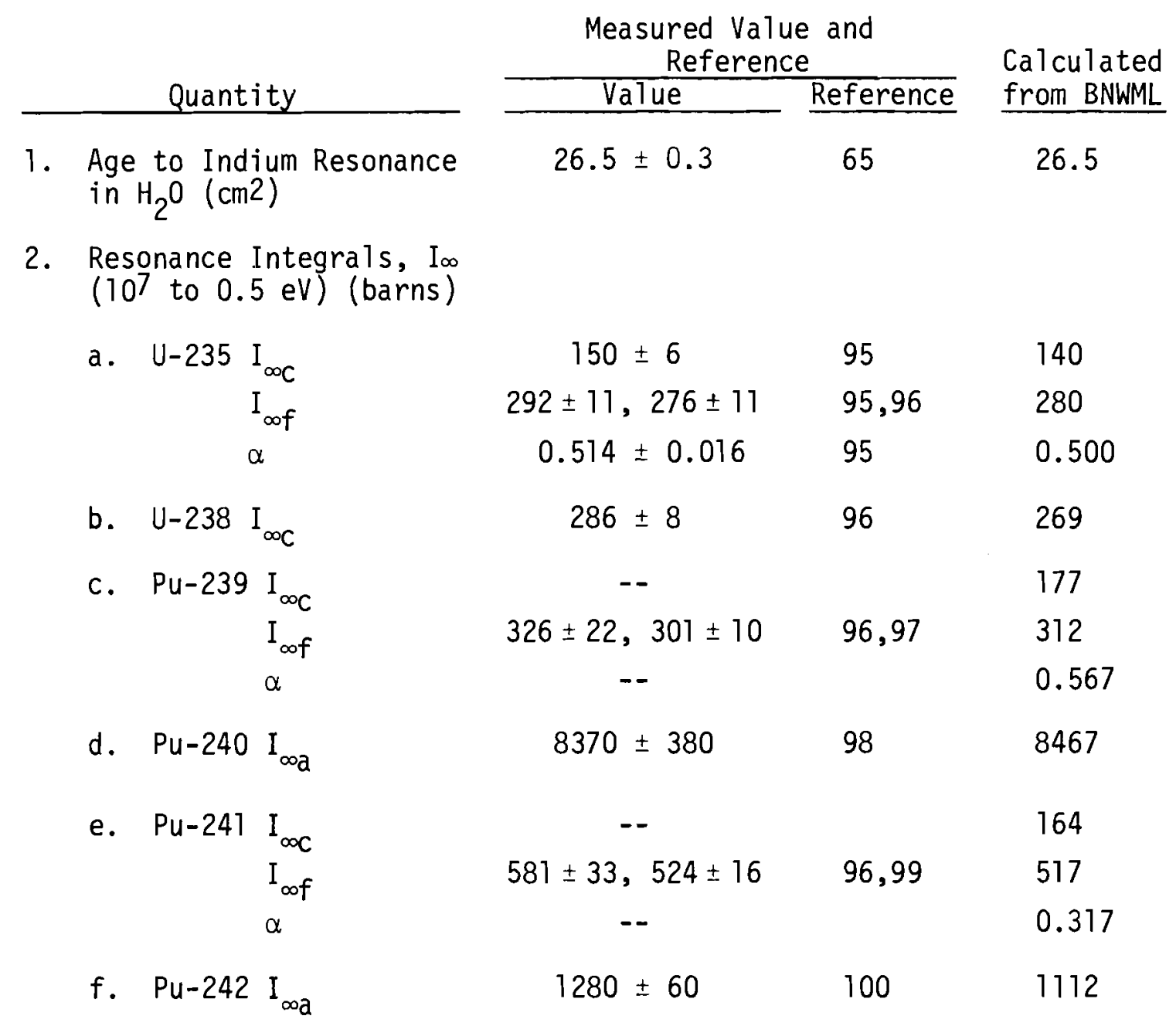


TABLE A-2. Summary of Thermal Cross Sections

\begin{tabular}{ll} 
& $2200 \mathrm{~m} / \mathrm{s}$ Value \\
Isotope & from BNWML, b \\
\hline
\end{tabular}

1.
a. Hydrogen
0.332
b. Boron
759.0
c. Nitrogen
1.88
d. Aluminum
0.235
e. Nicke?
4.6
f. Zirconium
0.188
g. Stainless Stee1
2.87
h. U-235 $\sigma_{a}$
679.9
$\sigma_{f}$
579.5
$\eta$
2.071
i. $U-238 \sigma_{c}$
j. Pu-239 $\sigma_{a}$
2.72
1008.1
742.4
2.114
k. $\mathrm{Pu}-240 \sigma_{\mathrm{C}}$
1. Pu-241 $\sigma_{a}$
281.1
1391
1009
2.154
m. $\mathrm{Pu}-242 \sigma_{\mathrm{C}}$
20.01

2.

$g$ Values

for $20.44^{\circ} \mathrm{C}$
a. U-235 $g_{a}$
0.97696
b. Pu-239 $g_{a}$
0.97595
1.0787
c. Pu-241 $g_{a}$
1.0550
1.0463
1.0456 
Measured values of the infinite dilution resonance integral have also played a useful role in evaluating cross sections. In Part 2 of Table A-1 we show how the values calculated from the BNWML compare with some of the measured values. For some of the isotopes wide variations exist in measured values; hence, it is difficult to quote a best value. With the exception of ${ }^{238} \mathrm{U}$ and ${ }^{242} \mathrm{Pu}$ a11 of the calculated values are within the standard deviation shown for at least one of the measured values. The departure in values for ${ }^{242} \mathrm{Pu}$ is not significant for the critical assembly calculations presented in this paper. However, for ${ }^{238} U$ the difference between the measured and calculated infinitely dilute resonance integrals is significant in terms of the impact on the critical assembly correlations. The calculated value of 269 barns using the cross sections from the BNWML is very nearly the value of 279.7 barns quoted for the ENDF/B-I cross sections. (40)

\section{Thermal Cross Sections}

The thermal cross sections for the fissile nuclides from the BNWML were normalized at $2200 \mathrm{~m} / \mathrm{s}$ to the parameters recommended in the 1965 IAEA evaluation. (33) The $2200 \mathrm{~m} / \mathrm{s}$ absorption cross sections for the other materials of importance in our calculations were our best estimate values. These values are all shown in Table A-2.

The variation of the fissile nuclide cross sections with energy in the thermal region is also of importance. ${ }^{(57)}$ The shapes of these BNWML cross sections give the $\mathrm{g}$ values at $20.44^{\circ} \mathrm{C}$ shown in Section 2 of Table A-2 for ${ }^{235} \mathrm{U},{ }^{239} \mathrm{Pu}$ and ${ }^{241} \mathrm{Pu}$.

\section{B. CELL METHODS}

The neutron distributions in space and energy within a unit lattice cell are computed using the multigroup transport theory codes HRG3, (8) Battelle-Revised THERMOS (BRT-I), (7) EGGNIT ${ }^{(101)}$ and GRANIT. (102) The spectrum-averaged multigroup cross sections are then collapsed to broad group values for subsequent use in the reactor calculations. The bulk of 
the calculations were made using HRG3 and BRT-I. The EGGNIT and GRANIT codes were used only for evaluating the effect of neutron self shielding due to particulate mixed oxide fuels.

1. The Thermalization Calculation

The computer code BRT-I is based on the original THERMOS ${ }^{(5)}$ code, but contains certain revisions made at the Pacific Northwest Laboratory over the years.

The BRT-I code solves the integral transport equation in one dimension using a multigroup cross section library which was derived from the BNWML. The code was used in this analysis to compute the thermal neutron distribution in space and energy in a cylindrical geometry unit cell composed of three regions: fuel, clad and associated moderator.

Twenty space points describe this unit cell with seven being allocated to the fuel, three to the clad, and ten to the moderator. The thermalization region is assumed to be from 0.0 to $0.683 \mathrm{eV}$. Thirty energy groups were used to describe the isotopic cross sections for this energy region. Reflecting boundary conditions were used in the calculations reported here.

In BRT-I the calculation of the thermal diffusion coefficient is based on the neutron current. An approximate method for correcting the scattering kernel to account for anisotropic scattering is available for all materials used in the cell calculation. This method involves altering the diagonal elements of the scattering kernel so that the sum of the matrix at each initial energy added to the absorption cross section yields the transport cross section at each energy. The scattering kernel that was used for $\mathrm{H}_{2} \mathrm{O}$ is based upon the Nelkin model $(76)$ and was calculated using the GAKER code. (5) The Brown-St. John ${ }^{(75)}$ model is used for calculating scatter transfer from all other materials. The computed space- and energy-dependent flux and current solutions are used to average the multigroup cross sections to derive one thermal group flux/current weighted and volume weighted constants for the homogenized cell. 
BNWL -1656

\section{The Slowing-Down Calculation}

The computer code HRG3 is used for calculating the fast and epithermal neutron spectrum in a homogenized system by solving the time independent Boltzmann equation with isotropic sources using either the $P_{1}$ or $B_{1}$ approximation. The energy range from $0.414 \mathrm{eV}$ to $10 \mathrm{MeV}$ is covered in 68 groups, each group one-fourth of a lethargy unit wide. With this calculated spectrum, the code forms broad group averages of parameters for use in spatial multigroup calculations. HRG3 is the latest of a series of versions which have evolved at Battelle-Northwest from GAM-1. (6) It still retains the basic characteristics of its predecessor.

For the calculations reported here the $B_{1}$ approximation was used with the measured geometrical buckling, $B_{g}^{2}$, as the leakage factor. The fission spectrum for ${ }^{239} \mathrm{Pu}$ was used in a 11 plutonium fueled lattices. For those lattices containing only uranium fuel, the ${ }^{235} \mathrm{U}$ fission spectrum was used. The effect of heterogeneity in the resonance region, that is, the shadowing caused by neighboring rods in the lattice, is accounted for using the method described by Carlvik. (103)

The resonance integral is calculated by a modification (104) of the method of Adler, Hinman and Nordheim. (105) This includes an intermediate resonance approximation for both the resonance absorber and an admixed moderator, (106) and the cross sections for resonances can be allocated to more than one fine group. An approximate correction to account for upscattering by hydrogen in water $(72)$ is included in the calculation.

The intermediate resonance approximation, resonance allocation and correction for upscattering in water are improvements to the slowing-down calculation that have been made since earlier reported correlations. (30-34) The effects of these modifications in HRG3 on the calculation of $k_{\text {eff }}$ is illustrated in Appendix C. In HRG3 there are two ways in which the transport cross section is calculated. These are referred to as the "standard" and "consistent" definitions. The latter definition was used in our analysis. 
BNWL-1656

3. Calculation of the Reactivity Effect of Pu0 2 Particles

The reactivity effect of the finite $\mathrm{PuO}_{2}$ particles in the mixed oxide fuels was evaluated using the codes GRANIT and EGGNIT. These codes permit one to calculate the self-shielding within finite absorber grains embedded in a matrix of diluent material.

The GRANIT code is an extended version of THERMOS. It computes the position-dependent thermal neutron spectrum in a heterogeneous unit cell in which finite absorber grains ( $\mathrm{PuO}_{2}$ in our case) are imbedded in the fuel rod. The granular region is handled by extending the normal region-toregion collision probabilities, using an extension of the approximate method of Lane, Nordheim and Sampson, ${ }^{(108)}$ to explicitly include particle and diluent interactions.

The EGGNIT code is a major revision of the GAMTEC-II code. (109) Only the slowing down segment of the EGGNIT code was used in this study since the GRANIT code was used for the thermalization calculation. An iteration technique is incorporated in the slowing down segment of EGGNIT which extends Nordheim's numerical integration method ${ }^{(110)}$ to multiregion situations. A collision probability routine allows one to treat the problem of finite absorber grains embedded in a matrix of diluent material. The GRANIT and EGGNIT codes were run using the same cell conditions used in the BRT-I and HRG 3 calculations as explained in Parts 1 and 2 of this subsection.

\section{REACTOR METHODS}

In most cases the solution of the reactor neutron balance equation was obtained using the HFN ${ }^{(9)}$ one-dimensional diffusion theory code. To evaluate the effects of neglecting anisotropy, a few solutions were obtained using the one-dimensional transport theory code DTF-IV. (86)

The reactor model assumed for all of the critical assembly calculations is a simple two-region reactor consisting of a homogeneous core and a water reflector. A one-dimensional description of this model in the radial direction is used in calculating the neutron leakage and associated value of $k_{\text {eff }}$ for the assembly. The radial neutron distribution in each broad group is 
determined exactly whereas the axial neutron distribution is approximated by using a monoenergetic transverse buck 7 ing, $B_{z}^{2}$, in both the core and reflector regions. The transverse buckling is determined in each case from the physical height of the fuel, $H$, and measured reflector savings, $\lambda$, by the relationship:

$$
B_{z}^{2}=\pi^{2} /(H+2 \lambda)^{2}
$$

\section{Diffusion Theory Calculations}

The HFN code solves the homogeneous or non-homogeneous, multigroup diffusion theory equation in one space dimension for its lowest eigenvalue and the corresponding direct and/or adjoint vectors, in both multiplying and the non-multiplying systems. The code allows a maximum of 20 energy groups and 50 homogeneous regions. Provision to account for neutron leakage in directions transverse to the single coordinate being considered are included in the code.

The HFN code was run to obtain the direct flux solution and corresponding eigenvalue for a multigroup system. The mesh utilized was 50 points in the core and 50 points in the reflector. Thus, the mesh spacing in the core and reflector regions were dependent on the radius of the core. The convergence criteria used for the flux and eigenvalue solutions in HFN were $10^{-4}$ and $10^{-7}$ respectively.

\section{Transport Theory Calculations}

The DTF-IV code computes the neutron flux distribution as a discrete ordinates solution of the Boltzmann transport equation. The multigroup form of the transport equation with anisotropic scattering is solved in onedimensional plane, cylindrical, or spherical geometry. The quadrature order and the order of anisotropic scattering are input variables which are left up to the user to select. The code allows a large number of energy groups and space points. Neutron leakage in directions perpendicular to the flux solution are accounted for by a $D^{2}{ }^{2}$ leakage term. 
The transport theory calculations made with DTF-IV are analogous to the diffusion theory calculations made with HFN. The DTF-IV code was run in cylindrical geometry with various numbers of energy groups and quadrature orders. First order anisotropic scattering cross sections were used in all cases. A total of 100 mesh points were used with 50 mesh points used in the core and 50 mesh points in the reflector. A convergence criteria of $10^{-4}$ was used for both the eigenvalue and flux solutions.

\section{MOCKUP OF THE CRITICAL ASSEMBLY}

As mentioned above, the two region cylindrical reactor consisting of a homogeneous core and an $\mathrm{H}_{2} \mathrm{O}$ reflector is equivalent to the fully inundated heterogeneous assembly. The analysis proceeds with the calculation of lattice constants for the homogeneous core and the reflector. The derivation of broad group parameters for the core was described above. Reflector cross sections were averaged over a neutron spectrum calculated for fission neutrons slowing down and thermalizing in an infinite medium of water. The non-thermal cross sections for water are obtained from the HRG3 code calculations assuming the $P_{1}$ approximation, no leakage, and a ${ }^{239} \mathrm{Pu}$ fission spectrum for plutonium fueled cores and a ${ }^{235} U$ fission spectrum for uranium fueled cores.

Parameters for the reflector and homogenized core are obtained for four broad energy groups for use in the reactor calculation to obtain values of the multiplication factor $k_{\text {eff }}$. The energy boundaries for these four broad groups are given in Table A-3. The core is assumed to be a right circular cylinder whose radius $R_{c}$ is determined from the measured critical number of rods, $\mathbb{N}_{C}$, by conserving volume. The relationship is:

$$
\pi R_{c}^{2}=N_{c} A
$$

where $A$ is the area of a unit cell. 
Thus for a square pitch lattice the critical radius is:

$$
R_{c}=\ell \sqrt{N_{C} / \pi}
$$

and for a triangular pitch lattice it is:

$$
R_{c}=\ell \sqrt{\frac{N_{C} \sqrt{3}}{2 \pi}}
$$

where $\ell$ is the lattice pitch.

\begin{tabular}{|c|c|}
\hline Group & Energies \\
\hline 1 & $10 \mathrm{MeV}-11.7 \mathrm{keV}$ \\
\hline 2 & $11.7 \mathrm{keV}-2.38 \mathrm{eV}$ \\
\hline 3 & $2.38 \mathrm{eV}-0.683 \mathrm{eV}$ \\
\hline 4 & $0.683 \mathrm{eV}-0.0 \mathrm{eV}$ \\
\hline
\end{tabular}

TABLE A-3. Boundaries of Neutron Energy Groups 
BNWL-1656

APPENDIX B 


\section{APPENDIX B}

\section{ACCOUNTING FOR THE EFFECT OF ${ }^{241}$ PU DECAY TO ${ }^{241}$ Am}

The ${ }^{241} \mathrm{Pu}$ isotope decays with a half-Tife of approximately 14.5 years, resulting in a gradual depletion of fissile plutonium and a corresponding buildup of ${ }^{241} \mathrm{Am}$. The calculations mentioned above have taken into account this changing isotopic composition as a function of time (except for the Saxton criticals for which the necessary information was not available). The ${ }^{241} \mathrm{Pu}$ and ${ }^{241} \mathrm{Am}$ concentrations have been calculated for each individual experiment on the basis of some recent measurements ${ }^{(49)}$ of the ${ }^{241}$ Am content in some of these fuels, as well as on the basis of earlier isotopic measurements. For some of the fuel materials no measurements of the ${ }^{241} \mathrm{Am}$ content have been made. In these cases the amount of ${ }^{24 l} \mathrm{Pu}$ originally in the plutonium was relatively small.

In some cases the amount of ${ }^{241} \mathrm{Pu}$ originally contained in the plutonium was quite small, and in these cases, of course, neglecting the buildup of ${ }^{241}$ Am since the time of chemical separation of the plutonium will not result in significant errors in reactivity calculations. However, for some of the fuels the amount of ${ }^{241} \mathrm{Pu}$ in the plutonium is significant. For experiments reported in this paper the reduction in the calculated reactivity as a result of the presence of ${ }^{241} \mathrm{Am}$, ranges from about 0.1 to $0.7 \% \Delta \mathrm{k} / \mathrm{k}$. Therefore, if one wishes to perform accurate calculations of these critical experiments to evaluate calculational methods, one needs to take into account the exact amount of ${ }^{241}$ Am for any given experiment. (111) 
BNWL-1656

APPENDIX C 
BNWL-1656

\section{APPENDIX C}

\section{EFFECTS OF CERTAIN IMPROVEMENTS MADE IN THE THEORY OF THE SLOWING DOWN CALCULATION}

Many improvements recently made in theory of neutron slowing down have been incorporated into the HRG3 code. Of these three of the more significant in terms of their effect on the calculated values of $k_{\text {eff }}$ for the lattices as examined in this paper are discussed here.

Two improvements are in the resonance absorption calculation. The first involves the allocation of the resonance absorption contribution of an individual resonance to an energy group. (104) Before this, HRG3 followed the GAM procedure of assigning the entire contribution of a resonance to the fine group in which the peak of the resonance occurred. The revision incorporated a criterion which was developed for allocating the contribution of a resonance among several fine groups, on the basis of the parameters of the cell problem and of the individual resonance. The most significant effect of this revision is on the high peak, broad capture resonances, such as those at $6.67 \mathrm{eV}$ in ${ }^{238} \mathrm{U}$ and at $1.056 \mathrm{eV}$ in ${ }^{240} \mathrm{Pu}$. The result of the revision is to increase the capture probability in the resonance. In the previous method, the concentration of the contribution in a single fine group led to an excessive flux depression in that group and an excessive reduction in reaction rate. By spreading the contribution over several groups, the flux depression is reduced and the reaction rate increases. Said another way, if the contribution of a resonance is concentrated in a single group, that resonance appears narrow in the slowing down calculation and thus there is a large probability that a neutron is scattered past the resonance. If, on the other hand, the same contribution is spread over several fine groups, the resonance appears broad in the slowing down calculation and the probability that a neutron is scattered past the resonance without capture is reduced. 
The second change in the resonance treatment involved the evaluation of the contribution of the resonance to the capture rate. By the previous procedure, each resonance was classified as either narrow or broad with respect to the maximum energy loss of a neutron in a scattering collision with an atom of the resonance absorber, and its contribution to the capture rate was determined as arising from one or the other of these two limiting cases. In either case, the resonance was assumed narrow relative to the maximum energy loss of a neutron in a scattering collision with an atom of an admixed moderator. The consequence of this latter assumption was that the neutron flux used in determining the scattering into the resonance by an admixed moderator did not reflect any depression due to the presence of the absorber. In the revised procedure, an intermediate resonance approximation $(106)$ was used for both the resonance absorber and the admixed moderator. The practical effect of the intermediate resonance approximation on the absorber itself is small, because the assumption that the strongly absorbing resonances are broad is very good. On the other hand, the intermediate resonance approximation significantly influences the scattering by an admixed moderator into these same strong, broad resonances. Much of this admixed moderator scattering actually occurs at energies at which the flux is depressed by the effect of the absorber. The revised calculation of this scattering is therefore less than the preceding calculation, resulting in a lower reaction rate than before. The two changes in the resonance calculation thus produce reactivity effects in the opposite directions.

The third change is a correction for upscattering by hydrogen in water. (79) The neglect of upscattering in slowing down calculations is equivalent to assuming that, once a neutron has been slowed down past an energy, it no longer can participate in reactions at this energy or any higher energies. If upscattering can occur, then the same neutron can traverse the same energy range more than once, and an increased rate of absorption should result. At the lower energies of the slowing down range, upscattering, particularly by lighter atoms, becomes important. This is particularly true if there is a strong absorbing resonance present, as the one at $1.056 \mathrm{eV}$ in ${ }^{240} \mathrm{Pu}$. However, inclusion of upscattering seriously 
complicates the calculation of a slowing down spectrum if appreciable numbers of transfers to higher energy groups occur, for then an iterative procedure rather than a single pass through the energy mesh is required. Cady et al. (107) proposed a model for upscattering of hydrogen in water which conveniently bypasses the complication of an iterative procedure. They assumed that the magnitude of the upscattering of hydrogen in water at these lower epithermal energies can be calculated by considering hydrogen is an ideal mass 1 gas, but at an elevated temperature. They neglect the energy change of this upscattering, however. Corrections based on this model have been included in HRG3 by revision of the cross sections for water in the lower energy groups.

The reactivity effects of these three improvements to HRG3 for selected critical experiment lattices are listed in Table $\mathrm{C}-1$. The reactivity effect of the improved resonance allocation is seen to be important in those cases where significant amounts of ${ }^{238} \mathrm{U}$ are present. For the A1-Pu lattices that are illustrated, in which no uranium is present, the reactivity effect of the improved resonance allocation is seen to be quite smal1. Also, within any series of experiments with the same fuel rods, the reactivity effect is largest for the tightest lattice pitch and decreases in absolute magnitude with increasing lattice pitch.

The reactivity effect of the intermediate resonance approximation relative to the narrow resonance approximation is seen to be largest for the case of the oxide fuels. In these cases the intermediate resonance approximation significantly influences the scattering by oxygen into the strong, broad resonances, mainly of ${ }^{238} \mathrm{U}$. For the Al-Pu lattices in which the admixed moderator is aluminum, and where again there is no ${ }^{238} U$ present, the reactivity effect of introducing the intermediate resonance approximation is rather small.

The reactivity effect of accounting for upscattering in hydrogen in water is seen to be most important in those lattice which have plutonium in the fuel. Also, it is clear that the more ${ }^{240} \mathrm{Pu}$ there is in the fuel the more important the effect is. In the case of the uranium oxide criticals 
the effect of accounting for scattering in water is seen to be very small. It is mainly the presence of the ${ }^{240} \mathrm{Pu}$ resonance at $1.056 \mathrm{eV}$ which accounts for the reactivity effect in this case for the plutonium-bearing lattices.

It is interesting to note, by including all of these a cancellation of effects results. Neglecting any one of these improvements to the slowing down theory can clearly lead to errors in calculated multiplication factors. As was mentioned above, all of these effects are included in the calculations reported in this paper. 
TABLE C-1. Reactivity Effects of Some HRG3 Improvements

\begin{tabular}{|c|c|c|c|c|}
\hline \multirow{2}{*}{$\begin{array}{c}\text { Lattice } \\
\text { Spacing } \\
\text { in. } \\
\end{array}$} & \multirow[b]{2}{*}{$\frac{N^{H}}{N^{f i s S}}$} & \multicolumn{3}{|c|}{$\Delta \mathrm{k} / \mathrm{k} \times 10^{-3}$} \\
\hline & & $\begin{array}{l}\text { Resonance } \\
\text { Al location }\end{array}$ & $\begin{array}{l}\text { Intermediate } \\
\text { Resonance } \\
\end{array}$ & $\begin{array}{c}\mathrm{H}_{2}{ }^{\mathrm{O}} \\
\text { Upscattering }\end{array}$ \\
\hline & & $\underline{\mathrm{UO}}_{2}$ & 0.3 in. rods & \\
\hline \multirow[t]{2}{*}{$\begin{array}{l}0.405 \\
0.435 \\
0.470 \\
0.573 \\
0.615 \\
0.665\end{array}$} & $\begin{array}{l}113 \\
151 \\
200 \\
363 \\
439 \\
537\end{array}$ & $\begin{array}{l}-7.70 \\
-5.16 \\
-3.46 \\
-1.19 \\
-0.84 \\
-0.61\end{array}$ & $\begin{array}{l}8.60 \\
7.41 \\
6.33 \\
4.25 \\
3.68 \\
3.21\end{array}$ & $\begin{array}{l}-0.41 \\
-0.38 \\
-0.33 \\
-0.31 \\
-0.24 \\
-0.09\end{array}$ \\
\hline & \multicolumn{4}{|c|}{ Al-5 wt $\% \mathrm{Pu}\left(5 \%{ }^{240} \mathrm{Pu}\right) 0.5 \mathrm{in}$. rods } \\
\hline \multirow[t]{2}{*}{$\begin{array}{l}0.85 \\
1.05 \\
1.35\end{array}$} & $\begin{array}{r}384 \\
722 \\
1242\end{array}$ & $\begin{array}{l}-0.53 \\
-0.12 \\
-0.02\end{array}$ & $\begin{array}{l}0.43 \\
0.25 \\
0.17\end{array}$ & $\begin{array}{l}-2.68 \\
-1.74 \\
-1.17\end{array}$ \\
\hline & \multicolumn{4}{|c|}{$\mathrm{UO}_{2}-4$ wt $\% \mathrm{PuO}_{2}\left(18 \%{ }^{240} \mathrm{Pu}\right) \quad 0.5 \mathrm{in.}$ rods } \\
\hline \multirow[t]{2}{*}{0.85} & 156 & -4.69 & 8.21 & -5.98 \\
\hline & \multicolumn{4}{|c|}{$\underline{\mathrm{UO}}_{2}-2 \mathrm{wt} \% \mathrm{PuO}_{2}-\left(8 \%{ }^{240} \mathrm{Pu}\right) 0.5 \mathrm{in}$. rods } \\
\hline \multirow[t]{2}{*}{$\begin{array}{l}0.800 \\
1.143 \\
1.386\end{array}$} & $\begin{array}{l}185 \\
541 \\
868\end{array}$ & $\begin{array}{l}-5.79 \\
-1.09 \\
-0.59\end{array}$ & $\begin{array}{l}7.87 \\
3.61 \\
2.46\end{array}$ & $\begin{array}{l}-4.35 \\
-2.31 \\
-1.50\end{array}$ \\
\hline & \multicolumn{4}{|c|}{$\underline{\mathrm{UO}}_{2}-\frac{-2 \text { wt } \% \mathrm{PuO}_{2}}{2}-\left(24 \%{ }^{240} \mathrm{Pu}\right) 0.5$ in. rods } \\
\hline $\begin{array}{l}0.800 \\
1.143 \\
1.386\end{array}$ & $\begin{array}{l}213 \\
620 \\
996\end{array}$ & $\begin{array}{r}-7.17 \\
0.00 \\
0.42\end{array}$ & $\begin{array}{l}9.79 \\
4.49 \\
3.05\end{array}$ & $\begin{array}{l}-6.72 \\
-3.57 \\
-2.50\end{array}$ \\
\hline
\end{tabular}


BNWL- 1656

UC-80, Reactor

DISTRIBUTION

No. of

Copies

OFFSITE

1 AEC Chicago Patent Group

G. H. Lee

8 AEC Division of Reactor Development and Technology

Asst. Dir. for Project Management

Chief, Water Project Branch (2)

Chief, Gas Cooled Projects Branch

Asst. Dir. for Reactor Technology

Chief, Reactor Physics Branch (2)

Chief, Core Design Branch

1 AEC Division of Nuclear Materials Safeguards

H. Werner

1 AEC Directorate of Regulatory Operations

F. E. Kruesi

$1 \quad$ AEC Directorate of Regulatory Standards

L. Rogers

1 AEC Division of Production

F. P. Baranowski

3 AEC Directorate of Licensing

A. Giambusso

J. Hendrie

S. Smiley

$1 \quad$ AEC Division of Research

G. A. Kolstad

222 AEC Technical Information Center

$2 \quad$ American Electric Power Service Corp.

2 Broadway, New York, New York 10004

J. Cook

H. Sobel 
No. of

Copies

4 Argonne National Laboratory

Reactor Physics Constants Center (2)

R. Avery

P. H. Kier

Arizona Public Service Company Phoenix, Arizona

M. Brown

Arkansas Power and Light Company

Ninth and Louisiana, Litt]e Rock, Arkansas 72203

H. T. Holmes

2 Assoc. C.E.N. Belgo Nucleaire

35 Rue Des Colonies, Belgium

H. Bairiot

L. Bindler

2 Atomic Energy of Canada Limited

Cha7k River, Ontario, Canada

M. Duret

C. Millar

1 Atomic Energy Establishment

Dragon Project

Winfrith, Dorchester,

Dorset, England

H. Gutmann

1 Atomics International

H. Alter

1 Australian Atomic Energy Commission

AAEC Research Establishment

Private Mail Bag, Sutherland 2232

N.S.W., Australia

Dr. J. L. Symonds, Chief

Physics Division

1 Bangladesh Atomic Energy Commission

P.0. Box No. 158 Ramna, DACCA-2

Bangladesh

M. A. Mannan 
Babcock and Wilcox Company

D. M. Jones

D. H. Roy

W. A. Wittkopf

Baltimore Gas and Electric Company Baltimore, Maryland 21203

R. Fluegge

1 Battelle Memorial Institute Columbus, Ohio

John Batch

1 Battelle Seattle Research Center Seattle, Washington

F. G. Dawson

1 Bechtel Corporation

Vernon, California

M. Aronchick

Bettis Laboratory, Westinghouse Electric Company

J. J. Taylor

1 Bhabha Atomic Research Centre

Trombay, Bombay-85, India

S. R. Dwivedi, Theoretical Physics Section/RED Central Complex Bldg.

Brookhaven National Laboratory

0 . Ozer

S. Pearlstein

California Institute of Technology

H. Lurie, Engineering Div.

1 Carolina Power and Light Company 336 Fayetteville Street Raleigh, North Carolina 27602

A. Watson

Catholic University of America Dept. of Nuclear Sci. and Eng. Washington, D.C. 
No. of

Copies

3

$$
\text { C.E.N. - Saclay }
$$

Boite Postale 2

Gif-Sur-Yvette ( $S$ et 0 ), France

B. LaPonche

$P$. Lecorche

G. Vendryes

1 CNEN - Casaccia

$$
\begin{aligned}
& \text { O0060 - S. Maria Di Galeria } \\
& \text { Rome, Italy } \\
& \text { Paolo Loizzo }
\end{aligned}
$$

2 CNEN-Centro Studi-Nucleaire

$$
\text { Casaccia, Rome, Italy }
$$

Ugo Farinelli

Augus to Gandini

Combustion Engineering, Nuclear Division

R. Harding

R. Hellens

S. Visner

1 Commonwealth Edison Company

72 W. Adams

Chicago, Illinois
A. Veras

1

Consolidated Edison Company

4 Irving Place

New York, New York 10003

M. L. Lee

1 Consumers Power Company

212 W. Michigan Avenue

Jackson, Michigan

G. J. Walke

2 Cornel1 University

Ithaca, New York

R. T. Cuykenda11, Eng. Physics

M. Nelkin 
No. of

Copies

1 Detroit Edison Company

2000 Third Avenue

600 Service Bldg.

Detroit, Michigan 48226

D. Wehmeyer

2 Duke University

Durham, North Carolina

H. W. Newson, Physics Dept.

W. J. Seeley, School of Eng.

2 Duquesne Light Company

435 Sixth Avenue

Pittsburgh, Pennsylvania 15219

R. E. Martin

J. Seiber

1 Ebasco Services

D. R. de Boisblanc

2 Edison Electric Institute

750 Third Avenue

New York, New York 10017

John J. Kearney

Ed Kuhn

3 E. I. du Pont de Nemours \& Co., Inc., Savannah River Laboratory
G. Dessauer
H. Honeck
F. J. McCrosson

2

ENEL

Via G. B. Martini

(Pizaaz Verdi)

Rome, I taly

Mr. Paoletti Gualandi

Mr. Bruno D'Oghia

1 EURATOM

53, Rue Billiard

Brussels 4, Belgium

A. de Stordeur 
No. of

Copies

$2 \quad$ FFR - AB Atomenergi

Studsvik, Pa NYKOPING

Sweden

Erik Johansson

Evelyn Sokolowski

4 General Atomic

R. C. Dahlberg

J. M. Neill

H. B. Stewart

G. D. Trimble

$3 \quad$ General Electric Company

Knol1s Atomic Power Laboratory

R. Ehrlich

C. Lubitz

K. W. Seeman

$4 \quad$ General Electric Company

San Jose

P. Aline

R. L. Crowther

D. L. Fischer

S. Levy

$1 \quad$ General Electric Company

Nucleonics Laboratory

H. W. Alter

2 General Electric Company

Val7ecitos Atomic Laboratory

B. F. Judson

T. M. Snyder

2 General Public Utilities Service Corp.

260 Cherry Hill Road

Parsippany, New Jersey 07054

B. H. Cherry

R. F. Denning

2 Idaho Nuclear Corporation

R. M. Brugger

R. A. Grimesey 
No. of

Copies

1

Istanbul Technical University

Gi imi is, Suyer, Istanbu1, Turkey

Director, Nuclear Energy Institute

1

Japan Atomic Energy Research Institute (JAERI)

Tokaimura, Naka-gun, Ibarakiken, Japan

Hjime Sakata

1

Japan Atomic Energy Institute (JPDR-TCA)

Tokaimura, Ibarakiken, Japan

Shojiro Matsuura

1

Kansas State University

Manhattan, Kansas

W. R. Kimel, Nuclear Eng.

1

Kernforschungszentrum Karlsruhe

7500 Karlsruhe, Germany

Professor W. Haefele

Kerr-McGee

Oklahoma City, Oklahoma

$1 \quad$ Los Alamos Scientific Laboratory

G. E. Hansen

$1 \quad$ Manhattan Col lege

Riverdale, New York, New York

Brother Gabriel Kane

2 Massachusetts Institute of Technology

I. Kaplan

D. D. Lanning

$1 \quad$ Middle South Utilities, Inc.

230 Park Avenue

New York, New York 10017

L. Wilson

$1 \quad$ Niagara Mohawk Power Corp.

300 Erie Blvd. W.

Syracuse, New York 13202

K. D. Vrooman 
No. of

Copies

1

North American Aviation Science Center

E. R. Cohen

$1 \quad$ Northeast Utilities Services Company

176 Cumberland Avenue Wethersfield, Connecticut 06101

J. Himmelright

1

North Carolina State College

R. L. Murray

$1 \quad$ Northern States Power Company

414 Nicollet Avenue

Minneapolis, Minnesota

M. Voth

2 Nuclear Fuels Services, Inc.

Suite 906, Wheaton Plaza BTdg.

Wheaton, Maryland 20902

R. E. L. Stanford

W. Eich

2 Nuclear Materials and Equipment Corp. Apol1o, Pennsylvania

C. S. Caldwell

Karl Puech1

$1 \quad$ NUKEM

D-645, NANAU

POSTFACH 869

Germany

Mr. Wolgang K. L. Jager

2 Oak Ridge National Laboratory

F. C. Maienschein

A. M. Perry

$2 \quad$ Pacific Gas and Electric Company

72 Beale Street

San Francisco, California 94106

D. V. Kelley

A. Medcalf 
No. of

Copies

1

Penn State College

W. F. Witzig

$2 \quad$ Philadeiphia Electric Company

1000 Chestnut Street

Philadelphia, Pennsylvania 19107

Wayne C. Astley

R. F. Mantey

1

Power Reactor and Nuclear Fuel Development Corp.

9-13, 1-chome, Akasaka

Minato-ku, Tokyo, Japan

Setsuo Kobayashi

1

Public Service of Colorado

550 15th Street

Denver, Colorado 80202

$1 \quad$ Purdue University

P. N. Powers, Nucl. Eng. Dept.

1 Rensselaer Polytechnic Institute

E. R. Gaerttner

1 S.C.K. - C.E.N.

BRL

Mol-Donk, Belgium

Dr. H. Vanden Broeck

1 Southern California Edison

P.0. Box 800

Rosemead, California 91770

J. Ladesich

2 Southern Services, Inc.

300 Office Park Service

P.0. Box 2625

Birmingham, Alabama 07054

R. Chastain

J. Meier 
No. of

Copies

2 Tennessee Valley Authority

310 Power B1dg., Chattanooga, Tennessee

H. B. Brooks

R. Davidson

1 Union Carbide Corporation (ORNL)

E. B. Johnson

2 United Kingdom Atomic Energy Agency

Atomic Weapons Research Estab7ishment

Aldermaston, Berkshire, UK

R. C. Lane (1)

Authority Health and Safety Branch

Safeguards Division

Risley, Warrington, UK

J. H. Chalmers (1)

2 United Kingdom Atomic Energy Authority

General Reactor Physics Division

Winfrith, England

Dr. J. G. Tyror

C. G. Campbel1

1 United Nuclear Corporation

Elmsford, New York 10523

J. R. Tomonto

$1 \quad$ University of Arizona

Tucson, Arizona

Monte V. Davis, Nucl. Eng. Dept.

1 University of California

Department of Nuclear Engineering

V. E. Schrock

$1 \quad$ University of Florida Gainesville, Florida

R. E. Uhrig, Nucl. Eng. 
No. of

Copies

1

University of Illinois

Urbana, Ill inois

Frederick Seitz, Physics Dept.

1

University of Minnesota

Minneapolis, Minnesota

H. S. Isben, Chem. Eng. Dept.

1 University of Nevada Reno, Nevada

T. V. Frazier, Physics Dept.

$1 \quad$ University of Notre Dame Notre Dame, Indiana

E. W. Jerger, Dept. of Mech. Eng.

University of Oregon

Eugene, Oregon

J. L. Powe11, Physics Dept.

2 University of Tennessee Knoxville, Tennessee

A. H. Nielsen, Physics Dept.

P. F. Pasqua, Nucl. Eng. Dept.

$1 \quad$ University of Toledo

Toledo, Ohio

J. J. Turin

2

University of Washington

Seattle, Washington

A. L. Babb, Dept. of Nucl. Eng.

M. A. Robkin

1 University of Wisconsin

Madison, Wisconsin

M. W. Carbon, Nucl. Eng. Com. 
No. of

Copies

1

1

6

1

1

1

2
U.S. Atomic Energy Comission DNR
A. Radkowsky

Washington State University

Pullman, Washington

J. P. Spielman, Col. of Eng.

Westinghouse Electric Corporation

C. L. Bennett

R. A. Dannels

W. B. Henderson

W. D. Leggett

W. L. Orr

J. R. Worden

Whiteshell Nuclear Research Establishment

Atomic Energy of Canada, Ltd.

Pinawa, Manitoba, Canada

R. B. Lyon, Head-Assessment and Applied Math. Section

Wiscons in Michigan Power Company

807 South Oneida Street

Appleton, Wisconsin

0 . Zirbel

Wisconsin Public Service Corp.

1029 N. Marshall Street

Milwaukee, Wiscons in 53202

E. D. Novak

Yankee Atomic Electric

Turnpike Road

Route 9

Westboro, Massachusetts 01581

R. M. Grube

W. D. Hinkle 
No. of

Copies

ONSITE

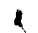

1

1

2

2

1

4

4

Exxon Nuclear

L. P. Bupp

G. J. Busselman

J. H. Brown

G. A. Sofer

2 United Nuclear Industries

H. Toffer

UNI File

1

Washington Public Power Supply System

L. Grunime

6 Westinghouse Hanford

R. A. Bennett

W. L. Bunch

P. L. Hofmann

W. W. Little

R. E. Peterson

W.H. Document Control 
No. of

Copies

82

Battelle-Northwest

S. R. Bierman

C. L. Brown

S. H. Bush

J. L. Carter

N. E. Carter

T. D. Chikalla

D. E. Christensen

R. G. Clark

E. D. Clayton

G. M. Dalen

D. E. Deonigi

B. H. Duane

E. A. Eschbach

P. L. Farnsworth

L. G. Faust

J. W. Finnigan

J. C. Fox

M. D. Freshley

J. J. Fuquay

G. L. Gelhaus

A. G. Gibbs

S. Goldsmith

R. J. Hall

0 . K. Harling

H. Harty

C. M. Heeb

R. E. Heineman

H. L. Henry

U. P. Jenquin (5)

B. M. Johnson

G. J. Konzek

D. A. Kottwitz

C. R. Lagergren

B. R. Leonard, Jr.

D. L. Lessor

R. C. Liikala (10)

C. W. Lindenmeier

R. C. Lloyd

E. T. Merrill

J. N. Morgan

D. F. Newman

R. E. Nightingale

D. R. Oden, Jr.

L. T. Pederson

W. W. Porath

D. L. Prezbindowski 
No. of

Copies

\section{Battelle-Northwest (contd)}

W. L. Purcell

W. A. Reardon

C. R. Richey

W. D. Richmond

L. C. Schmid

G. D. Seybold

R. I. Smith

D. B. Stewart

D. H. Thomsen

V. 0. Uotinen (5)

L. D. Williams

W. C. Wolkenhauer

F. R. Zaloudek

M. G. Zimmerman

Technical Publications (2)

Technical Information (3) 